\title{
Scientific
}

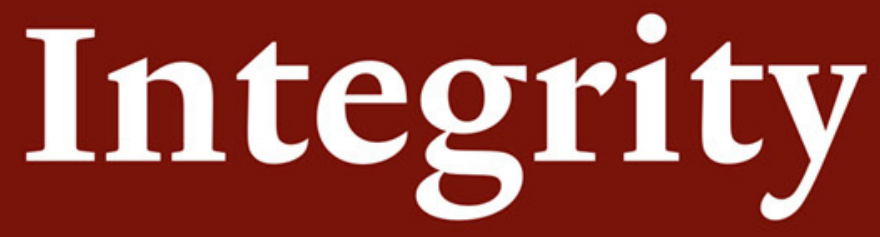

\section{The Rules of}

\section{Academic Research}

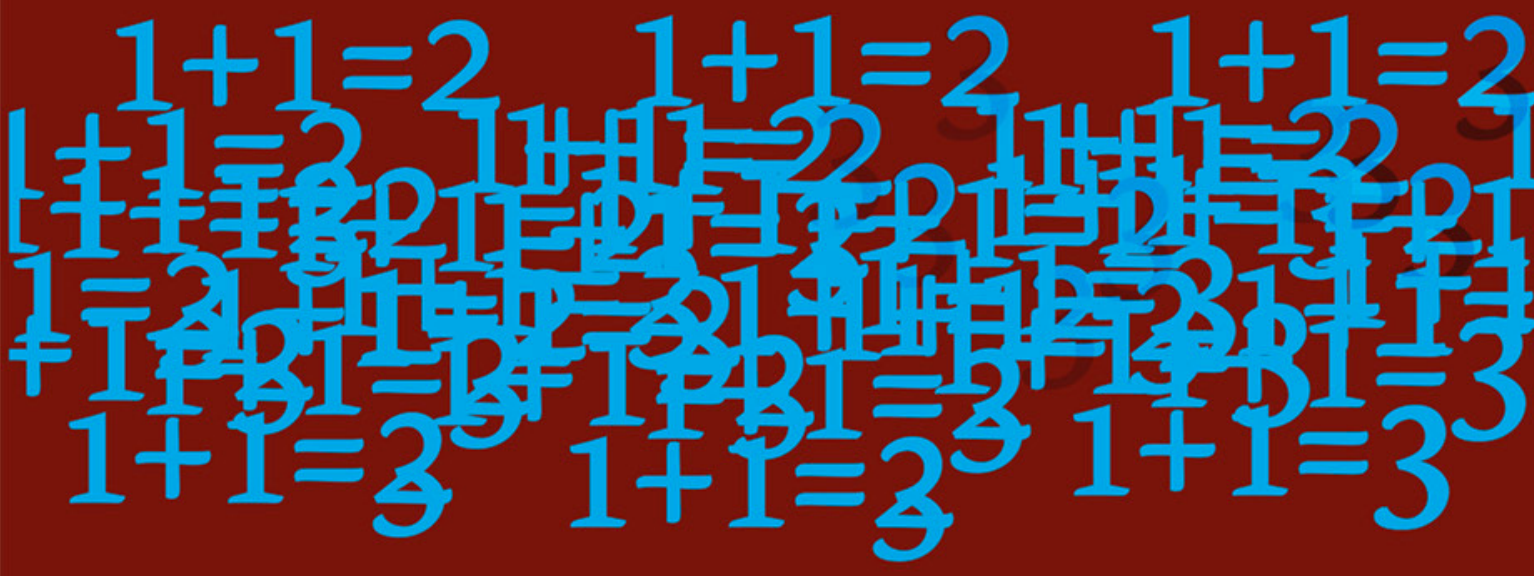

Kees Schuyt 
Scientific Integrity 



\section{SCIENTIFIC INTEGRITY}

The Rules of Academic Research

by Kees Schuyt

Translated by Kristen Gehrman

LEIDEN UNIVERSITY PRESS 
Translation: Kristen Gehrman

Cover design: Geert de Koning

Lay-out: Friedemann bvba

ISBN $978908728230 \mathrm{I}$

e-ISBN 9789400602 I8 2 (PDF)

e-ISBN 9789400602 I9 9 (ePUB)

nur 737,738

(C) Kees Schuyt / Leiden University Press, 2019

This work is licensed under the Creative Commons Attribution-NonCommercial 4.0 International License. To view a copy of this license, visit http://creativecommons.org/ licenses/by-nc/4.0/.

This book is distributed in North America by the University of Chicago Press www.press.uchicago.edu. 


\section{Table of contents}

$\begin{array}{ll}\text { Foreword } & 7\end{array}$

Introduction $\quad 9$

Chapter I

Scientific integrity: an exploration of an elusive concept $\quad$ I3

$\begin{array}{ll}\text { I.I Discredited by fraud } & \text { I3 }\end{array}$

I.2 Integrity as a standard linked to one's position I5

I.3 Integrity as a standard for one's own behavior I8

I.4 Scientific values and the basic standards of integrity 2I

I.5 Scientific integrity in practice: an initial exploration 25

Chapter 2

The codification of behavioral standards for scientific research $\quad 3 \mathrm{I}$

2.I Muddying the waters of science: the Stapel affair 3I

2.2 Some examples of fraud 32

2.3 Four conceptual distinctions 35

2.4 The emergence of norms in scientific practice $\quad 36$

2.5 A case study: the codification of norms in the Netherlands 4I 2.6 The Netherlands Code of Conduct for Scientific Practice of
2004/2012/20I4

2.7 The Netherlands Code of Conduct for Research Integrity of 2018

Chapter 3

Scientific fraud: lessons from history $\quad 57$

3.I A new phenomenon? 57

3.2 What phenomenon? A more precise definition of scientific fraud $\quad 59$

3.3 A frequent phenomenon? 62

3.4 Do performance pressure and dishonesty go hand in hand? 63

3.5 Commissioned research: under pressure to adjust? 69

3.6 Towards an explanation of scientific fraud? 72 
Chapter 4

Addressing scientific integrity complaints

4.I The establishment of committees for scientific integrity 79

4.2 The complaint procedure in the Netherlands: the legal framework 80

4.3 The current complaint procedure 83

4.4 Principles of fair trial in addressing fraud complaints 84

4.5 Setting the boundaries: practical problems and examples 88

Chapter 5

Plagiarism and self-plagiarism

97

5.I Violation of the basic rules of science 97

5.2 Taking credit for other people's work Io०

5.3 Scope and frequency of plagiarism $\quad$ I06

5.4 Self-plagiarism Io9

5.5 Plagiarism complaints: power relations and reporting II7

Chapter 6

Frequently asked questions about scientific integrity I2I

6.I Who can complain about whom? To which authority? I2I

6.2 Matters worthy of complaint (I): fabrication and falsification $\quad$ I25

6.3 Matters worthy of complaint (II): co-authorship I30

6.4 Is there a statute of limitations for scientific misconduct?

6.5 Minor errors, major negligence and questionable research practices $\quad{ }_{13} 8$

Chapter 7

Integrity: regulation, prevention, instruction

$\begin{array}{ll}\text { 7.I Trust in science: self-correction and self-regulation } & \text { I47 }\end{array}$

7.2 A closer look at the system of self-regulation $\quad$ I52

$7 \cdot 3$ Three conditions for self-regulation $\quad 156$

7.4 Prevention of fraud and misconduct: integrity policy $\quad 159$

7.5 Can integrity be learned? Education in science ethics and other skills $\quad \mathrm{I}_{62}$

7.6 Ten rules of scientific integrity $\quad$ I64

$\begin{array}{ll}7.7 \text { What can we learn from integrity? } & \text { I67 }\end{array}$

$\begin{array}{ll}\text { Works cited } & \text { I69 }\end{array}$

Index $\quad$ I8I 


\section{Foreword}

In 2006, I was asked by the Royal Netherlands Academy of Arts and Sciences president at the time, Frits van Oostrom, to serve as chairman of the Netherlands Board on Research Integrity (LOWI). Out of a desire to contribute to the general cause, I accepted. At first, the job wasn't so demanding, but after a few high-profile cases of scientific fraud came to light, the workload became significantly heavier. My term ended on January I, 2015, but the subject of "scientific integrity" has continued to fascinate me, and I've been exploring it in various ways ever since.

I guess you can say I have been studying scientific integrity for a long time. I have read a great deal of scientific literature on the topic, and over the years, I've collected countless articles from newspapers and magazines about fraud cases all over the world. This study is a report of my findings.

This book has become an analysis of the norms and values behind integrity and honesty in science and of their development since the mid-I980s. Around 1985, there was a shift in both the views on and the structure of scientific research. In the Netherlands, this shift coincided with the introduction of the system of conditional funding for scientific research (between I98I and I985), the institutionalization of $\mathrm{PhD}$ research, and the establishment of a system for research institutes (from I986).

This study details the development of the new rules established in various codes of conduct for scientific practice and the way in which suspected violations are evaluated and addressed. From 2006 to 2015, I participated in the evaluation of a large number of suspected violations of scientific integrity submitted to the LOWI. Thus, I myself have contributed to the interpretation of the rules and codes of conduct. However, this study is a reflection of my own personal views and appraisals. In no way does it represent the official position of the LOWI or any other body. That said, I do regularly refer to the LOWI's opinions, which are published in anonymized form on its website (https://www.lowi.nl/en/ Opinions?set_language=en).

The first reason for releasing a revised version of this study was the publication of a new Netherlands Code of Conduct for Research Integrity in 2018, which is discussed in Chapter 2. With this update, this study can offer a contribution 
to future discussions on scientific integrity that may arise as a result of the 2018 Code.

A second reason was the need for an English edition. There is a strong desire at Dutch universities to communicate the standards of scientific ethics and integrity to students at all levels, from Bachelor to $\mathrm{PhD}$, and English is the international language of science. It was Maghiel van Crevel, professor of Chinese language and literature at Leiden University, who submitted an urgent request to publish the new version in English. I am therefore very grateful to Maghiel for insisting on this translation and spontaneously supporting it. He has done me a great service with his many comments to improve and clarify the text, for which this acknowledgment is simply not enough. I am grateful to Leiden University, in particular to the Graduate School of the Faculty of Humanities, for their financial support for this publication. And I would particularly like to thank Anniek Meinders of Leiden University Press for her unfailing belief in and support for this publication in its original and revised form, in Dutch and in English.

I would also like to recognize the many people who, directly or indirectly, have helped me to form my opinions and standpoints on the sensitive subject of scientific integrity. First of all, my thanks and gratitude go to the LOWI members, former members and staff, with whom I have had extremely interesting discussions about many aspects related to scientific integrity and the many ways in which it has been violated.

Finally, I would like to recognize a number of people who have helped me write this study and its latest revision. First of all, I would like to thank the translator Kristen Gehrman for her excellent work and the very pleasant way in which we have untangled the many translation knots. I am also very grateful to Adriënne Baars-Schuyt, who provided professional and meticulous comments on my manuscripts, as she did for the first and second edition. Given the specific subjects addressed in this book, one of which was proper source-referencing, this was a crucial task. Finally, I'd like to thank my wife, Trees Schuyt-van Etten. In my first book, published in I97I, I thanked her for the "piano of her soul". Now, after all of these years, I'd like to thank her for the time she has given me and for allowing me to devote so much of my time to the subject of scientific integrity.

Kees Schuyt

Voorburg, June 2, 2019 


\section{Introduction}

The subject of scientific integrity has generated a lot of attention in recent decades, both in the media-which is all too happy to report on the latest fraud or plagiarism scandal — and in the boardrooms of the scientific institutions that have to respond to it. In the meantime, scientific research has continued, but researchers have become more attuned to the fact that scientific integrity is something they need to pay attention to in their laboratories and research institutes. Then came the question as to whether we should add courses in scientific ethics and integrity to university curricula, which are already full as it is. New courses for students and novice researchers have been established in recent years, creating a demand for teaching material on scientific integrity. But can integrity be learned? Or is it more a matter of gaining experience, following good examples and having outstanding scientific researchers as role models? This is one of the questions that will be addressed in this study.

This book is not designed to serve as a curriculum for prospective students or novice researchers. Although I know there is a need for this, I do not feel called to address all the possible ethical cases, dilemmas and temptations inherent to scientific research and explain how young researchers should respond to each one. Moreover, there are already plenty of good textbooks available on this topic (Macrima 2005; Comstock 2013; On Being a Scientist 2012). It is true that dilemmas can arise in the application of rules, especially when rules are not clearly formulated. However, I believe that the standards of scientific research are already clear enough: always present research results truthfully and never copy the work of others without properly referencing the source. These basic standards are not that difficult. How to uphold these standards is something that one learns from experience and from the good example of teachers, supervisors and experienced researchers. These veterans in the field are responsible for passing on their experience and scientific attitude to their students, colleagues and successors. 
This study is also not intended as a policy paper, although I do believe that universities in the Netherlands need a more conscious policy on scientific integrity. Over the past few years, I have been surprised by the lack of interest the Dutch universities have shown for this subject, even though many scientists and administrators consider it an important issue. Two studies that have served as shining examples are The Ethics of Science by David Resnik (I998) and The Great Betrayal: Fraud in Science by science historian Horace Freeland Judson (2004). Almost anything one would like to know about scientific integrity and responsible conduct for scientific research can be found in these two works; yet, as far as I could tell, neither of them have been widely consulted. Both books have served as an example for me in writing this book, and I have made extensive use of the authors' knowledge, experience and insights. They are often quoted because, as Marcel Proust put it, "One must never miss an opportunity of quoting things by others, which are always more interesting than those one thinks up oneself" (quoted by De Botton 2000: 49; Vanheste 20I2: I6).

This book is primarily intended for the academic community. The centuries-old concept of 'community' in academia is under pressure at universities from new terms derived from bureaucracy and economics. Traditionally, an academic community consists of scientists-who conduct research and teach-their students, Deans, research supervisors, librarians, library users, university administrators and treasurers. All of these individuals are faced with integrity issues from time to time and many have probably asked themselves what exactly integrity means and how it can be promoted within their community.

Integrity is based on the trust that exists among the members of an organization; it is this trust that makes an organization a community. If trust is lacking or at risk of being lost, honest behavior becomes more difficult to sustain. Eventually, the community is forced to reflect on its actions and formulate its own standards of honest behavior. This study aims to make a small contribution to this task by outlining and analyzing the developments in the field of scientific integrity over the past decades. I hope that readers will be able to decide for themselves how they wish to exhibit scientific integrity in science and research. Thus, this study is not a textbook but a kind of scientific essay from which one can draw inspiration for one's own work. 
But what exactly is scientific integrity? And why should we care about it? What are the issues at stake? What do we know about the nature and extent of these issues, and what do they tell us about the overall health of the scientific field? In this book, I will explore the general concept of integrity, describe the social values behind it, and apply those values to science specifically (Chapter I). I will then formulate two basic standards of scientific integrity, against the background of the establishment of codes of conduct for scientific practice, including the most recent such code in the Netherlands (Chapter 2). Thereafter I will focus on fraud and other forms of dishonest behavior in scientific research and, in doing so, address the difficult question of whether or not scientific integrity violations have increased (Chapter 3). Chapter 4 outlines how suspected scientific integrity violations are handled in the Netherlands. In Chapters 5 and 6, I delve into more specific topics, such as the definition of plagiarism and self-plagiarism (Chapter 5 ) and the important distinction between sloppy science and dishonest research (Chapter 6). Finally, in Chapter 7 , I examine the university system of self-regulation and consider how we can pass down the scientific spirit-of which integrity is a crucial part-to the next generation of researchers.

My personal assessment of the self-regulatory system for addressing scientific integrity complaints in Dutch universities is not entirely positive. In my opinion, the Netherlands Code of Conduct for Scientific Practice of 2004/20I2/20I4 and the Netherlands Code of Conduct for Research Integrity of 2018 leave too many questions about what exactly is and is not "against the rules" of scientific practice unanswered, which has resulted in all kinds of vague, unnecessary complaints about suspected integrity violations.

If this book contributes to a deeper awareness of the importance of scientific integrity within the academic community, it has met my goal. 



\section{Chapter I \\ Scientific integrity: an exploration of an elusive concept}

\section{I.I DISCREDITED BY FRAUD}

The growing interest in scientific integrity is a testament to a broader cultural trend: honesty is no longer self-evident as a core value of professional activity. In the Netherlands, integrity has become an important issue in various sectors. Since 1992, the theme of professional integrity has been the subject of numerous scientific studies, including one on the integrity policy of the Dutch police (Lamboo, 2005; Huberts 2005). But this focus on professional integrity has not prevented serious integrity violations at all levels of the Dutch police force from occurring over the last decade. Political integrity became a problem as well. Politicians from various parties have been found guilty of dishonesty and had to leave their posts. The construction and real estate sectors have also had their share of fraud cases, bringing the issue of professional integrity further into focus (House of Representatives Acts 2002-2003, 28244). Since the 2008 economic crisis, the issue of integrity and fraud in the financial and banking sectors has been on the political agenda. Apparently, some practitioners in these sectors are under the impression that fraud pays off. Scandals such as those involving Madoff (Stewart 20II), the Lehmann Brothers (McDonald and Robinson 2009) and other lucrative enterprises have prompted new measures against financial fraud in the United States. Major financial fraud and money laundering scandals at the Royal Bank of Scotland, the Rabobank of Europe and the ING bank of the Netherlands, have called the professional integrity of top-level European executives into question as well. 
In the Netherlands, we have seen serious cases of fraud in housing corporations, health care and special education funding. These cases have mostly involved the financial conduct and judgment of professional service providers. Social security fraud is another issue that has received a lot of attention in recent years, and the penalties have increased dramatically. The integrity of lawyers, public prosecutors, judges and notaries has been called into question following a number of notable cases in which rules of honor were violated. In the Catholic Church as well, we've seen long-concealed cases of sexual abuse come to light in recent decades, and a European chapter on sexual abuse in the church has been created as a result. Other cases of sexual abuse in the church have emerged in Ireland, the Netherlands, Belgium and Germany and other countries as well. And let's not forget all the scandals that have emerged in the world of professional sports, especially the numerous doping cases that have emerged in recent years. Anyone who wishes to compare today's scientific world to that of professional sports should know what such a comparison suggests: that winning is all that matters, by whatever means necessary. All of these cases raise questions about whether existing norms and deep-rooted values are still present in society and whether people still take them seriously.

In his Theory of Justice, philosopher John Rawls makes a general remark about the relationship between trust and integrity: "In times of social doubt and loss of faith in long-established values, there is a tendency to fall back on the virtues of integrity: truthfulness and sincerity, lucidity and commitment, or as some say, authenticity" (Rawls, I971: 519-520). One might ask whether there will be a large-scale crisis of trust in social institutions in the first decades of the twenty-first century. Of course, such a broad question cannot be answered in such a small study, but I do wonder.

It is therefore unsurprising that the interest in scientific integrity has increased. One case that attracted a great deal of attention in the US was the "Baltimore affair", which involved suspected research fraud by an employee of Nobel Prize-winning biologist David Baltimore. From I986 to I996, this case had a direct and indirect impact on the professional lives of many scientists and academics. Since the fraud was carried out with taxpayer money, members of the US Congress got involved. In 1989 , the US government established an Office of Scientific Integrity, which was renamed the National Office of Research Integrity in I992. The Baltimore affair would eventually become the subject of several extensive reports by the National Academy of 
Sciences and numerous individual studies (Kevles I998; Freeland Judson 2004: I9I-243).

Scientific integrity concerns all areas of science, not just research funded by the government. Following a much-discussed plagiarism case in the Netherlands (the Diekstra affair, I996-I998), three Dutch organizations, the Royal Netherlands Academy of Arts and Sciences (KNAW), the Association of Universities in the Netherlands (VSNU), and the Netherlands Organization for Scientific Research (NWO) joined forces in 200I to address the issue of scientific integrity. In May 2003, the Netherlands Board on Research Integrity (LOWI) was established, and a code of conduct for scientific researchers was drawn up. This code, known as the Netherlands Code of Conduct for Scientific Practice, was first published in 2004 and went into effect on January I, 2005 (with revisions in 2012 and 2014; hereafter, for convenience it will mostly be referred to as the "2004/2012/2014 Code"). In other countries, such as Norway, Denmark and England, a similar trend has been observed: a high-profile scientific fraud occurs and then governments and universities are compelled to take action. But is this all too little too late? And what is scientific integrity anyway?

\section{I.2 INTEGRITY AS A STANDARD LINKED TO ONE'S POSITION}

Scientific integrity falls under the umbrella of scientific ethics. In addition to integrity and honesty, scientific ethics includes issues such as the treatment of animals, the handling of subjects and patients, the permissibility of certain research methods (e.g. in the case of cloning and stem cell research), and the propriety of client relationships. Of these various aspects of scientific ethics, this study will focus primarily on the role of integrity. Client relationships are only mentioned in the context of commissioned research.

On the whole, I consider integrity to be a social value that is linked to one's role in society. Each profession has its own standards of conduct, which may vary according to the social context in which its practitioners operate. The definition of misconduct is linked to this context. For example:

- Officials may not accept money or favors for certain services or to help sway decisions. They may not use their position to distribute favors or offer jobs to friends, relatives or business partners outside of the standard regulations. 
- Doctors have a universal duty to help anyone in mortal danger, regardless of his or her nationality or of enmity; they are also bound by standards of professional confidentiality.

- Lawyers are also bound by standards of professional confidentiality and have a duty to maintain both professional and financial independence from their clients; thus, any funds entrusted to their care must be kept strictly separate from their own affairs.

- Judges must remain impartial at all times. They may not, as Judge Azdak in Bertolt Brecht's classic play The Caucasian Chalk Circle, use the seat of justice to serve private interests (Brecht I955; 2003: 90) or accept gifts from grateful citizens.

- Priests must uphold the values of their office. If they have taken an oath of celibacy, they are banned from all forms of sexual contact. This code of conduct is only applicable in the context of their faith, as there would be no reason to impose celibacy on the general public.

- Journalists have a duty to truthfully report what they see, hear, or otherwise gather as newsworthy facts; this can result in specific problems for spin doctors and embedded journalists aiming to convey a specific message.

- The business community has developed its own standards for handling bribes and established rules to prevent conflicts of interest and insider trading, but the use of lies and deceit in ordinary sales and purchases is less strictly regulated. When it comes to selling used cars or other items, for example, the caveat emptor is that all sales are at the buyer's own risk, no matter how naïve he or she may be. 
All of these examples illustrate how integrity is linked to specific standards, which are derived from the institution's core values. These values tend to vary from one social sector to another; this is to be expected in an open society where people have different tasks and roles. Thus, it goes without saying that values in academia differ from those in other sectors of society. However, this can create tension, particularly when leaders from other sectors-for example, politicians-with different values and interests interfere with scientific research or try to impose their values on it. In this study, integrity is narrowly understood as the maintenance of standards linked to specific social positions, and not as, for example, compliance with general legal obligations that already apply to all citizens, regardless of where they live or work.

In society, there is nothing wrong with inventing a story and calling it a work of fiction. In science, however, inventing research data constitutes a major violation of the standards of responsible scientific behavior. Thus, in literature, fabulation is a norm; whereas in science, it is a violation of a norm. A classic example of this (which will be discussed later) is the case of Cyril Burt, a British psychologist who was found guilty of fabricating research data from 1952 to 1962 . Of course, this is not to say that scientists are not allowed to use the power of their imagination to formulate new hypotheses, but they have to make sure their fantasies are not presented as facts.

There are plenty of instances where it is perfectly acceptable to copy other people's words. For example, it's not unusual to retell someone else's joke without mentioning the source. In journalism, press releases are often copied word-for-word without reference to the source. And in the church, old sermons from predecessors are sometimes reused. Government ministers will often adopt texts written by civil servants in their entirety and publish them under their own names at the end of their term in office; this is a generally accepted practice. And in the judiciary, copying judgments written by colleagues is far from forbidden. In fact, many judges prefer to copy the words of others because a departure from widely accepted formulations can raise questions. These are all cases in which the literal copying of others' texts is not regarded as a problem. In science, however, copying is not permitted, at least not without properly acknowledging the source. 


\section{I.3 INTEGRITY AS A STANDARD FOR ONE'S OWN BEHAVIOR}

Although there has been plenty of talk about integrity, there are only a few studies that delve into what the concept actually means and where it comes from. The Latin word integer was initially used in a quantitative sense to mean 'whole' (i.e. whole numbers), 'undamaged', 'untouched', 'unharmed' and 'complete down to the last detail'. But according to the classicist Cornelis Verhoeven, around the time of Cicero it took on a qualitative meaning of 'honest', 'inaccessible to corruption' and 'incorruptible' (Verhoeven 2002: 208). Around the same time, the poet Horace used the words integer vitae in one of his famous Odes (I, 22), which would be translated by Piet Schrijvers as "whose way of life is free from evil deeds" (Horace, tr. Schrijvers 2003: 232 and 233). In Cicero's De Officiis, the term integer is used as well, this time in the sense of "living in accordance with nature" (Cicero, Book III: 3: I3). Cicero notes that honest people are called to govern the masses and to protect the weak from injustice. He refers to Socrates, who said that the most direct way to a good reputation is to "be the person we wish to be" (Book II: I2: 4I-43; translation Higginbotham I967: II3-II4; Beebe I995: 7-I6). The essence of integrity lies in the intrinsic motivation to follow virtue, not in the desire to use it as an instrument of self-interest (Book III: 33: 18; Higginbotham, I967: I82). In this sense, the concept of integrity is still present in moral philosophy today.

In his description of integrity, the Anglo-American philosopher Bernard Williams emphasizes the responsibility one feels for one's own behavior, regardless of its usefulness or benefit and regardless of the behavior of others or the demands that others make of you:

"a consideration involving the idea, as we might first and very simply put it, that each of us is specially responsible for what he does, rather than for what other people do. This is an idea closely connected with the value of integrity" (Williams I973; I0 ${ }^{\text {th }}$ edition, I993: 99).

In other words, integrity is about commitment-the commitment that one makes to one's own chosen values. These values provide a moral identity to which one's behavior can be attuned, and the commitment to these values brings unity to one's thoughts, desires and actions. In my opinion, Wil- 
liams's general description of integrity can be applied to scientific integrity as well. Although certain aspects of his notion of integrity have been criticized (cf. Fleischacker 1992: 227-23I; Markovits 2009), it includes two aspects that are widely accepted. First, integrity is part of a whole; it's a plan or project that lasts a lifetime. Secondly, having integrity means that one does not carry out actions that are directly in conflict with one's values. In other words, when people with integrity fail to adhere to their own values, they can't bear to look at themselves in the mirror. Other writers note that integrity involves taking responsibility for one's own actions and speaking and acting with conviction (Carter 1996).

The Oxford English Dictionary defines integrity as "the quality of being honest and morally upright" and as "the state of being whole or unified" (OED 2012). In other words, integrity is striving for honesty, sincerity and truthfulness, or freedom from moral corruption. "Scientists have intellectual integrity insofar as they strive to follow the highest standards of evidence and reasoning in their quest to obtain knowledge and avoid ignorance" (Resnik, I998: 84). Integrity leads to mutual trust. In her short introduction to Research Integrity and Responsible Conduct of Research, Ann Nichols-Casebolt refers to a definition provided by the Institute of Medicine in 2002: "Integrity in the conduct of research has been defined as an individual's commitment to intellectual honesty and personal responsibility that embraces excellence, trustworthiness and lawfulness" (Nichols-Casebolt, 2012: 3-4; Institute of Medicine, 2002).

The fact that integrity as a social value has received so much more attention over the past decade isn't all that surprising. I suspect that this isn't only due to the rise in high-profile integrity violations, coupled with diminished trust in various social institutions (e.g. churches, banks, politics and government, science), but also-and perhaps even more so-due to the effect that so many rapid changes have had on people's personal identities. Grudin notes: "More than a virtue or group of virtues, integrity is an affirmation of self in a world where the defining outline of an individual often seems to be no more than a transparent and absorbent membrane between impersonal inner and outer forces" (Grudin, I982:48). According to Grudin, the characteristics of integrity are trust in oneself, stability of character, and spiritual perseverance. These qualities do not manifest themselves in a single instance of behavior, but in a series of challenges that take on different forms (idem: 47-48). The result is unity between one's internal standards and external 
behavior. People of integrity demonstrate a conscious consistency in their thoughts and actions, which persists over time. But just because someone has integrity does not mean that he or she is a superhero. Even honest people will be surprised, frustrated or confused from time to time. However, they are less likely to fall victim to morally compromising circumstances. A person of integrity is prepared for anything and always ready to act appropriately (Grudin, I982: 5I; I990: 73-75).

When it comes to understanding the concept of scientific integrity, I find Williams's description - 'consciously choosing to take responsibility for one's own behavior'- particularly useful because it implies that integrity is not bound by external pressures. It is also separate from the behavior and exhortations of others. This emphasis on autonomy is characteristic of most professions (doctors, lawyers, architects, etc.), but it also offers a good characterization of scientific research as a specific profession. Approximately $5 \%$ of all university graduates go on to pursue a career in science and research (Chion Meza 2012). The integrity required for such a profession must be personally internalized as a standard for one's own behavior: "This is how I want to behave; this is how I should behave; this is how I will behave."

In some professions, this promise is actually verbalized at the start of one's career in the form of a professional oath, for example the attorney's oath or the Hippocratic oath (Houtzager 2004: II-26). Would such an oath also be useful in the academic and scientific world? If so, when should it be taken? At the beginning of one's university studies, at the onset of a research project or upon graduation? Obviously, people aren't born with an internal standard of integrity. They are born with the ability to internalize cultural influences, which may later be reflected in their behavior. These cultural influences can lead to exemplary behavior among professional colleagues, who in turn can serve as sociological role models for others, particularly young people. Ultimately, they can internalize this behavior as well. This process of internalization, which goes beyond social control or the fear of punishment, is, in my view, crucial to the development of scholarly attitudes and scientific integrity. The scientific and academic community have an important role to play in this, namely in promoting the values of scholarship through role models (mentors, lecturers, promoters, research leaders) and passing them on to younger generations (see Chapter 7 ). 


\section{I.4 SCIENTIFIC VALUES AND THE BASIC STANDARDS OF INTEGRITY}

Anyone who chooses to enter a scientific field is also choosing to accept the specific values inherent to science. There is a higher demand for honesty and transparency in science than in everyday life, where a little lie can sometimes be justified. But given that science is primarily concerned with developing its own truths, which can sometimes be diametrically opposed to social judgments or prejudices, it is important to consider the way in which scientific truths are formulated. Science has developed its own values, which are generally associated with openness, honesty, scrupulousness, objectivity, an unbiased attitude, independence and a love of truth. Take the example set by two well-known sociologists, Max Weber and Robert K. Merton. Shortly after the First World War, Weber described the choice to enter the scientific field as one that should be approached with great care. The scientific profession adheres to specific values; it is a profession with a special ethos, quite unlike any other choice of profession. Weber drew a sharp contrast between Wissenschaft als Beruf [science as a profession], which is characterized by the independent and constant search for knowledge and truth, and Politik als Beruf [politics as a profession], which involves the pursuit and exercise of power. In his view, knowledge and power are two social values that are fundamentally opposed (Weber, I919; cf. Spinner 1985).

After the Second World War, R. K. Merton followed in the footsteps of his fellow sociologist. He gained recognition for his description of the five basic values of science (Merton, I949; I966: 550-561):

- Communalism: Scientists have a duty to exchange ideas and disclose information. The cooperative assessment of knowledge is necessary to stimulate knowledge growth.

- Universalism: Knowledge can be universally acquired and disseminated. It is not bound to any nationality, ethnicity, religion or political perspective (cf. the rejection of Einstein's theory of relativity on ethnic grounds in Nazi Germany; the acceptance of Lysenko's pseudoscientific theory of heredity on political grounds in the Soviet Union). 
- Disinterestedness: Science is its own domain; it is not dependent on other non-scientific or political interests.

- Organized skepticism: We don't know everything yet; our knowledge is not yet sufficiently precise. Scientific claims should be critically scrutinized before being accepted.

- Humility: in the face of the whole of reality, we only know the very beginnings of what exists.

The question remains whether these values offer an overly idealistic vision of scientific practice and whether they need to be revised for our times. Nevertheless, one thing is certain: science adheres to specific values that have been developed and solidified over time and that do not necessarily coincide with those of other social institutions.

In science, skepticism is a tremendous asset. The moment it is lost or forgotten the integrity of science is at risk. The notorious fraud of the London psychologist Sir Cyril Burt offers lessons we can learn from. In the late-I950s, at the end of a successful career, Burt made a grave mistake. Driven by the ideological assumption that intelligence is hereditary, Burt fabricated research results and published them along with two co-authors. In 1974, three years after Burt's death, statistician Leon Kamin published a book detailing the many gaps in Burt's research. He had discovered that three of Burt's experiments had the same high correlation coefficient of $0.77 \mathrm{I}$, which was statistically improbable (Kamin 1974: 59). Kamin tried to contact the two co-authors but couldn't find them. That's when things really heated up. At first, the scientific community attacked Kamin for accusing Burt of fraud, but after a few years, a definitive conclusion was reached: Burt's fraud was undeniable, the allegations against him were true, and his biographer couldn't find any trace of the two co-authors. In his review of Burt's biography, Mackintosh states that the unacceptability of Burt's data should have already been apparent: "It should have been clear to anyone in 1958 who had eyes. But it was only recognized after Kamin pointed out Burt's totally inadequate reporting of his data and the improbable uniformity of his correlation coefficients" (Mackintosh 1980: 174-175; quoted in Colman 1989: 32).

Why did Burt commit scientific fraud? Was it out of enthusiasm for his profession, honor, fanaticism for a political conviction? This is just one of 
numerous cases of blatant scientific fraud. Fraud occurs in all scientific fields at all levels. Unfortunately, it is often detected too late, and oftentimes not by the scientific community itself but by the media.

This brings me to the most basic standard of what constitutes a violation of scientific integrity, as formulated by LOWI in 2008:

"In the opinion of the LOWI, a violation of scientific integrity is any case where open publications and/or conduct violate the general obligation to truthfully present data from scientific research, including

(a) any effort to falsify, manipulate, conceal, fabricate or present fictitious data as authentic during the course of scientific research;

(b) any case where data, literal passages of text and unique and original scientific ideas are taken from other sources, without correct or complete reference to the source, and are published under the author's own name" (LOWI opinions 2008-I; 2013-2).

The first basic standard (a) refers to the invention or manipulation of research data, whereas the second basic standard (b) refers to plagiarism. While the first standard forbids a form of misrepresentation, the second prohibits the misappropriation of authorship (Freeland Judson 2004: 184-185). Together, these basic standards of science form three core rules of scientific integrity, or the avoidance of three core violations commonly known as FFP: "do not fabricate", "do not falsify" and "do not plagiarize."

Although these rules are fundamental to scientific practice, they cannot be regarded as an absolute norm. Why not? There are numerous instances of violations that can only be assessed on the basis of concrete circumstances. Let's consider, for example, the Sokal case. The physicist Alan Sokal wrote a completely fabricated article titled "Transgressing the Boundaries: Toward a Transformative Hermeneutics of Quantum Gravity" and submitted it to the journal Social Text, which published it (Sokal, 1996a). He then wrote another article describing the hoax and submitted it to another journal, Lingua Fran$c a$, questioning the critical standards of assessment employed by Social Text (Sokal 1996b). His article in Social Text was a parody of the jargon, rhetoric and postmodern reasoning styles common to cultural studies of science and 
technology. Yes, he had fabricated research data. Did he violate scientific codes of intellectual honesty? Did he cross a line by transgressing established boundaries? I don't think so. The fact that the article was a parody was as plain as day-arguably, it was already evident in the title. According to Sokal, the experiment was not intended to cast a bad light on the journal's editorial staff, but rather to protest against an overly subjective conception of science, knowledge and truth (see also: Sokal and Bricmont, I998: 259-267 and 268-280). In my opinion, the author successfully fulfilled his aim, and given the context and intentions, his case cannot be categorized as "fabricated science."

The values of the scientific ethos, as described by Merton and later by Spinner (1985), are by no means fixed. They need to be reformulated for our times to reflect the insights that have been gained from a justified criticism of an overly inward-focused and complacent scientific practice. It is not a question of whether old values should make way for new ones, but of a redefinition of the scientific attitude that can unite scientists young and old, that connects old values with new science and present-day challenges. Today, an honest and responsible scientific practice calls for:

- curiosity and skepticism

- an open mind and sufficient attention to the knowledge system

- tolerance and self-awareness of one's own choices

- cooperation and competition (when this stimulates innovation)

- universalism and attention to local values

- independence of mind and willingness to cooperate

- maintaining a criticial attitude towards institutional authority and a lasting belief in the value of scientific knowledge

- awareness that nothing is certain and the recognition that some things can be known more confidently than others (Schuyt 2006: 233-24I). 


\section{I.5 SCIENTIFIC INTEGRITY IN PRACTICE: AN INITIAL EXPLORATION}

Now that we've formulated the basic standards of integrity, I would like to conduct an initial exploration of general scientific practice, which is much more difficult to assess than isolated cases of scientific fraud. What does scientific integrity look like in practice? Unlike in the governmental, medical and real estate sectors, there has been relatively little research into fraud in science and academia. The question is whether research into dishonest behavior in scientific research is necessary or desirable. Opinions are divided on this matter, and it is difficult to determine whether the number of violations has actually increased. If one wants to answer the question from a purely quantitative perspective, the situation may not seem so dire (more on this in Chapter 3). In the United States, the Office of Research Integrity registered I 53 cases of fraud in biomedical and medical research over a period of thirteen years, from 1992 to 2005 , out of a total of more than 100,000 subsidized studies (http://ori.dhhs.gov; Huberts 2005: 29). More recent studies have reported that $\mathrm{I}-2 \%$ of all researchers surveyed admit to having fabricated and/ or falsified data (Fanelli 2009). The best conclusion that we can draw from this and other research is simply that we just don't know how much fraud is taking place in the scientific world. Only a well-designed study could provide us with a reliable answer to this question.

From a qualitative point of view, however, there is evidence to suggest that violations of scientific integrity may be on the rise. Nowadays, we have more technology to manipulate texts, data and images than ever before. Authors are now able to pluck material from any of the hundreds of thousands of scientific articles published each year and publish it under their own name without anyone noticing. Moreover, it is possible that the growing competition for jobs, research grants and contracts has increased the amount of fraud taking place. Again, the only real conclusion that we can draw from this is that we simply do not yet know if such a causal relationship exists.

What kind of violations should we be concerned about? What might motivate someone to abandon his or her commitment to scientific integrity? And how can we encourage students and researchers to internalize the standards of scientific integrity and apply them to their research? I will discuss these issues in detail in the following chapters. But first, allow me to begin with a brief introduction to the central questions at stake. 
Manipulation of research data: errors and mistakes

The fabrication of research data-which is fairly rare-is difficult to detect; but what is even more difficult to detect is the manipulation and falsification of data. Falsification can occur during all phases of data management, from collection to selection, registration, storing, analysis, interpretation and presentation. It is not always easy to distinguish intentional falsification (fraud) from accidental falsification (error), unless the falsification is systematic or evident in faulty statistical analysis and improbable results. Here, honesty plays a major role. The practices known as cooking, trimming and fudging should be avoided; however, all three commonly occur. Cooking refers to the omission of negative results in order to promote the expected results. This can be done by trimming, meaning tweaking statistical tests, or by fudging, meaning attempting to cast the results in a more favorable light (more on this in Chapter 3). It can be tempting to twist or embellish one's own research by omitting or manipulating data, especially in a cultural climate where embellishment, or "upgrading", is often encouraged. In a criminological study, $60 \%$ of the students surveyed said that they had no qualms with "pimping" their curriculum vitae, even if it meant bending the truth (personal communication F. Bovenkerk).

According to David Resnik, these forms of scientific dishonesty must be distinguished from mistakes and sloppiness (Resnik, I998: 56-58). Mistakes are part of the scientific process, and errors in measurement are inevitable. Errors in reasoning, calculation methods and evidence should be identified and corrected by peer reviewers and the scientific community. The same goes for typos that affect the accuracy of the data, for example the placement of a decimal point (e.g. o.or instead of o.oor). Even incorrect page references in footnotes, however sloppy and tedious they may be, are generally just mistakes; they are not violations of integrity. For theological reasons, Copernicus falsely assumed that God had created the world perfectly-and what is more perfect than celestial bodies moving in perfectly circular orbits? His theory proved to be incorrect, but his research met the standards of the scientific method, which means that by today's standards it would be called "honest", in spite of the faulty reasoning behind it. Mistakes and cases of minor carelessness do not constitute a violation of integrity. But according to the core rules of avoiding FFP, which certainly extend to the questionable research 
practices of cooking, trimming and fudging, these mistakes could be regarded as different forms and stages of data manipulation.

Adjusting research results: conflicts of interest

Adjusting research results, changing texts for non-scientific reasons, omitting outcomes that are unfavorable to the parties involved or providing incorrect or incomplete reports are all examples of dishonest research practices. If any of this is done under pressure from clients, the scientific independence of the researcher is also at stake. In the I95os, for example, the American tobacco industry started suppressing research that suggested a positive correlation between smoking and lung cancer. The industry even went so far as to commission research specifically intended to counter these claims (Oreskes and Conway, 2010: 136-168).

Researchers, at all levels of their careers, can succumb to external pressure to adjust their research results. Perhaps they are concerned about the future of their funding or feel pressured by politics or political ideology; regardless, the question remains as to what extent such adjustments can be tolerated. This question becomes even more urgent when scientific researchers share their clients' interests. Researchers may hold management positions or shares in the companies that fund their research, resulting in a conflict of interest. They may also serve as scientific consultants to the companies or public institutions they work for. Potential conflicts of interest such as these need to be clearly stated in their report, so that readers will know to examine the results critically. Of course, not all commissioned research leads to the manipulation of results, but the risk has prompted two new basic standards of scientific integrity: known conflicts of interest between the researcher and his or her non-scientific interests must be avoided at all times, and any potential conflicts of interest must be mentioned in the final publication of the research. The latter is intended to reduce the tension between the researcher's own interests and those of his or her clients by making these interests public.

It is impossible to say how often such tensions between clients and researchers arise, but one thing is certain: they do. In their aptly titled book, De Onwelkome Boodschap [The Unwelcome Message], Köbben and Tromp provide clear examples of how scientific freedom is under threat (1999); they maintain that this is largely due to the amount of funding from government 
ministries and other political institutions. However, these kinds of clashes can be easily avoided by drawing up contracts beforehand that establish the researchers' freedom to independently report and publish their results. Nowadays, such contracts are fairly commonplace.

All of this suggests that there is a problem with the position of science and scientists in politics and society. The method regularly used by the NWO to allow co-funding ministries to have a major say in the development of research needs to be critically examined and vigilantly monitored. These ministries are often terrified of receiving even the slightest criticism of their governmental policies-but criticism is the very breath of science! Thus, it is important to make sure that the specific values and interests of the funding institution, particularly those with a political agenda, do not interfere with the scientific research at hand. In all cases, there should be enough space for the specific values of science: openness, honesty, scrupulousness, nuance, freedom, truthfulness-in short, integrity.

\section{Unconscious bias}

The third (and in my opinion, trickiest) threat to scientific integrity is unconscious bias, often rooted in wishful thinking. Unconscious bias occurs when a researcher expects a certain outcome and keeps testing until that outcome is achieved. This does not necessarily mean that the results have been tampered with or deliberately manipulated, but insufficient skepticism and a less rigid approach to statistical testing can still lead to a one-sided representation of reality. For example, one group of biomedical researchers demonstrated how industry-funded research into the relationship between certain medication and thrombosis systematically indicated lower risks of thrombosis than the same type of research funded by public sources (Kemmeren et al. 200r: $\left.\mathrm{I}_{3} \mathrm{I}-\mathrm{I}_{3} 8\right)$. Where does unconscious bias end and manipulation begin? My intention here is not to promote a negative attitude towards privately funded research, but rather to underscore the researchers' obligation to report potential conflicts of interest and to encourage the scientific community to play a more active role in identifying breaches of scientific integrity. 


\section{Power relations}

One final threat to scientific integrity that I'd like to mention are the long-standing power relations in research centers. For example, professors may try to appropriate their students' ideas and data into their own research or demand that their assistants include their professor's name on publications, when in reality the assistants have done most of the research themselves. These practices are not uncommon, though again, we do not know when and how often they occur. Such power relations can lead to two serious violations of scientific integrity: the denial of authorship on the one hand, and the unwarranted attribution of authorship on the other. In the former case, an assistant researcher receives too little recognition for his or her work; in the latter case, the powerful professor or research leader receives more recognition than he or she is due. "Put my name on it" may seem like a simple request, but it is often a distortion of the person in power's actual contribution and an attempt to see his or her name on as many publications as possible (more on this in Chapter 6). 



\section{Chapter 2}

\section{The codification of behavioral standards for scientific research}

\section{I MUDDYING THE WATERS OF SCIENCE: THE STAPEL AFFAIR}

In early September 20II, the scientific community in the Netherlands was rattled by reports of a remarkable case of scientific fraud committed by social psychologist Diederik Stapel, a well-established and highly respected professor at Tilburg University. It turned out that Stapel had been inventing research data and fabricating his own experiment results for years. The fraud was discovered by a group of young PhD students, who, while repeating some of Stapel's experiments, did not arrive at the same results. Pretty soon, they began to doubt his statistical calculations and outcomes as well-and with good reason. Their distrust eventually compelled them to bring the case to the attention of the Rector Magnificus, who soon confirmed that Stapel was guilty of very serious academic fraud.

After a few days, Stapel confessed and resigned as professor. A committee chaired by Professor Pim Levelt carried out a deeper investigation into all of Stapel's scientific articles. It soon became clear that in previous years, when he worked at the University of Groningen, he had also manipulated and fabricated data in a large number of his articles, many of which were written with co-authors. A total of 55 articles with Stapel's name on them contained fraudulent information and ten dissertations carried out under his supervision were based on his fabricated and/or manipulated research data (Levelt et al. 2012). Stapel had knowingly put the careers of young scientific researchers in jeopardy. If you ask me, this is as reprehensible as the fraud itself, though this aspect of the case attracted far less public attention. Who knows how much damage his actions have had on the careers of others? 
What's going on here? Is this an extreme case of scientific fraud, the kind that only occurs once a decade? Or is it indicative of certain structural flaws in scientific research and/or the culture within scientific organizations themselves? The Stapel affair certainly warrants further research, especially given the fact that similar violations of integrity have occurred in other sectors of society as well.

\subsection{SOME EXAMPLES OF FRAUD}

The Stapel affair was not the first case of guile and deceit in science-and it wasn't the last, as we will see below. There have been countless cases of scientific fraud throughout history, some of which are downright absurd. There was the case of William Summerlin, a dermatologist in New York who, in 1974 , decided to treat his mice with a felt-tip pen to fake successful skin transplants. His fraud was discovered when his lab assistant gave the rodents a good bath (Grant, 2008: 32-33). Then there was Jan Hendrik Schön, a physicist once described as brilliant (Grant, 2008: 67-68), only to be found guilty of false measurements and other forms of deception in later years (Grant 2006; 2008; Broad and Wade I983). Long before the Stapel affair, the Netherlands saw its fair share of crazy schemes as well, many of which passed for reliable science for years. Take, for example, the VU Amsterdam professor Anthonie Stolk, who, in the I950s and ig6os, made up data on fish tumors and wrote numerous anthropological articles and reports on African populations that didn't even exist (Van Kolfschooten I993, 2012).

We can certainly learn from these extreme cases of fraud, but they don't bring us much closer to answering the primary question: Are these isolated incidents or is there something wrong with modern scientific practice? What conditions promote poor research practices? Without further research, we simply cannot say, and by only looking at spectacular cases like the Stapel affair, we aren't getting the full picture.

In some ways, we can compare these cases of fraud in academia to cases of abuse in the Catholic Church: both institutions are faced with a "numerator-denominator problem". How does the number of cases discovered compare to the total number of cases out there, including those that have gone undetected? In the Netherlands, in the early 20Ios, the universities employed 17,000 researchers, each of whom was involved in one or more rese- 
arch projects (Rathenau Institute, Chiong Meza 2012). Of the I02 allegations of fraud or plagiarism reported by Dutch universities from 2005 to January 20I2, more than half turned out to be unfounded (Berkhout and Rosenberg, NRC January I4, 20I2: 8-9). To me, this suggests that it is too soon to speak of a structural problem or a crisis of trust in science. Without further research, we know very little about the prevalence of scientific fraud and the extent to which it occurs. So, what do we know?

Since the Stapel affair, three issues have received more attention:

- scientific dishonesty and misconduct (which extends beyond fraud to include plagiarism and issues surrounding co-authorship as well),

- scientific integrity

- the importance of conducting sound scientific research (in other words, being a good scientist).

These three issues are often confused, and it's often the gray areas that attract the most attention. When does careless, sloppy research become so bad that the researcher's integrity is called into question? That a scientist produces sloppy research does not necessarily mean that he or she lacks integrity. The scientific community is also responsible for distinguishing between good and bad research and making sure that the body of knowledge is not polluted by a few bad eggs. Allow me to provide a few well-known examples.

Pons and Fleischmann's research into a technique for cold nuclear fusion in March I989 was poorly designed. The results of their controversial article, which had been published without peer review, were contradicted within a few months of the publication. Scientists around the world tried to replicate their study, but none succeeded (Grant, 2008: 65-67). Pons and Fleischman may have been poor researchers, but they were not fraudsters. Another case, the "discovery" of the Piltdown Man in England in I912-13 -in which bone fragments were presented as the fossilized remains of a previously unknown early human (Wikipedia) - was an outright hoax, born of an overzealous sense of patriotism. Although it took forty years before the fraud could be proven using new dating technology (Walsh 1996), it is a clear example of scientific fraud. 
Three other well-known cases require more discussion. In I865, Czech priest Gregor Mendel, assisted by a fellow friar and an ambitious gardener, presented the results of his genetic experiments with peas, which eventually brought him international fame. However, it later turned out that some of these results may have been too good to be true. In I93I, the statistician-biologist Sir Ronald A. Fischer (creator of the Fischer t-test) noted the improbability of such beautiful regularity in successive generations of peas and presented his findings to the scientific community (Fischer, 1936 as cited by Klotz: 1992: 2272; see also Irving M. Klotz, 1992: 2271-2273). Later, Teddy Seidenfeld (Tudge 2002: 94-97) refined Fischer's assertions somewhat, but no one ever questioned Mendel's sincerity. His theory of genetics was and remains a fine example of scientific creativity (Broad and Wade 1983: 3I-33; Grant, 2008: 30-3I). Creativity in science can sometimes be at odds with prevailing opinions (Klotz, idem). In the I840s, Hungarian researcher Ignaz Semmelweis was the first to discover the causes of postpartum infections and propose simple hygienic measures such as washing one's hands after administering medical treatments. He was right about the spread of bacteria, but this was not recognized. His research was long regarded as questionable, largely due to suspicions raised by the director of the famous Vienna General Hospital (Hempel I970: 12-I7).

In an article from I9I3, physicist Robert A. Millikan omitted a significant number of negative measurement results from his analysis and publications. These omissions were only discovered upon scrutiny of his original lab journals after his death. In I923, however, Millikan received the Nobel Prize for his measurement of the elementary electric charge-incidentally, without mentioning his collaborator, Fletcher, who had conceived and carried out the original research (Broad and Wade, 1983 : 33-35; Johnson 2008: 155-156). Millikan omitted data to establish his theory, combining scientific creativity with selective reporting. All in all, these examples show the whole spectrum of scientific research at the very edges of scientific integrity: from blatant fraud that went undetected for forty years (the Piltdown Man) to highly innovative empirical and theoretical research that went unrecognized for years (Semmelweis) to poorly designed-but not fraudulent-experimental research (Pons and Fleischman) to the use of scientific-theoretical imagination with some questionable research practices (Mendel, Millikan). 


\subsection{FOUR CONCEPTUAL DISTINCTIONS}

These insightful examples from history not only illustrate how figures and research data have been tampered with in the past, they also underscore the importance of continuing to distinguish between the various issues at stake. There are four important conceptual distinctions to be made:

I. honest, bona fide research vs. fraudulent, mala fide research

2. questionable research practices vs. poor research practices

3. scientific controversies vs. integrity issues

4. game rules vs. goal rules

Game rules determine how the game is played (in chess, for example, a pawn cannot be moved three steps forward), whereas goal rules are guidelines for how the game can best be played (start with your pawns in the middle rows; don't play your Queen too soon-you can, but you'll regret it later in the game). Failure to follow the game rules renders the game invalid. Failure to follow goal rules won't help you win, but it's not a violation of the game rules (Wittgenstein I953: par. 33; 66; 197-206; Bird I972: IIO-II6; Rhees 2006: I67-I68).

The same goes for science: a poorly designed study, such as the one carried out by Pons and Fleischmann, may be foolish, but it is not necessarily a violation of the rules of integrity. In Wittgenstein's terminology, science is bound by certain constitutive rules, and violations of these rules render scientific research invalid. The basic standards of science formulated in the previous chapter (e.g. honesty, no FFP) are constitutive rules-i.e., they are game rules. In the development of the game rules of science, two other fundamental violations of integrity have emerged: conflicts of interest and failing to declare personal interests. Both pose a threat to "open and honest science". The same applies to denials of authorship and co-authorship, and conversely, to the unwarranted attribution of authorship and co-authorship. In the game of science, honesty matters above all else. 
Scientific fraud is not innocent. Misconduct breeds misunderstanding. One might think that fake experiments or fabricated data don't hurt anyone, but this is not true. Think of the damage to Stapel's students' careers. They had to withdraw all their publications with Stapel's name on them. Some of his $\mathrm{PhD}$ students even ended up leaving the scientific field altogether due to the resulting gap in their publication history. Not only was the scandal devastating to these young researchers, it also undermined people's trust in scientific research and called the integrity of science into question.

Stapel fabricated data in social psychology, but things can be even worse. In the biomedical field, for example, patients often serve as subjects for scientific research. The results of these studies can determine how new medicines are implemented and have a direct impact on the health of those involved. In 2013, it was discovered that Joachim Boldt, a highly reputable anesthesiologist in Ludwigshafen, Germany, had published no less than ninety articles based on fabricated data, causing one of the greatest scandals in medical research of all time. What's more, his fabricated data posed a serious risk to intensive-care patients at many hospitals because his so-called "findings" had served as a basis for special treatment methods. According to The British Medical Journal (March 19, 2013), it took a long time to separate Boldt's lies from established truths and to reevaluate research that was previously rejected based on Boldt's research.

All in all, dubious scientific behavior comes in many forms: from extreme cases of deliberate deceit to questionable research practices to the many examples of poor, sloppy research. All this research can be dangerous or harmless, depending on its application. And finally, research results are often disputed. Sometimes it's the method that's called into question; other times it's the researcher's integrity. This brings me to one of the most critical questions in scientific research: what constitutes a violation of the scientific code of conduct and what does not?

\subsection{THE EMERGENCE OF NORMS IN SCIENTIFIC PRACTICE}

When assessing suspected violations of integrity, it is important to keep the four conceptual distinctions described above in mind. Both the distinction between bona fide and mala fide research and that between good and bad 
scientific research are highly relevant. Poor or careless research does not necessarily lead to false results, and there are certainly cases of poor research with no dishonest intentions. On the other hand, some fraudulent research can be so cleverly hidden that it goes undetected during the peer review process.

Mala fide research always involves deliberate fraud, which has to be proven. The best-known examples of this can be found in the aforementioned 2004/2012/2014 Code and in other codes of conduct such as the European Code of Conduct for Research Integrity, also known as the ALLEA Code, adopted by the European Science Foundation for all research funded by the ESF (2010/2017; ALLEA stands for All European Academies). And then there are the internationally recognized FFP:

- Fabrication: the fabrication or creation of data and the publication of self-constructed research data

- Falsification: manipulating research data by, for example, changing measurement results and other results of research (e.g. survey results), changing or adjusting images, spectra, arrays, and/or deliberately withholding unwelcome or negative research data and results

- Plagiarism: taking literal passages of text and original scientific ideas from other sources and publishing them under one's own name without giving due credit to the original author and source.

These standards are deeply rooted in modern science. They have long functioned as norms, even before the establishment of codes of conduct. Codes of conduct can be regarded as codifications of standards that have evolved and become widely accepted in the scientific field over time. The fabrication and falsification of data pollutes the body of knowledge, thereby undermining trust in science. Plagiarism, on the other hand, undermines the reward structure in science, though it may not necessarily affect the body of knowledge, assuming that the plagiarized texts have been properly transcribed (see KNAW opinion 2012: 13). However, these serious violations of scientific conduct must be distinguished, both theoretically and practically, from poor 
and sloppy research work, especially when the research has been carried out with good intentions. Poor research can and should be corrected, but it does not necessarily mean that the researcher is a person of low integrity or that there has been a breach of the code of conduct. Questionable research practices remain a gray area, and cases of carelessness in research continue to raise questions (more on this in Chapter 6).

Here we can draw an important parallel with integrity issues in other sectors-take medicine, for example. A surgeon can make a mistake (i.e. malpractice, against which he or she is most likely insured), but that's not the same thing as a surgeon who has been strongly advised to stop doing surgeries because he or she no longer has a steady hand. If this person chooses to continue working anyway, it would be a violation of integrity. In the business world, a director of a large corporation can make a bad management decision without violating any standards of integrity. Only when certain codes of conduct have been violated or crimes have been committed (such as forgery or unlawful payments) can the case be considered a violation of managerial integrity. The line between a judgment error and an integrity violation is not always clear, so further discussion of the subtle boundaries of integrity violations is needed.

Then there is the matter of scientific controversies, which should be kept separate from integrity violations. If one does not agree with another researcher's results, it may be tempting to say, “Those findings can't be true-this must be a case of fraud." These types of controversies have become quite common in recent debates on climate change, for example, and the strong convictions on both sides make it all too easy to accuse the other of dishonesty, to use integrity as a weapon. But let's not forget that controversies are part of science. In fact, it is thanks to this constant discussion and debate that science is able to advance. Criticism is the breath of science.

Many countries, the Netherlands included, have been slow to codify the standards of scientific research, only taking action after a scandal has occurred. In the United States, an intense debate arose in the late I980s and early I99os around the handling of the above-mentioned Baltimore affair, in which the very freedom of science was at stake (more on this in Chapter 3). In I992, the National Science Foundation (NSF) and the Academy of Sciences established a code of conduct based on the forms of misconduct revealed in previous years: 
"(I) Fabrication, falsification, plagiarism or other serious deviation from accepted practices in proposing, carrying out, or reporting results from activities funded by National Science Foundation; or (2) Retaliation of any kind against a person who reported or provided information about suspected or alleged misconduct and who has not acted in bad faith" (my emphasis; National Academy of Sciences, I992; see also: Freeland Judson, 2004: I72).

In its simplicity and brevity, this wording is a good reflection of the basic FFP standards, and it also stresses the importance of protecting those who report cases of suspected misconduct. A similar definition of misconduct was provided by the National Institute of Health (NIH), which, as part of the United States Public Health Service, annually provides federal grants for biomedical research and thus has a vested interest in ensuring that the projects it subsidizes are carried out in an indisputably correct manner. The NIH also mentioned FFP and "other practices that seriously deviate from those that are commonly accepted within the scientific community". At one point, however, the NIH's description of what constitutes a violation of integrity differed from that of the National Science Foundation (NSF), which "does not include honest error or honest differences in interpretations or judgments of data" (Freeland Judson, 2004: 172). In other words, scientific controversies and differences in interpretation are, according to the NSF, explicitly excluded from the notion of "scientific integrity". The discussion did not elaborate on FFP or what constitutes an "honest error", a matter which is certainly open to interpretation. Moreover, the notion of "honesty" can be quite problematic when it comes to assessing errors.

This public discussion in the US after the Baltimore affair focused primarily on the "serious deviation from generally accepted research practices." What did this mean? Members of the scientific community were quick to point out that plenty of innovative and creative research deviates from standard norms and practices. Could such research now fall under a strict definition of misconduct? Moreover, the wording was so vague that some feared it would create a great deal of uncertainty as to what was permissible and what wasn't. Many saw it as a government-led attack on scientific freedom. Howard Schachman, a biochemist at UC Berkeley and well-known advocate for research ethics, laid out his objections in Science magazine: 
"Not only is this language vague but it invites over-expansive interpretation. Also, its inclusion could discourage unorthodox, highly innovative approaches that lead to major advances in science. Brilliant, creative, pioneering research often deviates from that commonly accepted within the scientific community" (Schachman I993: I48-I49).

Schachman even went so far as to cite examples from history, where such definitions facilitated government interference in science: for example Einstein's theory of relativity in Nazi Germany and Lysenko's theory of heredity in the Soviet Union (Freeland Judson, 2004: 176), as mentioned in Chapter I.

On the other hand, supporters of the broad NSF definition raised an equally essential point, namely that the use of the term "accepted practices" implied that the evaluation of standards and breaches of those standards would be left to the scientific community itself, not to a public body. In other words, scientists would continue to judge the research practices of their fellow scientists, so the independence and freedom of science would not come under threat (Goldman and Fisher, 1997). In his commentary on this heated debate, Freeland Judson (2004: I78-I80) remarked that the notion of "accepted practices" is not unusual in other sectors. In codes of conduct for lawyers, notaries and engineers, one generally finds a clause referring to the professional standards of behavior that must be observed. In other words, a lawyer needs to act like a lawyer. What exactly the specific standards of behavior in a given profession do and do not entail is often the subject of disciplinary procedures.

Nevertheless, the broad definition did not survive the ongoing debate. In I999, following the work of several committees, the Ryan report recognized FFP as three categories of scientific misconduct, but all reference to deviations from common practices had disappeared. The notions of "honest error" and "honest differences of opinion" survived the national debate, which went all the way up to the White House. The NSF scientific code of conduct has since been incorporated into US federal law, which means that in the US, committing one of the FFP crimes in government-subsidized research projects is a violation of the law, and the perpetrator may be subject to imprisonment. 


\subsection{A CASE STUDY: THE CODIFICATION OF NORMS IN THE NETHERLANDS}

The creation of a national scientific code of conduct in the Netherlands was less of a struggle than it was in the United States. The Netherlands Code of Conduct for Scientific Practice was drawn up in 2004 by a VSNU committee led by the Rector of the University of Amsterdam at the time, Paul F. van der Heijden, and went into effect on January I, 2005, under the auspices of the KNAW, VSNU and NWO. The Code applies to all employees at Dutch universities and to all researchers at KNAW and NWO research institutes. Unlike in the US, there has been virtually no public debate on the matter in the Netherlands. However, prior to the Code, there had been several notes and protocols that served as building blocks for rapid formulations, fueled by various integrity scandals at the time (Buck 1990-I994; Diekstra 1996-1998).

In October 1995, a memorandum on scientific misconduct was published under the auspices of the KNAW, VSNU and NWO. This was the first attempt to define the habits and practices of scientific research and create a normative force-and hence, to codify scientific conduct. The Dutch term for scientific misconduct, wetenschappelijk wangedrag, was introduced with reference to the NIH's publications in the US. However, the English term "misconduct" implies both improper professional conduct and mismanagement, financial or otherwise. At the time, the Dutch notion of "misconduct" had not yet been defined, so the concept was rather vague. According to NIH publications, some form of misconduct had been found in one out of every 2,000 NIH-subsidized studies. The Dutch memorandum concluded that although such misconduct seemed rare, no concrete data on the subject was available. The memorandum also emphasized the importance of education and training to prevent misconduct: "It is important that an awareness of standards be passed on, particularly with respect to reliable data processing and the application of statistical techniques, careful reporting, giving credit where credit is due, providing complete bibliographical references, correct quotations, etc." (KNAW 1995). Research organizations need to take action on matters related to scientific misconduct and alert their members to its existence in order to minimize dubious and fraudulent behavior as much as possible. This memorandum already addresses the basic standards of scientific integrity in a nutshell. 
Following investigations into the alleged plagiarism of clinical psychology professor René Diekstra, the Faculty of Social Sciences at Leiden University adopted its own guidelines in 1998, titled Protocol: Ethics for Scientific Research and Guidelines for Dealing with (Alleged) Scientific Misconduct (Leiden I998). It is interesting to note the motivation behind this Protocol, which is described as follows:

"There are generally accepted ethical standards and rules of conduct for conducting research at Dutch universities, but they are rarely established in protocols. In most cases, it is informally clear when scientific misconduct has taken place. However, clear rules and guidelines for procedures for dealing with scientific misconduct are generally lacking. This memorandum aims to fill in these gaps for both staff and students of the Faculty of Social Sciences, and to make explicit what has always been implicit regarding the ethics of scientific research" (Protocol, 1998: I; my emphasis).

The text then proceeds to lay out a set of well-formulated and unambiguous ethical rules for all stages of socio-scientific research, from study design to publication standards, with particular emphasis on handling subjects and participants in the research. The rules themselves are mainly derived from the Ethical Principles of Psychologists and Code of Conduct of the American Psychological Association and from privacy regulations in the Netherlands, which had just been drawn up by an advisory committee of the Ministry of Education, Culture and Science (Privacy-wetgeving en het gebruik van persoonsgegevens voor wetenschappelijke en statistische doeleinden, OCW, I997). No clear distinction is made between general scientific ethics and the specific issue of scientific integrity. However, this Protocol defines scientific misconduct and the possible sanctions that may come as a result. Compared to the 2004 Code, drawn up six years later, the Protocol's summary of the forms of misconduct is remarkably clear and concrete. Thirteen short and well-formulated specifications of misconduct are given:

"causing physical and emotional harm to the participant, violating promises to keep data anonymous, falsifying data, selectively and covertly rejecting undesirable results, entering ficti- 
tious data, deliberately misusing statistical methods to reach conclusions other than those justified by the data, deliberate misinterpretation of results and conclusions, plagiarism of results or (parts of) publications of others, deliberate misrepresentation of the results of others, acting unjustifiably as an author or co-author, carelessness in conducting or commissioning research, trying to obtain subsidies through deception" (Protocol, I998: I3-I4).

At the end of the section on misconduct, there is a general formulation, similar to the one that caused such a stir in the US:

"Misconduct also occurs when a member of the academic community has seriously violated the written and unwritten ethical standards for the practice of science. This shall be determined at the discretion of the Executive Board, after having heard the opinion of a committee of independent experts and that of the researcher concerned" (Protocol I998: I4; my emphasis).

Simply put, this Protocol already identifies the essential forms of scientific misconduct (according to the game rules) and the principles for how to act in cases of alleged misconduct.

In 200I, the three national research organizations KNAW, VSNU and NWO turned their focus from "scientific misconduct" towards "scientific integrity". Their 1995 memorandum on scientific misconduct was replaced by a memorandum on scientific integrity, titled the Notitie Wetenschappelijke Integriteit, over normen van wetenschappelijk onderzoek en een Landelijk Orgaan voor Wetenschappelijke Integriteit [Memorandum on Scientific Integrity: On Standards of Scientific Research and a Netherlands Board on Research Integrity] (KNAW, 200I). The purpose of this memorandum was "to promote scientific research in accordance with generally accepted standards of scientific practice. Special attention shall be paid to how to handle breaches of these standards" (200I: 5). The memorandum is particularly focused on the general standards of "professional scientific activity" common to all areas of science, not the specific "mores" of individual fields. The term "misconduct" has been replaced by "forms of infringement of scientific integrity". 
The memorandum goes on to describe fifteen examples of infringement of scientific integrity, which are more or less the same as those mentioned in the Leiden protocol, but described in more detailed terms. One example was left out (causing physical and emotional damage to participants) and three new ones were added, namely "uncourteous treatment of colleagues and subordinates in order to influence the results of research; omitting the names of co-authors who have made a substantial contribution to the research or adding those who have not made a substantial contribution to the research; unauthorized copying of test designs or software" (2005: 7).Thanks to its concrete description of inadmissible conduct in scientific research, this memorandum became a sort of constitution on scientific integrity, to be applied in all affiliated Dutch universities and research institutes.

In addition, these institutions were instructed to draw up their own regulations and to establish bodies that could take responsible action in the event of alleged violations of integrity:

"The institution should establish a procedure that allows the complainant and the defendant to be heard. Anonymous complaints cannot be processed; the institution should make sure that whistle-blowers are adequately protected. The procedure for handling complaints should thus be carried out with sufficient speed, and confidentiality should be ensured in order to minimize reputational damage caused by rumors. While it is not unusual for differences of opinion to spark debate in the news media, they are not grounds for addressing a complaint about improper scientific behavior" (KNAW, 200I: I0).

In integrity violation procedures, it is also important to appoint a Confidential Advisor. The role of the Confidential Advisor is to "make a clear and unambiguous statement about the suspected violation of integrity and submit their advice to the Executive Board" (idem). This statement allows the special investigation committee to formulate an opinion on the matter. The Netherlands Board on Research Integrity (LOWI, mentioned above) was established in order to ensure that all Dutch institutions handle integrity violation cases equally. Both the complainant and the defendant may appeal to the LOWI, which will then check that the institution in question has handled the case in a fair, efficient and confidential manner. Where necessary, this national body 
may re-examine the substance of the complaint with the assistance of two experts in the relevant scientific field. The LOWI then advises the institution's Executive Board, which makes the final decision in the case and determines whether any legal measures should be taken. The LOWI was founded in 2003 by the KNAW, VSNU and NWO, began operation on January I, 2004, and has since worked independently of its founders.

In the 200I national memorandum on scientific integrity, reference was made to an informational brochure published by KNAW, titled Scientific research: Dilemmas and Temptations (KNAW 2000), which was primarily intended to bring the subject of scientific integrity and misconduct to the attention of researchers at all stages of their careers. However, it wasn't very effective. The brochure outlines various fictitious examples of potential misconduct and discusses whether or not researchers have crossed a line. However, as Köbben pointed out in his review of the brochure, there is more to be learned from real-life cases: "Not an unpleasant read, but a bit childish, with artificial examples. There is more to be learned from real cases from the field, from seasoned researchers who can draw on their own experience" (Persson 200I: 17). The brochure was revised and republished in 2005 (KNAW 2005). The new version is greatly improved and provides a more thorough description of the dilemmas and temptations that researchers can face. However, even though the brochure can be used as an educational tool, let's not assume that standards of conduct will automatically emerge from it. For this, we need a professional code of conduct.

\subsection{THE NETHERLANDS CODE OF CONDUCT FOR SCIENTIFIC PRACTICE OF 2004/2012/20I4}

After the notorious Diekstra and Buck Affairs, interest in scientific integrity waned, only to re-intensify with the Stapel affair in 20Ir and 2012. In the meantime, as a result of the $200 \mathrm{I}$ memorandum, Dutch universities had set about establishing regulations, appointing Confidential Advisors and forming committees on scientific integrity (known as Commissie Wetenschappelijke Integriteit or CWI), some more quickly than others (the last university to establish official regulations did so in 2010, and the last university to appoint a Confidential Advisor did so in 2012). From 2004 to 20II, the average number of complaints about scientific integrity at each university 
can be counted on two hands (Berkhout and Rosenberg, NRC Handelsblad, January I4, 2012).

Meanwhile, as mentioned above, the 2004 Code went into effect on January I, 2005. The Code contains a preamble and sections on the five main principles of scientific research and education. Sections 4 and 5 of the preamble states: "The integrity of each scientific practitioner is an essential condition for maintaining stakeholders' faith in science. Integrity is the cornerstone of good scientific practice. The Code contains principles that all scientific practitioners affiliated with a university (teachers and researchers) should observe individually, among each other and towards society. The principles can be read as general notions of good scientific practice; they are not intended as supplementary judicial rules." (2005:3). So how are they intended then?

"The Code describes desirable conduct and is, in this regard, complementary to the regulations established by the universities and the Netherlands Board on Research Integrity (Landelijk Orgaan Wetenschappelijke Integriteit, LOWI) on how to deal with undesirable conduct. Therefore, this Code does not contain sanction rules or complaint procedures. The principles defined in this Code are detailed further in 'best practices'. These best practices, which provide a certain set of norms for the conduct of teachers and researchers, reflect the national and international understanding of good scientific teaching and research. Under particular circumstances, deviation may be justified." (2005: 3-4; original emphasis).

Five principles are mentioned: scrupulousness, reliability, verifiability, impartiality, and independence. These principles are self-evident and undisputed. But while the Code expresses the specific values of science, it lacks a clear and unambiguous set of standards that characterizes other codes of conduct. The specific standards of scientific integrity are vaguely formulated and are therefore difficult to identify (see also Chapters 4 and 7).

- Art. I.I: Scrupulousness is expressed through precision and nuance in providing scientific instruction and conducting scientific research and the publishing of results thereof. 
- Art. I.3: Accurate source references serve to ensure that credit is awarded where credit is deserved. This also applies to information gathered via the Internet.

- Art I.4: Authorship is acknowledged. Rules common to the scientific discipline are observed.

- Art. I.5: Scrupulousness is not restricted to the transfer of information, but also applies to relations among scientific practitioners and with students.

- Art. 2.I: The selective omission of research results is reported and justified. The data has indeed been collected. The statistical methods employed are pertinent to the acquired data.

$-(\ldots .$.

- Art. 2.3: The system of peer review can only function on the assumption that intellectual property is recognized and respected.

$-(\ldots .$.

- Art. 2.5: In transferring information in education, a selective representation of available knowledge is either avoided or justified. A clear distinction is made between transferred knowledge and personal opinion or related speculation.

With a bit of effort, one can recognize traces of FFP. In regard to plagiarism, the text basically states that one should not try to pass someone else's work off as one's own. The Code makes clear that plagiarism is not allowed, but it does not explain what plagiarism actually is. Plagiarism of ideas is prohibited through references to source-referencing and to a necessary condition for the peer review system. With some effort, the obvious ban on the fabrication and falsification of research data can be inferred from the first elaboration of the notion of scrupulousness. When it comes to co-authorship, the text indicates the desired behavior of those involved, but it does not mention the issues of non-recognition or the unwarranted attribution of co-authorship. 
If researchers simply want to know where they stand, they would be better off referring to the Leiden Protocol of 1998 , which has now been forgotten, or the 200I KNAW memorandum on scientific integrity, which is now also little known and underappreciated, as both of these documents provide more clarity.

Also confusing about the 2004 Code is the fact that research and education seem to be lumped together, with the same principles of integrity for relationships between scientists and relationships between teachers and students. However, teacher-student relationships are subject to their own rules and complaint procedures. What happens if disgruntled students start using the Code as a basis for filing integrity complaints against their teachers?

Scrupulousness is certainly an important principle when it comes to the interaction between scientists, but without further elaboration on what it means to not be scrupulous, in other words, to be unscrupulous, there remains a great deal of uncertainty on the matter. And according to the Code, does writing a critical review of a colleague's article fall within the scope of uncourteous behavior towards one's colleagues? Is it considered a violation of the rule that one must treat colleagues with care and thus a form of misconduct? Is it considered careless to decide not to respond to critical emails from colleagues, or to forget to respond? The Code needs to provide a clearer formulation of which behavior is absolutely prohibited and which behavior is undesirable but not necessarily a violation of integrity. This would help prevent many misunderstandings and unnecessary accusations of integrity violations. All in all, too many questions remain unanswered.

The Code was hastily revised in May 2012 following the Stapel affair and two provisions were added: one on the obligation to report one's side activities and side positions, and the other on the obligation to promote compliance with the Code within the organization itself. As a result of yet another affair (self-plagiarism by well-known Dutch economist Peter Nijkamp, as alleged by a journalist), the Code was once again amended in the autumn of 20I4, and a new provision on the reuse of one's own texts was added (see Chapter 5 for more on this subject). Two amendments in two years, both directly following a major "affair" - that's a few too many adjustments to call this a clear and stable code of conduct. 


\subsection{THE NETHERLANDS CODE OF CONDUCT FOR RESEARCH INTEGRITY OF 2018}

It was not surprising that the KNAW, VSNU and NWO felt the need to revise the 20I4 Code yet again. In 20I6, they established a committee to this end. Following consultations with experts on scientific integrity issues (chairpersons of CWIs and the like) and online focus groups, the committee drew up a new code of conduct, which was endorsed by the boards of the KNAW, VSNU and NWO and eventually went into effect on October I, 2018 for all researchers affiliated with these organizations. The 2018 Code also applies to universities of applied sciences and other government-funded scientific organizations and research institutes, which have since adopted it as well.

The Preamble to the 2018 Code acknowledges that, given the many minor changes in previous years, "the need has arisen for a new text with clear standards and a clearer internal system that is in line with international developments and can be used for both fundamental and applied and practice-oriented research" (Netherlands Code of Conduct for Research Integrity 2018: 7). This latest addition of "applied and practice-oriented research" was primarily aimed at aligning the Code with the new Code van de Vereniging Hogescholen [Code of the Association of Universities of Applied Sciences] and "De samenwerkende organisaties in toegepast onderzoek" ["The cooperating organizations in applied research"].

The 2018 Code clearly differs from its predecessor in a number of respects. First of all, in the title, the words "Scientific Practice" have been changed to "Research Integrity". Secondly, the principles on which the Code is based have changed. The 2004 Code laid out five principles for the establishment of codes of conduct and best practices: scrupulousness, reliability, verifiability, impartiality, and independence. The 2018 Code is based on five basic principles (values), but it is the first to mention "honesty" as a fundamental principle of good scientific practice. In my opinion, this is completely justified, as honesty is the hallmark of science: a true scientist does not deceive. The other four are scrupulousness, transparency, independence and responsibility. These are excellent principles upon which to build a code of conduct, but general principles are a long way from concrete standards of behavior. Translating values into behavioral norms is no easy feat and major leaps are required to move from abstract principles to concrete standards of behavior. 
Based on these five principles, the 2018 Code derives no less than 6r "standards of good research practice" (p.7), which are systematically built upon throughout the various phases of a scientific research: design, implementation, reporting, assessment and peer review, as well as during the communication phase, when research results are presented to a wider audience or when researchers enter into public debate (p. I8).

In the Preamble, the Code's three main functions are mentioned (p.7). The first is to offer researchers and students an "educational and normative" framework within which the standards of research can be internalized. The second is to provide the Executive Boards of scientific institutions and their committees for scientific integrity with "an evaluative framework for the assessment of scientific integrity", and the third is to lay out a number of duties of care for scientific institutions. This third function is new and unique to the 2018 Code, making the Netherlands an international leader in this respect. The Code explicitly outlines the responsibilities that scientific institutions have for ensuring the scrupulousness of scientific practice. While this responsibility is not completely new (it is based on Article 5 of the Higher Education Act), the 2018 Code defines numerous specific duties, such as protecting research culture, training researchers, supervising research, supporting data management, setting ethical standards and ensuring careful and fair procedures for dealing with scientific integrity complaints (pp. 20-2I). So far, so good.

Interestingly, the 2018 Code aims to fulfill two purposes: to serve as a normative and educational framework for all researchers and students, and, at the same time, to provide an evaluative framework for the assessment of alleged violations of scientific integrity. But can these two functions really go hand in hand?

The Code's normative and evaluative framework involves a description of good, if not 'the best', research practices, accompanied by vaguely formulated standards and educational advice, with phrases like "be precise and accurate", "be open about the role of external stakeholders and potential conflicts of interest", "use scientific methods", "be clear", "be honest" and "be transparent", and "make sure that sources are verifiable", "do justice to all research results obtained", etc. (p. I6-I8). This are good tips for carrying out proper research, but without further elaboration, the Code assumes that all researchers have a shared understanding of what accuracy, precision, clarity, transparency and honesty entail. 
The key question here is: do researchers know when they fail to meet these standards and run the risk of displaying "a lack of integrity" (p. 24) and being called before the Board? In other words, do the 6r standards laid out in the Code provide researchers with a clear understanding of what they are not allowed to do and certainty about the appropriateness of their own behavior? The Code explicitly states that all 61 standards must be respected, and failure to comply with any of these standards may result in an integrity violation of varying degrees of seriousness. This leads me to my next question: can these 6 I standards also serve as an evaluative framework for violations of scientific integrity?

The answer is yes and no. Upon close inspection, the 2018 Code does address the three deadly sins of scientific integrity, FFP. While most national and international integrity codes are structured by level of seriousness, with the most serious violations mentioned first, followed by less serious violations and examples of reprehensible behavior and carelessness, the 2018 Code is structured according to the logical flow of the research process. For example, here are some of the rules mentioned during the execution and reporting phases:

"I9. Do not fabricate data or research results and do not report fabricated material as if it were fact."

"2I. Do not remove or change results without explicit and proper justification. Do not add fabricated data during the data analysis." (p.I7)

Although these formulations lack precision (what exactly is "data"?) and seem narrowly focused on a particular type of quantitative research, they clearly denounce the fabrication and falsification of data, the FF in FFP. If you look closely at standards 34 and 40 , there is a ban on plagiarism, the $\mathrm{P}$ in FFP, as well.

"34. Present sources, data and arguments in a scrupulous way."

“40. When making use of other people's ideas, procedures, results and text, do justice to the research involved and cite the source accurately." (p.r7). 
Although these standards regarding the treatment of sources are mentioned, we also need a clear standard for the assessment of plagiarism, such as, for example: "plagiarism is not, under any circumstances, permitted and shall be treated as a serious violation of scientific integrity", followed by a clear definition of plagiarism and examples of various forms of violations (see Chapter I; for more information on plagiarism, see Chapter 5).

However, the 2018 Code does highlight the seriousness of violations to the 6r standards. The Code's Chapter 5 , on matters of non-compliance, states: "The clearest examples of research misconduct are fabrication, falsification and plagiarism" (p. 23) and refers to the aforementioned standards I9, 2I, 34 and 40. But only violations of these standards are referred to as violations of integrity. And while the Code does offer an evaluative framework for CWIs and other decision-making bodies, it only applies to these four standards: four out of 61 !

In reference to nineteen other standards, which are identified by their list number in Chapter 5.2, the Code states the following:

"In the event that the following standards are not met, the determination of whether the case in question constitutes 'research misconduct' or a less serious violation will depend on the outcome of an assessment using the criteria as mentioned in section $5.2 \mathrm{C}$ " (p.23).

Some examples from this group of nineteen standards include:

"8. Be open about the role of external stakeholders and possible conflicts of interest."

"22. Ensure that sources are verifiable."

"23. Describe the data collected for and/or used in your research honestly, scrupulously and as transparently as possible."

"36. Be explicit about any relevant unreported data that has been collected in accordance with the research design and could support conclusions different from those reported." 
"38. Be explicit about uncertainties and contraindications, and do not draw unsubstantiated conclusions."

"58. Do not delay or hinder the work of other researchers in an inappropriate manner."

These recommendations seem sensible enough, but they are too broadly formulated and could give rise to countless controversies: When are conclusions "unsubstantiated"? When is unreported data "relevant"?

Violations of the remaining 38 standards are classified as "questionable research practices" or "minor shortcomings" in Chapter 5 . In the case of a minor shortcoming, "there will be no reason to impose measures or sanctions" (p. 24). In my opinion, the notion of "questionable behavior" is, in itself, questionable. On the one hand, it evokes associations with "fraudulent" and "inadmissible" behavior, but on the other, the standards it seemingly refers to are so vaguely formulated that it is difficult to determine what a violation of them would look like. For example, standard 43 states: "Avoid unnecessary references and do not make the bibliography unnecessarily long." Which references are "unnecessary" and how long is too long? Standard 46, "Be honest and scrupulous as an assessor or peer reviewer and explain your assessment," could also lead to complaints in cases where a reviewer has rejected a substandard article without sufficient explanation of his or her assessment.

We already have enough integrity complaints to deal with as it is, including those which are aimed at tarnishing a fellow colleague's reputation. My concern is that the vagueness of many of the 2018 Code's standards will open the door for more unwarranted complaints.

A novice researcher who wants to know which behaviors are and are not permitted under the 2018 Code must first pick out the nineteen 'unqualified' standards in the list of $6 \mathrm{r}$ and then look up the no less than twelve assessment criteria in Chapter 5 , some of which are so vaguely formulated that they can be interpreted in any number of ways. Take for example, criterion c: "the possible consequences for the validity of the research in question and for the prevailing scientific knowledge and scholarship; or d: "the potential effects on the trust in scientific and scholarly research and between researchers"; or e: "the potential impact on individuals, society and the environment". 
Does the novice researcher really understand the consequences of violating one of these $6 \mathrm{I}$ standards? The answer to this question is no. The 2018 Code creates uncertainty about what constitutes permissible and impermissible scientific behavior. Moreover, it also creates legal uncertainty for anyone who has been accused of violating one of these vague standards by an unfriendly colleague; and then there are the vaguely formulated "assessment criteria". It is the duty of each institution's Executive Board to protect their employees from these kinds of legal uncertainties, especially when it comes to the critical matter of scientific integrity.

This double vagueness has predictable consequences. The Code's standards open the door for minor complaints about colleagues' behavior, which can lead to insecurity, unrest, jealousy and harassment. Then there is the fact that decisions on these complaints are largely left up to the discretion of the Executive Board of the institution in question, due to the ambiguity of the Code's assessment criteria. In such cases, the Board can wield its administrative power arbitrarily. The assessment criteria could be used to acquit an esteemed researcher of a serious violation of scientific integrity, assuming that this has not "damaged the trust in science" or not had "negative consequences for individuals, society or the environment." But the same assessment criteria could also be used to punish another researcher for a relatively minor violation. I predict that, in the next ten years, we will see this arbitrariness manifested not only in minor cases, but in major cases as well-and the latter could end up being dismissed with reference to the Code's assessment criteria. For who is keeping an eye on the assessors?

In all, the 2018 Code is a considerable step backward from what had already been achieved. It's as if we've gone back twenty years. The first steps towards a codification of standards of scientific integrity came in the rg9os, back when there was hardly any standardization and hardly anyone knew how to handle integrity violation scandals. As noted above, in 200I the KNAW, VSNU and NWO drew up a memorandum on scientific integrity. Like its predecessors from the I99os, this memorandum contains clearer standards for what is and is not permitted in scientific research than the 2018 Code. As noted in the Code's Preamble, there is certainly a need for "clear standards"; but the assertion that this Code provides that clarity for is untenable.

Unlike the $200 \mathrm{r}$ and $1995 \mathrm{KNAW}$ memoranda, the 2018 Code confounds the goal rules and the game rules of scientific research. Its purpose was both to create a normative framework for the transfer of standards for good 
science practice (goal rules) and to provide an evaluative framework for the assessment of serious breaches of scientific integrity (game rules). Instead, the Code blurs the distinction between the two, creating a situation that will soon be characterized by uncertainty and arbitrariness in what is grounds for complaint, how complaints should be handled, and what decisions on scientific integrity should be made. With regard to the codification of the behavioral standards for scientific research, all of this is very worrying. 



\section{Chapter 3 \\ Scientific fraud: lessons from history}

\section{I ANEW PHENOMENON?}

Many of history's greatest financial fraudsters started out stealing small amounts. An accountant or administrator illegally transfers a small amount to his own bank account. When he discovers that no one has noticed, the temptation to do it again grows. Pretty soon he starts transferring larger amounts until his network of illegal transfers and accounts becomes so complex that he has to transfer even larger amounts just to cover it up. This downward spiral can occur in science as well—not with money, but with data.

Since the Stapel affair, there has been a great deal of speculation into the cause of the Tilburg professor's peculiar behavior and extreme deceit. One cause could have been the growing pressure on academics to publish and perform. Stapel said himself that he was under tremendous pressure from the contemporary scientific system, which holds researchers to exceptionally high standards (Stapel 2012: 256-259). Abma indirectly agrees and associates the increase in scientific fraud with current science policy in the Netherlands, which, he believes, places far too much emphasis on measurable achievements, such as the number of publications (Abma 2013).

In my opinion, these explanations are too simple. For starters, I find the parallel with financial fraud more interesting and perhaps more scientifically fruitful. When Stapel first started filling out his own surveys and submitted an article based on the fabricated data to a scientific journal, he must have been nervous: Will I get caught? When nothing happened and he realized that no one had noticed, he continued (Schuyt 20I4: 73-85). When a young criminal's small robberies go undetected the first nine times, and he finally gets caught on the tenth, he gets off with a warning. When the next nine robberies go undetected as well, he receives more positive reinforcement for his 
negative behavior, which is not taken into account when he is finally caught and punished (Schuyt 2006: I63).

This is, in my opinion, a better explanation for the causes of scientific fraud than the pressures of present-day university life. Yes, the pressure to perform has certainly increased within the university sector over the last thirty years. In the Netherlands, this trend began in the mid-rg8os with the introduction of the system of conditional research funding and the arrival of university-appointed PhD students. Meanwhile, sensitivity to scientific fraud was on the rise, and more cases of fraud were attracting public attention. However, let's not jump to the conclusion that these two trends were causally linked. Although it may seem that way, there may have been other, underlying, more fundamental factors at play.

To gain a better understanding of what these factors might be, it may help to take a look at the history of scientific fraud. The same kinds of behaviorfabrication, falsification, and plagiarism—certainly existed in the past, even before scientists were under pressure to publish. Scientific fraud is not a new phenomenon. Since the seventeenth century, modern science has been marked by competition to be the first to come up with a new idea or theory. From I7II to I7I3, Newton and Leibniz battled over who was the first to invent calculus (Ackroyd 2006: I52-I55). One hundred and fifty years later, Alfred Russel Wallace and Charles Darwin competed to be the first to formulate an evolutionary theory. The history of scientific fraud also provides plenty of examples of research data that were just "too good to be true", from Mendel to Nobel Prize-winner Millikan (Broad and Wade, 1983: 31-35; Tudge, 2002: 94-97; see Chapter 2 above). Both Burt and Stapel got caught because of their improbable statistical data, but Stapel was not the first scientist in the Netherlands to be found guilty of fabrication. As mentioned in Chapter 2, from 1950 to 1962 , the physician and VU Amsterdam professor Anthonie Stolk wrote several articles on fish tumors, which were largely based on fictitious data. He also published countless articles and books on the prehistoric lives of animals and non-existent tribes in Central Africa. Nevertheless, his work was widely accepted at first and published by scientific journals (Van Kolfschooten, I996: I22-136; Van Kolfschooten, 2012: 156-I66). Another VU Amsterdam professor, Mart Bax, was also found guilty of publishing fieldwork reports based on falsified data for years. He did this to "confirm" two of his own personal theories: one related to religious miracles and the other on religious-political violence (VU report, Baud et al. 2013). Eleven 
articles, all originally published without the slightest suspicion of fraud in the Amsterdams Sociologisch Tijdschrift and the Sociologische Gids respectively, had to be withdrawn (editorial, Sociologie, I0.4, 2014: 3-4).

Given that there has not been sufficient research into the frequency and causes of scientific fraud, I will try, through descriptions of several wellknown cases of scientific fraud from the recent past (1980-2015), to shed some light on a phenomenon which, in my opinion, remains grossly under-researched. For now, all I can offer are a few hypothetical ideas and a speculative typology of scientific fraudsters, but it's a start.

\subsection{WHAT PHENOMENON? A MORE PRECISE DEFINITION OF SCIENTIFIC FRAUD}

All we know about how often scientific fraud occurs is that we don't know. Whether or not scientific fraud has increased in recent years, we cannot say. There is very little research into the nature and extent of scientific fraud. However, there have been guesses and estimates, as well as a number of studies that have asked researchers whether they or someone in their vicinity has ever committed fraud with questions like, "In the last three years, have you seen a colleague fabricate or manipulate data?" (Verbeke 2013: 25). It is well known that there are methodological problems with research into hidden behavior and the numerical estimates of crime that remains unknown to the authorities (often referred to as the "dark number"). The problem with self-reporting is that it requires a (self-)definition of the reprehensible behavior in question and a specification of the time period in which this behavior took place. Furthermore, asking respondents whether they are aware of fraud in their own environments raises the issue of double counting. Respondents in the same environment may recall the same well-known cases. Moreover, it can be difficult to define what the boundaries of an environment actually are. For example, Verbeke's research into forms of fraud and misconduct in biomedical research in Belgium concludes that, of the 315 medical researchers surveyed (response $\mathrm{I}_{2} \%$ ), "one in twelve" physicians admit to having carried out some form of data manipulation themselves (i.e. "fabricating or manipulating data"). But whether they have "fabricated" (I. $3 \%$ ) or "manipulated" $(7.3 \%)$ makes a big difference. When asked about their colleagues' behavior, respondents reported much higher figures: $47 \%$ reported that they had seen 
their colleagues fabricate or manipulate data (Verbeke, 2013:25). What did the respondents perceive as "manipulating"? When it comes to research based on self-reporting, one cannot be too precise.

A response about the nature and extent of scientific fraud is thus closely linked to the definitions of fraud used by the researchers and the respondents respectively. What is meant by scientific fraud? This question is difficult to answer in a normative sense, and answers provided by individual respondents in survey form cannot necessarily be trusted.

The international scientific community agrees on three obvious forms of misconduct in science: fabrication, falsification and plagiarism (FFP). However, these three major violations of scientific standards become more complicated when one also considers the many so-called questionable research practices (QRPs). Some questionable research practices have been around for a long time, but they are still regularly applied and defended today. Charles Babbage (I79I-I87I), a British mathematician and one of the forefathers of computer science (cf. Nudds, I969: I-34), was already battling scientific standard violations in 1830 . He identified four types of scientifically dishonest behavior (i.e. misconduct) that are still relevant today: hoaxing, forging, trimming, and cooking (Babbage, I830; 1989). The first two items on the list, hoaxing and forging, are quite similar to the two main forms of misconduct recognized today, fabrication and falsification, whereas the other two, trimming and cooking, still occur in contemporary scientific practice as well. In I830, Babbage described the two dishonest practices as follows:

Trimming: "consists of clipping off little bits here and there from those observations which differ most in excess of the mean, and in sticking them on to those which are too small";

Cooking: "to give ordinary observations the appearance and character of those of the highest degree of accuracy. One of its numerous processes is to make multitudes of observations, and out of these to select those only which agree, or very nearly agree. If a hundred observations are made, the cook must be very unlucky if he cannot pick out fifteen or twenty which will do for serving up" (Charles Babbage, I830; cited by Broad and Wade, 1983: 29-30). 
Personally, I find the metaphor of the cook very appropriate. The cook only serves the recipes that he or she considers successful and leaves the rest behind in the kitchen of science-that's where the fraud takes place. Babbage's elegant formulations reveal that academic dishonesty most certainly occurred in the science of his day. Unlike today, however, no action was taken against offenders.

Scientific fraud is a violation of trust. Scientists, knowledge consumers and the general public all expect scientific results to be accurate and trustworthy; they trust that they have not been tampered with or manipulated. It is interesting to observe how various other sectors of society have experienced a loss of trust over the last decade as well. Although it may be difficult to determine how often fraud occurs, its variety of forms across sectors may be an indication of a shift in today's cultural standards. There is a tendency to combat violations of integrity with increased supervision, but maybe we should reflect on what the common denominator among these violations may be.

Criminological theory can shed light on the difference between "crimes of trust" and other crimes. The Norwegian criminologist Johannes Andenaes reported on the development of crime during the Second World War in Copenhagen in 1944. The Danish police-a hotbed of the Resistance-was disbanded by the Nazis during the last seven months of the war, greatly reducing the control over the behavior of ordinary citizens. In those seven months, robberies and theft increased tenfold. It didn't matter that the thieves who were caught were punished much more severely-the chances of being caught were almost zero. What struck Andenaes the most, however, was the fact that cases of embezzlement and fraud did not increase during that time. This led him to the tentative conclusion that it is the nature of the social relationship that largely determines the violation of particular standards and the threat of punishment. Breaches of trust (i.e. embezzlement and fraud) are apparently not influenced by the risk of punishment; there seem to be other factors at play (Andenaes 1952: I76-198, cf. Schuyt I97I: I46). The way that professional standards are internalized and transferred seems to have a greater impact on decision-making than supervision and (police) control, a fact which offers an interesting starting point for further research into breaches of trust in various sectors of society. Starting with science. 


\section{$3 \cdot 3$ A FREQUENT PHENOMENON?}

Estimates of how often scientific fraud occurs depend on how scientific fraud is defined. According to Fanelli's well-known meta-analysis of data from eighteen surveys, $\mathrm{I}-2 \%$ of scientists are guilty of the two serious forms of fraud: fabrication and falsification (Fanelli 2009). This is in line with the estimate made by the European Science Foundation in its 2010 report Fostering Research Integrity in Europe. This report states that in a three- to fiveyear period, one in a hundred researchers was guilty of serious misconduct (ESF 2010; Jump 2010: 20). Once the definition of fraud is broadened to include questionable research practices as well, self-reported data suggests that $3 \%$ to $30 \%$ of scientists are guilty of misconduct (Steneck 200I). Such a wide disparity leads one to question the reliability of these estimates. In 2005, Martison, Anderson and De Vries estimated that $30 \%$ of the researchers interviewed were guilty of minor forms of misconduct compared to the $\mathrm{I}-2 \%$ who confessed to more serious forms of scientific fraud (FFP). Many of these self-reporting studies were small in scale and limited to specific disciplines. One interesting example is a study among criminologists, who are certainly aware of the issue of "dark number" figures and often rely on self-reporting to gain insight into various types of legal violations. In a self-reported survey of 500 US criminologists, $2 \%$ reported having committed some form of plagiarism "at some point" and $\mathrm{r} \%$ during the past year (Robinson and Zaitzow, I999, quoted by De Haan 20II: I09).

One particularly elaborate study was carried out by Swazey, Anderson and Seashore Louis in the United States. They sent a carefully designed fifteen-question survey to 2,000 $\mathrm{PhD}$ students and 2,000 professors and scientific staff members in four fields (chemistry, civil engineering, microbiology and sociology). The response rate was satisfactory, at $72 \%$ and $59 \%$ respectively. Of the three main types of misconduct (FFP), plagiarism was reported to occur the most frequently, with an overall score of $8 \%$, followed by $6 \%$ for falsification (with $13-15 \%$ among $\mathrm{PhD}$ students). The survey also included thorough definitions of "questionable research practices", which resulted in a score of $22 \%$. As expected, the results varied from one scientific field to the next: in sociology and civil engineering, scores were higher for plagiarism (I8\%), whereas in microbiology, falsification scored higher (I2\%). However, given that these statistics cannot be generalized, the value of this data should not be overestimated. The authors themselves were extremely cautious, sta- 
ting that the figures say more about the way in which faculties and disciplines influence the education and socialization of $\mathrm{PhD}$ students than about the frequency of misconduct (Swazey et al., I993: 542-553). Komter provides a clear overview of this and other similar studies in the US, looking at demographic factors, such as the perpetrator's age, social status, personality traits and motives (Komter 2012). Systematic research into scientific fraud didn't come to the Netherlands until 20I6, and most of the results of this research have not yet been published, with a few exceptions. At the same time, however, speculation about the extent and nature of scientific fraud persists, and there is no shortage of theories about the causes behind it. One thing is certain, however: scientific fraud and misconduct are nothing new-they have been troubling the sciences for more than three centuries.

\subsection{DO PERFORMANCE PRESSURE AND DISHONESTY GO HAND IN HAND?}

A common explanation for contemporary scientific fraud is the growing performance pressure on university researchers, especially in the area of publications. The competition in some fields has become so fierce that some believe this to be the cause of new cases of fraud and plagiarism. There have been numerous comparisons of top-level science and top-level sport in recent years, and some say that academic misconduct is like using illegal substances to gain a competitive edge. Stapel, one of the most famous fraudsters, cited performance pressure as an explanation for his actions, both in his initial statements to the press and later in his own reflections on his case (Stapel 20I2). A month after his fabricated research data was discovered, he told De Volkskrant: "In modern science, the level of ambition is high and the competition for scarce resources is enormous. In recent years, this pressure has become too much for me. I was under pressure to score, to publish, to constantly do better. I wanted too much, too fast" (De Volkskrant 3I October 20II). Later, in an interview in The New York Times that made him more internationally famous than he had ever been as a researcher, he made similar statements (28 April 2013). In the book about his own "derailment", published the day the Levelt report came out, he wrote: "Science is a battle of interests. Scientists will defend their interests, their research topic, their insights, their theories with sword and horse against other scientists no matter what. They're all 
competing to conduct as much research as possible for as little money as possible in the shortest possible amount of time, and they'll stop at nothing to achieve this goal" (Stapel, 2012: 257-258, my emphasis).

The image of modern science presented here may appeal to some, but it is a gross generalization. It is undeniable that competition has increased, but the notion that scientists are willing to resort to any means necessary, even illegal ones, is not yet proven. It is a useful hypothesis, perhaps, but one which requires further investigation and testing.

First, we need to establish exactly what this pressure consists of and where it comes from. Is it from society? From the business world? From academic institutions striving to become the "best"? What is "the best" anyway? There has always been a drive to achieve in science, but nowadays there is also pressure to publish. Research positions have become scarce, especially for young researchers who want to continue in science after completing their dissertations, and in order to obtain a research grant or renew their contracts, they need to get their work published, preferably in leading journals. These criteria are observed by supervisors, professors and directors of research institutions and are often adopted by the university administrators who formally approve appointments. In other words, the pressure is not from above, it's from within.

Editors of scientific journals play a key role in this assessment process because they determine which research results are worth being published. However, most editors and leading professors come from the same scientific circles as those who carry out assessments, distribute awards and make appointments. Many researchers, especially younger ones, experience this pressure as imposed by "the system". The same criteria are also used to appoint candidates to tenured, senior-level positions, in this case not just by committees of professors but also by administrators. It is interesting to note that since the system of conditional funding was introduced in the Netherlands in 1985 , the number of publications has been used as an indication of quality more often than before. Moreover, publications have come to weigh far more heavily than other important skills for university work, for example teaching skills and organizational skills. However, pressure on established scientists—such as professors with good, steady positions-is relatively rare in the Netherlands. No appointed professor with a tenured position has ever been dismissed in the Netherlands because he or she published too little, and publication requirements (two to three articles per year) are flexible. There 
was nothing forcing Stapel to publish 25 articles a year, and he certainly didn't need to do so to keep his position.

That national science policies and the policies of individual universities have led to a shift in the assessment criteria for scientific research is undeniable (Abma 2013). It is also undeniable that this shift has created certain negative incentives for research. This is especially true in the socio-cultural fields of science, which are being held to the standards of the harder sciences (Gutwirth and Christiaens 20I4: 267-287). However, a critical analysis of the current scientific climate does not in any way suggest that, as a result of this situation, scientists are now more inclined to commit scientific malpractice. The influence of environmental factors on one's freedom to choose one's own course of action is more complex than most of the current critics assume. No one is forced into ambition or jealousy, and compared to other professions, scientists still have a great deal of freedom to carry out their research in the way they see fit.

In short, the pressure to perform has certainly increased, but the causal relationship between this pressure and scientific fraud has yet to be established. For beginning researchers, cheating is extremely risky and could put their careers in jeopardy; for more established researchers who have already received a certain level of recognition, there are risks as well, and there is no reason to cheat unless they are unable to resist their own ambitions. Thus, Stapel's claim that researchers are willing to resort to any means necessary, including illegal ones, to achieve their goal seems highly doubtful, assuming their goal is to practice good, valuable science. Plus, given the strict requirements of scientific control-even if, in practice, they are not always watertight - there is most likely not a great deal of fraud taking place, and certainly no more than in the past. The most reliable meta-analyses from $200 \mathrm{I}$ and 2009 indicate that, based on self-reporting, I-2\% of researchers are guilty of serious forms of misconduct (Steneck 200I; Fanelli 2009, ESF 2010).

Another explanation for the perceived increase in fraud is more obvious: when two phenomena occur simultaneously, it is quite possible that they were both caused by a third phenomenon, which could be the underlying explanatory factor. In this case, that underlying factor could be the increase in the scale of universities. The intensification of competition over the last twenty to thirty years can be explained by the fact that, despite the sharp increase in the number of graduates and qualified research staff, the financial resources for scientific research have remained more or less the same (in the 
Netherlands, less than $2 \%$ of GNP goes to research and development). This explains why research funding and positions have become harder to come by. While scientists have always had to fight to achieve recognition, the battle has intensified in recent years due to the scarcity of resources and the number of positions available, and because the power of prestige can be seen to translate into funding and rank.

Despite the fact that the percentage of funding for scientific research has stagnated, or in some cases even slightly decreased, there has been tremendous growth in the total number of researchers. It has even been claimed that $80-90 \%$ of all scientific researchers who have ever existed are currently alive and working (Freeland Judson 2004: 407; Broad and Wade I983: 53). In the US, the current number of researchers is estimated at approximately 200,000 to 300,000 , with an annual production of more than one million publications; in 1960 , there were around 50,000 researchers. Hence, if the percentage of fraudsters, estimated at $\mathrm{I} \%$ by previous research, has remained more or less the same, then the absolute number of questionable cases would have increased fourfold since i 960 , from about 500 to about 2000. Something similar has taken place in the Netherlands. The number of students enrolled in universities rose from 40,000 in 1960 (Schuyt and Taverne 2000: 316 ) to 205,000 in 2010. In 1960, the number of researchers at all Dutch universities was about 4,000 (Kersten 1996: 157; Van Berkel 2000: 336). Nowadays that population has risen to about 17,000 , of whom approximately 6,000 are $\mathrm{PhD}$ students; especially in the biomedical, natural and technical sciences, a large proportion of research work is undertaken by $\mathrm{PhD}$ students (Chiong Meza 2012). If the average researcher carries out three studies in four years, and $\mathrm{I} \%$ of these researchers is guilty of fraud, that means that the number of potentially fraudulent researchers has quadrupled from forty to I70. As such, the fact that more cases are being reported as potentially fraudulent is not surprising and can be explained by the increase in the scale of scientific research. Since 1985 , the number of young academics who only do research (most of whom are PhD students and postdocs) has increased dramatically. Before then, there was little pressure to publish or to obtain a PhD at Dutch universities.

Fabrication, falsification and plagiarism occurred in the past as well, even when there was little pressure to publish at all. Back then, researchers were motivated by the desire to be the first to come up with something. If fraud was observed, great lengths were taken to conceal it. From I950 to 
I980, there were certainly cases of FFP in the Netherlands, but according to the journalist Van Kolfschooten, the number of these cases in 1992 could be counted on two hands (Van Kolfschooten I993; 1996: 4). Later on, however, he discovered more cases. One of the oldest recorded cases of modern plagiarism-in which a Netherlands-based researcher was the plagiarized, not the plagiarizer-concerned the writings of the Dutch economist Nicolaas Pierson (I839-1909, president of the Dutch Bank, minister of Finance, and professor of economics and statistics at the University of Amsterdam). In 1866, he wrote an original study on "Italian economists of the 17 th and I8th century", which in 1872 was shamelessly published in its entirety in German in Strasbourg by Professor A. von Schwarzkopf without any reference to the original author (Verrijn Stuart, I9II: 44-45, with thanks to H. Trapman for drawing my attention to this unique case). This deceit was mentioned in newspapers (e.g. Het Handelsblad, 29 March I873), but no action was taken at all. There are numerous instances of such cases throughout the first half of the twentieth century.

Since the first decade of the twenty-first century, more and more scientific publications (first) appear in digital form. This has created more opportunities for quick, digital forms of plagiarism, which often go undetected. However, this does not provide a definite answer to the empirical question of whether plagiarism has in fact increased. As long as the scientific standards of "never plagiarize" and "always give credit where credit is due" are firmly anchored in scientific practice, the internet does not have to pose a threat to honest science.

Oftentimes, the motivation to plagiarize stems from a lack of time. Upon being caught, plagiarizers will sometimes claim that it was never their intention to copy someone else's work, but that they were running out of time. For example, a researcher who has to write a scientific report on a particular psychological disorder every week, on top of all the other work he or she has to do, may be tempted to copy from another source without properly citing it. Although this self-imposed "pressure to publish" may not justify the integrity violation, it does help explain the causal links between self-imposed pressure, systemic pressure, and certain forms of dishonesty.

There are, however, indications that the pressure to perform can lead to carelessness and other questionable practices. Publication pressure is also accompanied by time pressure: who will be the first to publish certain results in a small, restricted field of research? In some disciplines, only a few rese- 
arch centers in the world are devoted to a certain topic, and most researchers in the field know each other and are aware of one another's current projects. Since most journals are not interested in publishing research that has already been released elsewhere, there is a constant race to get into the top journals. Whereas in the past, experiments could be repeated up to five times to verify the results, nowadays it is enough to conduct a single experiment, and if the results are favorable, to submit them for publication as quickly as possible (KNAW 20I2: 23). Such haste is rarely a good thing, especially in science. Not only does it increase the chances of errors and negligence, it also reduces the rigor of the peer review process, particularly given that peer reviewers may also be in a hurry to see the work published so that they too can profit from it. In most cases, those guilty of questionable research practices do not intend to commit fraud, but they may have still undermined the reliability of scientific knowledge.

That said, practices considered "questionable" in one discipline may be permitted in another, for example, the omission of outliers. Disregarding negative results is also common practice in some fields and not always classified as fraud (Fanelli 20II). In my opinion, there may be good scientific reasons for not publishing negative test results for example because they may have been influenced by unknown variables. Classifying research data and/or searching for a statistical analysis that does achieve the desired level of significant correlation can, under certain circumstances, be regarded as an acceptable practice. However, deliberately omitting inconvenient research results in the final publication of one's research results is more than questionable. The gray area between error and fraud, between unintentional mistakes and deliberate cheating, must be well monitored. Performance pressure does not have to lead to dishonest behavior, assuming that performance means carrying out sound, sustainable research and reporting on it in a clear and careful manner. This process takes time, which explains the call for "slow science" as a counteractive force: not against real achievements or ambitions, but against bad science. 


\subsection{COMMISSIONED RESEARCH: UNDER PRESSURE TO ADJUST?}

In discussions about the perceived increase in scientific fraud, reference is often made to the publication pressure exerted by universities. There is, however, another possible cause worthy of attention: commissioned research. When scientific research is carried out on behalf of commercial companies and government organizations, this may increase the risk of dishonesty. In this case, the main concern is not necessarily the pressure to publish-most likely some results will not be published-but rather the pressure to produce a particular outcome. Commissioned researchers are often under pressure to produce results that the commissioning party can put to good use, for example, in industry.

The relationship between scientific research, industrial exploitation and economic application is nothing new. During the scientific revolution in the seventeenth century, scientific knowledge and industrial production went hand in hand. At that time, it was often trade and industry practitioners who initiated scientific innovation (Shapin I996; Zilsel I985). That relationship continues to this day, and as long as the fundamental principles of science (i.e. the critical testing of ideas and the honest description of results, which in turn lead to new ideas) are respected throughout the process, there is nothing to worry about. But over the last thirty years, there has been a major increase in scientific research commissioned and funded by external clients (KNAW report, Wetenschap op bestelling [Commissioned Research] 2005). At the same time, patents allow scientists to put their new knowledge to work in industrial companies. The modern knowledge economy is, in fact, largely dependent on these kinds of mutual incentives.

In terms of scientific integrity, this can lead to two problems. First, there is the question of whether research driven by specific commercial interests is still as reliable as independent university research. Fellow researchers need to know which interests are driving the research, and any conflicts of interest must be reported. If the research is funded by or otherwise linked to a private company or special-interest organization, this must be stated in the final publication. Many journals have made it mandatory for researchers to mention any potential conflicts of interest regarding their clients (the biomedical field also requires a declaration of all conflicts of interest). Failure to disclose this information can lead to a violation of scientific integrity, as experienced by a group of medical researchers in the Netherlands in 2013. The group was 
conducting research into the effectiveness of medical products sold by companies that they founded themselves and in which they maintained a vested interest (University of Groningen, NRC, October 3, 2013). In another case, a medical researcher started his own company in the United States and then used this company to conduct a population study in the Netherlands under his supervision, while concealing the fact that he had a personal interest in the company's success (VU Amsterdam, the Meijer case, NRC June I3I4, 2015, NRC April 20 and May 22, 20I6, NRC October I, 2018). No matter how scientifically sound their research may be, researchers should always mention potential conflicts of interest in their scientific articles. At the very least, this will provide readers and consumers with some insight into the researchers' background.

Secondly, the increase in commissioned research raises the question as to whether the influence of the client, consciously or unconsciously, could jeopardize the independence of researchers. If a client (or a commissioning governmental agency) tries to directly influence research results for its own benefit, this is clearly a violation of the standards of honest scientific practice. However, there are many less overt forms of influence, for example: requests to leave negative results out of the final publication, requests to change the wording of conclusions, or threats to terminate the research relationship if the researchers reveal certain research results. Köbben and Tromp provide several examples of cases in the Netherlands where governmental institutions commissioned scientific research as part of their policy and then attempted to influence the results. In one case, the Ministry of Education, Culture and Science commissioned a study into teacher absenteeism in secondary education, but when the study revealed that the teachers were suffering from an enormous workload the Minister preferred not to reveal the results (Köbben and Tromp 1999). Such conflicts of interest between researchers and their clients can be avoided by establishing clear agreements about the publication of research results in advance: good fences make good neighbors, as the saying goes. Clear research contracts can prevent major disputes over the publication of research results.

We have seen a number of important and instructive cases in other countries where commissioned research has led to improbable results. In I998, medical specialist Andrew Wakefield published an article in The Lancet that claimed that vaccinations against measles, mumps and rubella were not safe for children (Mersch, 2012: 165-173; Goldacre 2009: 290-323). This was due 
to the fact that numerous cases of autism had been observed within a year of vaccination (mostly within a child's first year of life, when the first symptoms of autism can occur). His findings had a major impact on public opinion, raising concern among parents that vaccinations cause autism. Wakefield even produced new evidence highlighting the link between the measles vaccination and intestinal infections. Eventually, official agencies got involved. Other researchers who investigated the same relationship found no connections between vaccinations and autism (Mersch 2012: I69). A large-scale study of 440,000 vaccinated and non-vaccinated children in Denmark from I99I to 1998 showed no difference in the prevalence of autism in vaccinated and non-vaccinated children. People began to question Wakefield's theory. After conducting its own research, the Immunization Safety Review Committee in England concluded that there was no reason to assume that vaccinations cause autism. Soon after, it was discovered that, before Wakefield wrote his article in 1998 , he had received $\$ 50,000$ from a law firm trying to hold the vaccine producer liable for massive damages. Wakefield also planned to develop a test that would allow parents to determine whether their child had been harmed by the vaccine. In 2010, The Lancet withdrew the article. Wakefield was found guilty of scientific misconduct and stripped of his position and doctoral degree (Mersch 2012: 179).

Also notorious are the researchers who, funded by American tobacco companies, produced results indicating that, contrary to study carried out by the Environmental Protection Agency, there was no link between second-hand smoke and lung cancer (Oreskes and Conway 20ro). Later, it turned out that the tobacco companies had known about the dangers of smoking and second-hand smoke for years. Nevertheless, the tobacco industry accused researchers from the Environmental Protection Agency (EPA) of pursuing their own political objectives and restricting individual freedom, and the EPA worked to combat the tobacco industry's disinformation campaigns.

What is the difference between bad science and good science, and what is the difference between poor science and dishonest science? Is this case a matter of scientific controversy or a deliberate distortion of research results? Regardless, the tobacco industry is a prime example of a client that was able to exert great influence on both the research results and the dissemination of those results, making certain "unwelcome facts" seem suspicious. The politicization of science is the predictable consequence of this kind of interference and one that has been observed in other cases where controversial 
scientific issues are at stake (e.g. climate change, reduction of the ozone layer, ecological protection of the natural environment). These examples highlight the importance of independent research and researchers. Any attempt to undermine this independence can thus be seen as a violation of scientific integrity.

There have been similar discussions concerning the relationship between drug research and the pharmaceutical industry. In general, research commissioned by large pharmaceutical companies is regarded with suspicion (see Goldacre 2013). There is always the question of whether open and demonstrable manipulations have occurred under the client's influence or whether the initial research question has been formulated in such a way as to create the "right mindset" for obtaining favorable results. The pharmaceutical industry is also known for exerting more control over certain points of research than the free scientific community. This is generally due to the simple fact that official governmental approval is required to introduce new drugs on the market and the criteria for doing so are very strict. The industry cannot afford, or is uwilling, to invest large sums of money in research that later turns out to be wrong or that quickly falls by the wayside due to excessively one-sided or careless data collection. Here, too, honesty in science remains key.

\subsection{TOWARDS AN EXPLANATION OF SCIENTIFIC FRAUD?}

In the absence of thorough research into the frequency, nature and forms of scientific fraud and its possible causes, I'd like to examine several cases of scientific fraud from history to serve a starting point for future research. From 1985 to 2005 , there were approximately twenty major cases of scientific fraud in the US, where the details of integrity violations are generally fully disclosed after the case in question has been closed (Resnik I998; Freeland Judson 2004; Marks 2009; Goodstein 2010). One of the most blatant examples of scientific fraud, the case of Helena Wachslicht-Rodbard, was described by both Freeland Judson and Marks. This case is a manifestation of nearly all forms of scientific integrity violation: plagiarism of ideas, plagiarism of texts, lack of supervision, unwarranted co-authorship and the nasty consequences that come with being caught. As Ben Goldacre so aptly put it: "With science as we have seen repeatedly, the devil is in the details" (Goldacre 2009: 238). It is precisely by studying cases of scientific fraud in 
detail and observing the events and circumstances behind them that we can better understand behavior that may well strike us as unexpected. This is the first step towards formulating hypotheses and ultimately a scientific explanation. Marks described Wachslicht-Rodbard case as follows:

"A researcher at the NIH named Helena Wachslicht-Rodbard submitted a research article on hormone levels in anorexic women to the New England Journal of Medicine in 1978. The journal sent it out for review to three anonymous referees, among them a high-ranking endocrinologist at Yale named Philip Felig. Felig agreed to review it but simply passed it on to his protégé, Dr. Vijay Soman. Soman, who was working on a similar project, promptly plagiarized the ideas and some of the sentences in the manuscript and told his boss to recommend rejecting it, which the boss did. Then Soman sent his own newly augmented manuscript (co-authored with his boss) to the American Journal of Medicine. The American Journal of Medicine sent it out to a distinguished researcher at NIH named Jesse Roth, who agreed to review it but instead also just passed it on to his own protégé, who was Helena Wachslicht-Rodbard.

Imagine her surprise at finding parts of her own work submitted to another journal under someone else's names!” (Marks 2009: I8I; see also: Broad, I980: 38-4I; New York Times, November I, I98I).

This case involves so many violations that it's almost too ugly to be true, but it all really happened and has been described and analyzed several times since. We see many of the previously discussed forms of integrity violation at play: no time for careful peer review, the "just put my name on it" mentality from the boss, the plagiarizing researcher's ambition, and the outrage of the plagiarized. What would have happened if the professor had not outsourced the review to his protégé, but rather done it himself? Would he have noticed the plagiarism of ideas? Or was he not really that well informed about his protégé's work? The outcome is not very encouraging: neither of the professors was reprimanded in the end, and both were allowed to continue their careers. Both of the junior researchers left the scientific field, one in shame and the other disgusted that the high-ranking professors were not held re- 
sponsible and that she was ultimately blamed for bringing the case to light (Marks 2009: I8I; Freeland Judson 2004: IIO-II2).

By looking at famous cases of scientific fraud, which, in some cases, have included well-known scholars like Newton, Mendel, Freud, Pasteur, Millikan, Summerlin and others, we can start to identify some of the common types of "fraudsters". Of course, such a typology says little about the frequency at which scientific fraud occurs, but it does offer some insight into certain types of behavior.

As far as I can tell, there are six types of scientific fraudsters:

- The Crafty Types: Great theorists, such as Darwin, Mendel, Pasteur and Millikan, who sometimes adjusted (or omitted) research data to reinforce their own ideas or intuitions. Their scientific theories live on today, though some historians have questioned the greatness of the theorists behind them (see also: Klotz 1992: 227I-2273).

- The Panic-Stricken: Researchers who, due to a lack of time, resort to using other people's texts. Time constraints do not justify an integrity violation, but they can explain it.

- The Sneaky Devils: Researchers who secretly alter measurement results. Examples include Imanishi-Kari, central to the Baltimore affair and discussed below, and Summerlin, the skin-transplant specialist who marked his mice with felt-tip pens (Broad and Wade, 1983: 153-158).

- The Self-Satisfied Pushers: Researchers who are completely convinced of their own theories and ideologies and try to force them on the scientific community with all their might. They will do anything to get noticed, even if it means committing fraud. One example is the above-mentioned German physicist Schön, whose breakthroughs on semi-conductors turned out to be fake (Beasley et al 2002; Bell Laboratories 2002); other examples could include Burt and Bax.

- The Naïve Ones: Researchers who will continue to insist that "nothing is wrong"; they have-admittedly-made some minor mistakes and been a bit sloppy, but never on purpose. 
- The Budding Criminals: Offenders who notice over time that no one is watching and start to believe that there is no risk of getting caught. After a while, they start thinking that crime pays off, and the self-reinforcing rewards of their negative behavior compel them to continue committing fraud-until they finally get caught. These fraudsters (be they accountants, financial managers, or scientific researchers) usually start out small but soon find themselves in a complex swamp of larger crimes. They continue to do wrong because they don't know how to stop. I would place Stapel in this criminologically interesting category of scientific fraudsters.

However interesting it may be, a typology is far from a hypothetical model. It still puts too much emphasis on personality traits. Good hypothetical reasoning calls for careful consideration of the interaction between the most important factors: in this case, the combination of one's individual characteristics and the characteristics of the social system in which one lives and works. A detailed study of one of the most notorious cases, the Baltimore affair, provides a good basis for further reflection. The case was described by Resnik, Frank, Goldstein and most extensively by the science historian Freeland Judson. For more than ten years (from I986 to I996), the affair was a major topic of debate among American scientists. There are detailed reports from four different committees that lay out everything that was gradually brought to light in this case.

David Baltimore's employee, Thereza Imanishi-Kari, was highly ambitious but tended to avoid contact with her colleagues and supervisors. This had already been observed by her professors in Sweden and Germany on a number of occasions, but she still managed to obtain a prestigious position at MIT. Her research was judged unpromising by a review committee, but she insisted that her project was highly innovative and in line with Nobel Prize-winner David Baltimore's work. Imanishi-Kari commissioned her employee, Margot O'Toole, to conduct certain experiments and when O'Toole did not obtain the results that Imanishi-Kari had expected, a quarrel broke out between the two. Later, however, in an article published in the scientific journal Cell with Baltimore as co-author and herself as the last author (Weaver et al., I986: 247-259), Imanishi-Kari included the research results that O'Toole had been unable to confirm. O'Toole sounded the alarm and 
demanded that the article be withdrawn because of the manipulated data. Nevertheless, Baltimore ignored these signals, presumably because he felt that an article with his name on it, published in a top magazine, could not be incorrect.

Shortly afterward, O'Toole was fired. However, in the ten-year integrity violation trial that followed, it turned out that she had been right: the laboratory data had indeed been falsified by Imanishi-Kari. A CIA investigation revealed that, during the course of the experiment, Imanishi-Kari had used special ink to falsify data and personally changed dates on the research reports. Further investigation revealed that she had also lied about degrees obtained in Europe. She hadn't really earned a PhD; she'd only followed special courses. Eventually, in an appeal to the US Department of Health and Human Services, she was acquitted of scientific fraud on legal grounds, but it was clear to experts in the field and those involved that fraud had indeed taken place (Freeland Judson 2004: I9I-243; Goodstein 2010: 6I-64).

Slowly but surely, the legal handling of this complex case became a subject of discussion. According to Resnik, the Baltimore affair boiled down to a question of ethics:

"Should Baltimore have paid closer attention to the research that was being done under his supervision? If he could not adequately supervise the research, should he have been listed as an author? Should O'Toole have been given more protection for her whistle-blowing? Should the initial investigators have conducted a more thorough and careful inquiry? Should people outside of science be allowed to investigate and adjudicate cases of scientific misconduct? Should fraud cases be decided on scientific or on legal standards of evidence? Did politicians, scientists and the media 'rush to judgment'? Assuming that Imanishi-Kari did not fabricate or falsify data, could her poor record-keeping be viewed as irresponsible or unethical? How could one prove the allegations of fraud that were made in this case?" (Resnik 1998: 8)

From this case study, Freeland Judson identified what I believe to be one of the most important and widespread causes of scientific fraud (and extending to fraud in other sectors of society): a lack of supervision and mentor- 
ship. Supervision and mentorship are founded on a relationship of trust and mutual respect between more experienced and less experienced scientists. Mentorship creates a bond that goes beyond work. It is based on the power of the role model; someone a junior researcher can look up to as an example of the norms and values in the field. He or she sees the role model and thinks: "This is how I want to work; this is who I want to become." In some cases, however, mentorship can be marked by a lack of supervision. Freeland Judson mentions possible causes for this: too much distance between the laboratories and other workplaces where the supervisor and trainee work, or the young researcher showing so much promise that he or she is allowed to continue without supervision.

When I add this analysis of one of the most notorious fraud cases of the last thirty years to the other national and international fraud cases that I've studied, I arrive at a hypothetical model, which could not only help prevent scientific fraud but, as previously suggested, may even be transferable to other sectors in which fraud occurs. Though still somewhat primitive, this model consists of four clusters of factors that, when combined, can lead to fraudulent behavior.

I) Misplaced ambition or overambition, particularly among those who are still building their careers and in need of supervision and/or mentoring. "Misplaced ambition" refers to cases where one's ambition is not in proportion to one's proven capacities, as was the case with Imanishi-Kari. "Overambition" refers to the very talented, who think they can conquer the world at lightning speed, like Schön; medical researcher John Darsee, found guilty of the fabrication of data in the early Ig8os, is another example.

2) Too little supervision or mentoring, either due to organizational hierarchies, large and complex organizational structures, bureaucracy between researchers and management, or through a folie à deux, in which the supervising researcher is so impressed by the young talent that supervision is no longer taking place, and the young researcher takes this to mean that he or she no longer needs supervision. 
3) Lack of oversight in the overall system (failures in the peer review system, disregard for statistical anomalies, insufficient measurement checks, no replication of experiments).

4) Ignoring early signs of deviant behavior: lying, stubbornness, a pattern of non-cooperation, keeping to oneself. Darsee, for example, already had a prior conviction for check fraud and was later found guilty of forging diplomas.

The combination of these four complex factors, all of which involve individual and systemic characteristics, can give rise to scientific misconduct and dishonest behavior: overly ambitious people who avoid supervision and a system that does not adequately provide it can be a recipe for dishonest behavior. And when this goes unnoticed, the risky practices continue.

Naturally, these hypotheses need to be tested by means of large-scale inductive research. Scientific ethics can certainly play a role in the prevention of fraud, but without good mentorship within a well-designed social system, ethical convictions are unlikely to take root. 


\section{Chapter 4 \\ Addressing scientific integrity complaints}

\section{I THE ESTABLISHMENT OF COMMITTEES FOR SCIENTIFIC INTEGRITY}

In many countries, scientific integrity only became a matter of interest after a high-profile case of scientific fraud, such as the Baltimore affair in the United States. In Norway, for example, a scandal regarding the manipulation of medical research by Jon Sudb $\phi$ in 2005 led to a new law prohibiting scientific fraud and plagiarism (The Norwegian Law on Research Ethics/Integrity in Research, 2006). Since then, regional medical ethics committees have been established along with an umbrella organization called the National Commission for the Investigation of Scientific Misconduct, whose members are appointed by the Minister of Education (Kalleberg 2013). In Denmark, a fraud case in 2009 involving neuroscientist Milena Penkopva led to the creation of a legally sanctioned national body (Calaway 20II). In the Netherlands, the Buck (1992-1996) and Diekstra (1996-I998) affairs inspired action among members of the scientific community. And the Belgians followed the Dutch example in imposing self-regulatory measures after the VUB Brussels and

other universities (e.g. KU Leuven) were confronted with several serious cases of scientific fraud and plagiarism. Fraud in science became an issue, not only for universities and governmental bodies but for the media and the general public as well. 


\subsection{THE COMPLAINT PROCEDURE IN THE NETHERLANDS: THE LEGAL FRAMEWORK}

In response to growing national and international concern about integrity in science, the KNAW, VSNU and NWO drew up their aforementioned memorandum on scientific integrity in 200I. In it, the LOWI is already mentioned as a forthcoming appellate body, and it was formally established in 2003. The motivation behind these initiatives was that, in light of recent scandals, a procedure was needed for addressing scientific integrity violations. Until the early 2000 s, there was very little protocol for how to handle integrity cases. Academic disciplinary law, which had been regulated by the Academic Statute (Academisch statuut) from 1874 to 1960 and primarily served as a guideline for students' public behavior, had been abolished. After that, cases of suspected plagiarism were dealt with quietly until well into the I97os (Van Kolfschooten I996: 4I-46). Only labor laws offered a narrow basis on which university researchers could be held accountable for plagiarism or fraud, and only on the grounds that they had behaved in a manner "unbefitting of a good employee". Rarely was anyone fired or sanctioned. Most cases were kept internal, and the details were not always well documented. After the scandals of the I9gos, this was no longer possible.

The 200I memorandum is interesting for several reasons. First, it explicitly opted for a complaint procedure, with a complainant and a defendant, and emphasized the importance of hearing both sides of the argument. Second, the investigation and evaluation of complaints were primarily carried out by Confidential Advisors. The role of the LOWI was somewhat unclear: Was it a quasi-judicial body that would be allowed to issue binding rulings or more of an administrative advisory council? The first cases brought before the LOWI resulted in "rulings", which were later changed to "opinions" that are addressed to the Executive Board of the institution in question. Around the same time the 2004 Code was adopted and went into effect on January I, 2005 .

Of course, this is not to say that plagiarism committed before that time could not be sanctioned, as one defendant tried to argue at the LOWI in 2008 (LOWI opinion 2008-I). A number of universities were slow to comply with the obligation to establish rules and regulatory committees, which, in the absence of regulations and a standing committee at the time, led to the inadequate handling of integrity complaints (LOWI opinion 20I0-2). It 
was not until the 20II Stapel affair that universities realized how serious the matter of scientific integrity is; this was when the universities that did not yet have permanent committees for scientific integrity finally established such committees.

It is interesting to examine the systematic legal framework for addressing scientific integrity complaints. What kind of behavior constitutes a violation of the provisions of the relevant code of conduct and what kind of sanctions can be imposed?

As noted earlier, the $200 \mathrm{I}$ memorandum serves as a sort of "constitution" on how to handle scientific integrity complaints. The text states that there is no legal basis, but that the parties involved can turn to the civil courts at any stage of the proceedings. Both the position and the competence of the LOWI are based on the regulations drawn up by the three founding organizations, the KNAW, NWO and VSNU. The regulations themselves have a legal basis pursuant to Article 5.I of the Higher Education Act, in which the KNAW is instructed to actively ensure the advancement of scientific practice-in addition to its other tasks, such as advising the Minister of Education and Science. Article 3.I of the LOWI regulations states that the LOWI is responsible for advising institutions on how to manage scientific integrity complaints. The LOWI offers its advice without the intervention of the KNAW Board; in other words, the LOWI operates independently of its three parent organizations. The LOWI's independence was confirmed by a judgment of the District Court of Amsterdam (May 22, 2013) in a case in which a complainant demanded that the KNAW Board correct an opinion issued by the LOWI and exercise more supervision over the organization.

In addition, the above-mentioned European Code of Conduct for Research Integrity or ALLEA Code calls on the relevant institutions to carefully investigate alleged scientific integrity violations: "It should be fair and speedy, and lead to proper outcomes and sanctions. Confidentiality should be observed where possible and proportionate action is taken when necessary." (ALLEA-Code 20I0). In addition, the new version of this ALLEA Code (2017) states the following: "Investigations are carried out with due process and in fairness to all parties" and "Anyone accused of research misconduct is presumed innocent until proven otherwise" (ALLEA Code, 2017: 9).

The ALLEA Code also states that the primary responsibility for addressing cases of scientific misconduct lies with the researchers' employers. These institutions should have an ad hoc or standing committee to investigate al- 
legations of misconduct. Moreover, Academies of Science and other bodies should have a code of conduct that all members are expected to abide by, which also includes rules for handling cases of alleged misconduct.

In the end, only the employer can impose sanctions, but the LOWI is authorized, according to its regulations, to advise on possible sanctions. In addition to the LOWI regulations, universities and research institutes have their own regulations for handling scientific integrity complaints, which lay out the respective roles of the Confidential Advisor, the scientific integrity committee and the institution's Executive Board. These regulations stipulate that if the complainant or the defendant does not agree with the Executive Board's decision, he or she may, within six weeks after this decision, request the LOWI's opinion on the matter. The LOWI will then evaluate both the complaint itself and how it was addressed by the institution in question. For administrative bodies recognized by law, this complaint procedure is governed by Book 9 of the General Administrative Law Act (AwB), which lays down rules for how administrative bodies should handle complaint. Pursuant to Article 9.3 of the $\mathrm{AwB}$, a decision on these complaints is not subject to appeal in court; however, it may be taken to the National Ombudsman.

The legal framework outlined here can be described as a form of self-regulation by the associated administrative bodies, in this case the universities and research institutes affiliated with NWO and KNAW. Self-regulation implies that the standards and rules of good conduct are set by the professionals themselves and not imposed by the state. This means that, in cases of suspected integrity violations, scientists judge scientists. Self-regulation is thus the opposite of government regulation, where the government sets the standards for good scientific conduct and determines how violations are addressed and by whom (as is the case in Norway and Denmark, for example). The self-regulation of scientific research also makes sense given that much of what already occurs in the scientific field involves evaluating the quality of other scientists' work (e.g. peer review, appointments) and research proposals (e.g. applying for funding).

This system of disciplinary self-regulation is similar to the one found in the legal profession, where lawyers assess each other's conduct and investigate alleged violations of the attorneys' code of conduct. The only difference is that the code for lawyers is backed by a special Act: the Attorneys Act (Advocatenwet). The same goes for the medical profession, where the assessment of professional standards is entrusted to a board of mixed membership, 
which operates outside of the hospitals' own organizations and the medical field. The pros and cons of these different types of disciplinary systems, whether they be state-sanctioned or self-regulatory, composed of professionals inside or outside the field in question, will be discussed in Chapter 7 .

\subsection{THE CURRENT COMPLAINT PROCEDURE}

If a person suspects that scientific misconduct has taken place, the current procedure is as follows:

- This person can report the case to the Confidential Advisor or take it directly to the Executive Board of the institution in question. It is the duty of Confidential Advisors to advise the complainant and the defendant, guide them through the proper procedure, assess the seriousness of the complaint and discuss the matter with those involved. Confidential Advisors can also serve as mediators in a conflict.

- If necessary, the Board will order that the complaint be investigated by the CWI. If there is no established CWI, the Board will set up a temporary one. The complainant and the defendant can both present their case, witnesses can be heard, and advice can be sought from experts in the field.

- Based on the CWI's advice, the Board will make a provisional decision.

- The complainant and the defendant then have six weeks to appeal to the LOWI. The LOWI may initiate a re-examination of the complaint itself, after which it will provide an opinion on the provisional decision and the procedure followed to reach that decision. This advice is then submitted to the Executive Board.

- The Board will then make a final decision on the complaint, any violations of scientific integrity and measures to be taken under employment law (e.g. warning, reprimand, suspension 
or dismissal). Under special circumstances, the Board's decision may deviate from the LOWI's opinion.

- An Executive Board's final decision cannot be appealed in administrative court (Article 9.3 of the AwB), but complaints about the procedure can be submitted to the National Ombudsman. An appeal may be requested in civil court (particularly in cases involving the VU Amsterdam, Tillburg University and Radboud University, which are not administrative bodies within the meaning of the $\mathrm{AwB}$ ). In cases involving measures taken according to employment law, an appeal may be lodged with the Civil Service Tribunal, and eventually taken before the Central Appeals Tribunal.

These steps indicate the formal order in which an integrity procedure takes place. Both university regulations and the LOWI regulations state specific timeframes within which certain actions or decisions must be taken. Some time limits are mandatory, such as the time limit for appeals; others, such as the time limit within which a decision must be taken, may be extended if necessary. The two parties, the complainant and the defendant, are given the opportunity to present evidence and counterarguments during the proceedings, which can then be responded to by the opposing party once. The CWI or the LOWI may also set time limits for this exchange of evidence, within which the parties must submit any documents or material that they wish to be taken into consideration.

\subsection{PRINCIPLES OF FAIR TRIAL IN ADDRESSING FRAUD COMPLAINTS}

Just as important as these formal steps are the principles on which the entire procedure is based. In any case of suspected fraud or misconduct, one thing is paramount: there must be a fair trial, in which the defendant has the opportunity to defend his or her actions. Likewise, there should be no fear of retaliation for reporting suspected scientific fraud. The principle of fair trial is indisputable. 
At the University of Oxford, there are special rules for addressing plagiarism in academic dissertations. In describing this procedure, lawyer Nicolas Bamforth, who has been involved in the handling and assessment of these cases for years, emphasizes the importance of protecting the defendant's legal rights: "Within Oxford, considerations of academic integrity and fair play are balanced through the University's procedures in plagiarism cases, with a deep concern to ensure procedural fairness" (Bamforth, 2013: 79, my emphasis). This goes without saying. If the accusation of plagiarism or other serious misconduct turns out to be true, the person's academic career will most likely be destroyed. But even an accusation of misconduct, whether it's true or not, can damage a person's scientific reputation, which is why all complaints need to be investigated with the utmost care. Only after a thorough investigation can a careful, well-founded judgment be made.

Thus, the principles of fair trial for integrity complaints run parallel to the general principles of due process. This means that, in all cases, both sides of the argument must be heard, the accuser must provide evidence of a breach of integrity, and it must be clear which behavior is being examined as a violation of which specific provision of the relevant code of conduct (a general accusation that "there has been a breach in scientific integrity" is too vague to be taken into account).

The fact that both sides of the argument must be heard means that legally, pursuant to Book 9, especially article 9.4 of the $\mathrm{AwB}$, an anonymous complaint cannot be taken into consideration (due to the increased possibilities to anonymously accuse someone of a violation of scientific integrity via digital means, this has become a serious point of consideration, and one which universities tend to take too lightly). If a complainant is not identified, there is no way for both sides of the story to be heard, thus disadvantaging the defendant, because a fair trial presupposes equal treatment of the accuser and the accused (the so-called 'equality of arms' principle). If there are good reasons not to disclose the name of a complainant, there is a whistle-blower procedure that can be applied. In that case, at least one person (usually a member of the Executive Board) knows the complainant's identity so that he or she cannot evade legal liability for a false accusation.

Fair trial is also necessary when one considers the fact that if the defendant is found guilty of a violation of scientific integrity, he or she may face administrative consequences, such as dismissal, suspension, reprimand and other far-reaching labor law measures. From a legal perspective, these 
consequences can be considered "punitive sanctions", to which the European Court of Human Rights in Strasbourg, in its current case law based on Article 6 of the European Convention on Human Rights (ECHR), has attached special minimum requirements. When imposing severe punitive sanctions, such as dismissal and suspension from office, the following applies:

(I) Pre-established, clear and unambiguous standards should be formulated so that violations can be identified.

(2) There must be a second, independent body that one can call upon to determine whether these standards have been violated.

(3) The principle of equality of arms must be respected throughout the procedure.

In a fair trial, an investigative committee, such as a CWI, should reach an impartial, independent and objective opinion. Thus, it is important for members of this committee to maintain an objective distance from the disputing parties, which can be difficult in small scientific organizations or highly specialized fields. The investigative committee should not include anyone who knows the complainant or accused, works in their department or has collaborated with them in the past. For this reason, universities now require that Confidential Advisors, who are responsible for providing advice to all parties involved, not be part of the CWIs.

In addition to fair trial, there are two other important principles for addressing integrity complaints: confidentiality and transparency. Although these two principles may seem at odds with each other, if the rationale behind them is understood the tension between them is not really an issue. As the employer, the university's Executive Board is the authority that, in concrete cases, weighs the two principles against each other: the importance of confidentiality for the complainant or the defendant versus the importance of openness and transparency in one's own decision-making.

All university regulations on the handling of integrity complaints state that all parties involved are bound to confidentiality throughout the entire procedure. The reason for this is that a large number of accusations are dismissed as unfounded, and the defendant is free to go. Allegations of an 
integrity violation that are made public before a verdict has been reached can cause grave damage to researchers' careers; therefore, it is in the interest of both the complainant and the defendant to keep all matters related to the case confidential and not publicize their suspicions, allegations or evidence. This is particularly true for young researchers, for whom a false accusation, however unjustified, can ruin a budding career.

Journalists tend to think otherwise. Science journalists have been devoting more attention to scientific integrity violations in recent years, and many are eager to find out who is involved, what accusations have been made and which way the research committee is leaning. Naturally, the press wants full disclosure. After the Stapel affair, universities realized that, when it comes to integrity violation cases, openness is key to building trust. The universities agreed that, from 2012 onwards, all integrity violation cases would be published on the VSNU website in anonymized form (in contrast to the integrity procedures in Denmark, where the names of both the complainant and the defendant are made public). The anonymization of advice and the final decision ensures both the protection of the wrongly accused and transparency with the public. The LOWI also publishes all recommendations in anonymized form on its website. For journalists, it has become something of a sport to uncover the names of those involved using these websites and all the other electronic means available to them.

Out of concern for the interests of young researchers, who are often the victims of false accusations, I am in favor of keeping this information anonymous. At the end of the day, it is about how the rules of scientific integrity are applied in specific cases, not the identity of the defendant.

In terms of fairness, there is also the question of how long a conviction for a violation of scientific integrity should be carried out. Oftentimes, a serious violation results in lifelong exclusion from science, but-as in the case of life sentences for criminals - this also raises some pertinent questions. How long is lifelong? Is there not a right to rehabilitation or at least a second chance after the punishment has been served? In criminal law, there is still a sharp distinction between the act and the perpetrator. An act can be unforgivable, but the person who committed it can change. So, the question is: Is there life after fraud? (Gallagher 2009; McCook 2009: 28-36). The issue has already been raised in the United States, where the "punishment" usually involves a period of time during which one is barred from funding (from three to ten years) and because the names of the offenders are generally 
published and remain on the institutions' websites for a long time, the impact of the punishment can last much longer than the punishment itself. A minor integrity violation can follow a researcher for years and prevent him or her from pursuing a scientific career. Gallagher wonders whether this regime has become excessively punitive and suggests that the names of offenders be removed from the Internet after a certain period of time.

In the Netherlands, some offenders have been reasonably well rehabilitated (e.g. Diekstra, and neuropsychologist Margriet Sitskoorn). Personally, I think it is right for them to be given a second chance, with one major caveat: if it is morally right to give guilty scientists a second chance, we also have to make sure that scientists who have been wrongly accused are able to maintain their place in the scientific world. For example, it would be very unfair if someone who had been found guilty of plagiarism could return to work as a professor, while someone who has not committed any plagiarism or fraud, but was only accused of it could no longer keep his or her position due to relentless university gossip. This is yet another reason why scientific integrity cases must be held to the highest standards of fair trial.

\subsection{SETTING THE BOUNDARIES: PRACTICAL PROBLEMS AND EXAMPLES}

The substantive legal framework therefore consists of the 2004/2012/20I4 Code and the 2018 Code, as discussed in Chapter 2. Both Codes are effective as of October I, 20I8: research that started before October I, 20I8, is still covered by the old 2004/20I2/20I4 Code, whereas research that started after October I, 2018 is covered by the 2018 Code, which sets out newly formulated rules and regulations. The Codes describe the main forms of misconduct, but they are still not very well known among researchers and they do not provide much guidance on how researchers should behave, although the oldest standards of scientific practice, namely no plagiarism and no manipulation of data, are still evident. Moreover, on the basis of the literal text, the 2004/2012/20I4 Code seems to apply to education as well, but the LOWI has indicated in a number of recommendations that there are separate procedures for educational complaints (Committees for examination complaints, Cobex, and eventually the Higher Education Appeals Tribunal, the CBHO). Issues related to education are therefore not dealt with by CWIs or the LOWI. 
Although the three deadly sins of scientific misconduct (FFP) are somewhat recognizable in the 2004/2012/2014 Code, they are difficult to pinpoint. The Code mentions desirable behaviors, such as exercising due care when reporting research results, treating colleagues and co-researchers with respect, and a willingness to correct errors. If a violation occurs (e.g. a researcher fails to properly provide a reference or misapplies a statistical test), the circumstances under which this violation occurred must be considered: Was the violation intentional, accidental, unconscious, due to insufficient knowledge, etc.? This was already mentioned in the KNAW brochure titled Scientific Research: Dilemmas and Temptations, published in 2000:

"If a researcher has made a mistake but it has already been published, then a rectification should be issued. This should preferably be in the same periodical as the original article. If this is done quickly and unambiguously, then the researcher will rarely come in for blame. Errors made in good faith - just like differences of opinion regarding the results produced - are something entirely different to misrepresentation and fraud, and do not constitute any kind of scientific misconduct." (KNAW 2000: Ig).

This quote more or less summarizes what the US Code of Conduct would refer to as an "honest mistake". Mistakes are part of science, and I'm not just talking about inevitable measurement errors (i.e. the statistically acceptable margins for differences in repeated measurements), but also careless errors and genuine mistakes. There is, however, a wide range of transgressions between a simple mistake and serious fraud. In many cases, complainants will regard an error as blatant fraud and defendants will try to write off fraud as a careless mistake. Therefore, it is essential that all cases of alleged scientific integrity violations be investigated with extreme care and assessed on a case-by-case basis.

In this chapter, I would like to review several other key questions that are particularly relevant when it comes to determining which behaviors could be considered integrity violations under the Netherlands Code of Conduct. Over the last ten years, the LOWI, which, as an appellate body, is also responsible for coordinating the interpretation of the Code, has had to test these boundaries and set limits. I will devote the rest of this section to discussing five types of borderline cases. 


\section{Intellectual property and patents}

There have been several cases where the LOWI was confronted with disputes over patent applications. Most of them followed a similar pattern: two researchers who had once worked together on a project got into a fight because one of the researchers had not been included in the patent application. The latter then attempted to undermine the application by submitting an integrity violation complaint, which prompted the other party to do the same. It is not unusual for a disgruntled researcher to file an integrity complaint as a means of achieving another goal, namely the defamation of the defendant. If the accuser can show that the patent application contained manipulated or erroneous research results, then the patent application would likely be denied. One such case involved the allegation of manipulated results in statistical tables. In this case, the LOWI ruled that patent cases must be taken to civil court, which is equipped to settle disputes over intellectual property. The fact that the research had taken place at a university and that the university had approved the patent application was not reason enough for the LOWI to judge the case. Nevertheless, LOWI did investigate whether the research results in question had been manipulated and found that they had not (LOWI opinions 2008-2; 201I-4).

In these cases, it was easy enough to set a boundary between a civil case concerning intellectual property rights and a scientific integrity violation. The LOWI regulations support this distinction: Article 3.2 states that a complaint cannot be dealt with if civil or criminal proceedings have been instituted against the same conduct.

Another case, which had nothing to do with patent applications, raised the question of whether an alleged case of plagiarism constituted a violation of scientific integrity. An ad hoc committee investigating the claim applied copyright law in this case and disregarded the Code of Conduct and the university regulations on scientific integrity violations. Of course, a case of blatant plagiarism may-in addition to being a violation of the Code of Conduct-also constitute a copyright violation, but determining whether a subjective right has been infringed is a matter for the civil court.

In general, university researchers are quick to refer to the plagiarism of texts and ideas as "intellectual property theft", and some may wish to combat it by filing a scientific integrity complaint. However, only the court can decide if such a "theft" has actually taken place (see Chapter 5 ). 
The distinction between a scientific integrity violation and a civil law case is again at issue when it comes to the simultaneous submission of one article to two scientific journals. Publishers and journal editors often prohibit the simultaneous submission of articles, referring to the Committee on Publication Ethics (COPE) regulations issued by the publishers of scientific journals. There are some who argue that this practice is a violation of scientific integrity; however, this is a question of the contractual relationship between the researcher and the publisher, not a question of scientific integrity.

\section{Labor disputes and other quarrels}

Similarly, we can draw a line between labor law disputes and integrity violations. Sometimes allegations of scientific integrity are a cover for serious labor conflicts. Researchers who have worked together for years get into a fight, which leads to accusations of integrity violations (e.g. plagiarism, denial of co-authorship, manipulation of research data). Sometimes these accusations are justified, and the research committee (i.e. the CWI) will have to confirm that a violation has indeed occurred, but the committee also needs to determine when there are primary labor law issues are at stake. As the employer, the university and its Board are responsible for taking action in labor disputes, and if necessary, parties can seek the help of a mediator. Confidential Advisors, who are appointed to monitor scientific integrity, need to be aware of the types of conflicts that can be addressed through an integrity complaint procedure and the types of conflicts that cannot (e.g. allegations of sexual harassment). As a general rule, the scientific integrity complaint procedure is not designed to address labor disputes.

In the same vein, arguments and complaints about $\mathrm{PhD}$ procedures should be submitted to the Committee of Deans of the institution in question and not to the CWI (for example, there was a case where someone was rejected as a co-supervisor and this was seen as a violation of scientific integrity towards that person). Likewise, one cannot use the scientific integrity complaint procedure to challenge the quality of a dissertation. This is a matter for the doctoral examination committee and ultimately the Committee of Deans, on whose behalf the doctoral degree is awarded. Universities also have separate complaint procedures for sexual harassment. Although sexual harassment is, by nature, a violation of integrity, this and other forms of criminal violations must not be confused with matters of scientific integrity. 


\section{Scientific controversies}

A third category concerns scientific controversies, which can arise when one disagrees with certain research results or with the interpretation of those results presented in a publication. If this leads to a negative opinion about the article in question, even without claiming that the research data have been manipulated, sometimes the disgruntled party will try to claim that there has been a violation of scientific integrity under the general provision in the Code of Conduct that states that a scientific researcher must always exhibit due care and report everything truthfully. For example, major and minor inaccuracies (e.g. a false quote) and careless behavior can lead to accusations of "scientific fraud" on the grounds that one has not complied with all the provisions of the Code, particularly those that describe desirable behavior.

In such cases, it is important to understand the distinction between scientific controversies and suspected violations of integrity. Controversies are part of science. Contradiction, alternative explanations, criticism of hypotheses or research that contradicts one's hypotheses, disagreement about the right methodology - these differences in opinion are the lifeblood of science. It goes without saying that science (and scientific journals in particular) provides the appropriate forum for "battling out" these controversies. The battle metaphor seems appropriate here: we often refer to the world of science as an arena, where hypotheses are bastions to be defended (Lakoff and Johnson, I980: 46-60; for metaphors in medical-scientific texts see Van Rijn-Van Tongeren, 1994). This spirit of debate must be sustained and protected; it is important to make sure that it does not become burdened by concerns about scientific integrity violations. What makes the scientific community so unique is that everyone, from professor to student, can participate in it and that there is no "Supreme Court of Science" to decide what is and is not a good scientific theory or opinion. Scientists should be able to withstand criticism, for example in the form of a negative review or a critical article. Neither the Scientific Integrity Committees nor the LOWI are equipped to act as final arbitrators in scientific controversies.

Here are a few examples of scientific controversies that have come to light in complaint procedures: 
- The right method of soil investigation: should samples be collected at four meters or two?

- How should archaeological findings best be interpreted?

- How do certain drinks influence young people's behavior?

- The use of a certain method in medical operations: Is there one right way to do surgery?

- Testing causal relationships between two variables: Is it better to use one- or two-sided statistical tests?

- What is the most scientifically probable cause of death of certain animals?

- Can canine scent tests be used to identify suspects in criminal proceedings?

These controversies, some of which have generated a significant amount of public attention, have certainly raised issues worthy of debate; however, we should not allow scholarly disagreements to spiral into accusations of dishonesty. When such cases are brought before scientific integrity committees (e.g. the CWI or LOWI), these committees first have to investigate exactly what is going on. Oftentimes, a complaint about the quality of a scientific article is submitted in the form of an integrity complaint, for example the accuser might claim that the research question is flawed, the conclusions cannot be supported by the facts presented, the figures are incorrect or the method used is "unscientific" and therefore "untrue". However, these claims are subject to interpretation and based on differences of opinion about what constitutes good scientific research.

Allowing these scientific controversies to be treated as integrity violations conjures the horror of a science police-and the 2018 Code, with its 6I "standards" for good scientific research, is bringing us closer to this nightmare. I consider such a "police force" undesirable for many reasons, but mainly because it would restrict the freedom of scientific research. Fortunately, there is no supreme power in science. There are only facts, interpretations and arguments-all of which are up for debate within the scientific community. 
Side activities, side positions and conflicts of interest

How far does the position of professor or scientific researcher extend? If the professor is involved in pseudoscientific activities in his or her own time, for example, serving as chair of an association in which his or her scientific knowledge is useful, can the professor be accused of a scientific integrity violation if that association makes a decision that is out of line? In other words, are you a scientist twenty-four hours a day? Do scientific codes of conduct require that scientists always behave "truthfully" and take the utmost care in all scientific activities, even those outside of their research position?

In one case, which questioned the private activities of an emeritus professor, the LOWI advised the Executive Board to set clear boundaries between activities carried out in one's role as researcher and activities carried out in one's private time. The Board had been right to reject the complaint on the grounds that the university's code of conduct only covers activities carried out in one's role as a university researcher. There are, however, some exceptions to this rule, particularly if the non-university activity stems directly from one's scientific expertise. For example, if a researcher is called to be an expert witness in a civil case and his or her scientific opinion is not properly established or contains manipulated data, the professor could be charged and convicted of misconduct (LOWI opinion 2012, no. 2).

Such a case can also be influenced by scientific controversy. When two experts in a particular field meet in the courtroom, their scientific testimonies may differ. It can be tempting to regard the other party's testimony as fraudulent ("that can't be true!"); however, in most cases, the problem is a difference of opinion, a difference in the weighting and interpretation of actual data, or from other methodological assumptions. The fact that scientists disagree with each other is not so surprising (although judges and outsiders may think otherwise), but it is surprising that these disagreements can result in accusations of dishonest conduct or fraudulent behavior.

Conflicts of interest can play a role here as well. Conducting research without mentioning that one has a vested interest in the results goes against the principle that scientific research should be carried out independently of economic or social interests. Failure to mention conflicts of interest is a breach of scientific integrity. In various scientific fields, one must include a statement of disclosure that mentions any potential conflicts of interest or states that there are no conflicts of interest to speak of. Such a statement 
offers a solution for scientific research funded or subsidized by companies and contributes to overall transparency. The readers of the future publication will know to look out for potential bias.

Trickier still is drawing the line between scientific research carried out in the context of a part-time university position (e.g. one day a week as an externally endowed professor in a highly specialized field) and other commercial activities carried out in the same field. Does research that is conducted in one's own private time and on a commercial basis fall under the Code of Conduct as well? If a lawyer who serves as an endowed professor in a specialized field of law and also has a private legal practice uses material from a client's case as data for a scientific article, she is obliged to mention this as a potential conflict of interest. For all activities carried out as a lawyer, she is subject to the attorney's code of ethics; for all activities carried out as a scientific researcher, she is subject to the code of conduct of the university in question. In sum, when publishing scientific research, researchers should take care to mention any vested interests they may have in the results of their own research. Commercial research, on the other hand, falls outside the scope of the 2004/2012/2014 Code and its successor, the 2018 Code.

\section{Scientific evaluations and advice}

The last boundary issue to be addressed is a question of scope: Does assessing research applications fall within the scope of conducting scientific research or not? The answer to this question depends on how strictly the Code of Conduct is interpreted. Is the Code limited to research one undertakes oneself? Assessing someone else's research is not the same thing as conducting one's own research. So, does this mean that evaluating applications for research grants falls outside the scope of the standards for scientific practice?

There was one case where a complainant accused the scientist charged with evaluating applications of referring to a non-existent scientific article, calling it a deliberate fabrication (rather than a typo in the publication date). The committee rejected the complaint, claiming that it had nothing to do with scientific research. On appeal, the LOWI took a different view. Scientific misconduct can also occur in the evaluation of applications, for example a senior researcher with a large number of applications to assess can pick out original ideas he wants to use and then reject the application. Conflicts of interest also need to be considered when forming an opinion in order to 
avoid cases where applications submitted by the evaluating organization's own employees are judged more favorably (LOWI opinion 2013-3). It is counter-intuitive not to consider the assessment of scientific research applications as scientific practice. Nowadays, the assessment of applications for research funding has become an integral part of scientific activities. It serves as a sort of precursor to the peer review process, in which scientific articles that have been submitted for publication are evaluated by fellow experts in the field after the research has been completed. Here, too, things can wrong, as demonstrated by one of the most spectacular and instructive cases of scientific misconduct in the United States, the Wachslicht-Rodbard case discussed in Chapter 3. This case confirms the view that scientific practice cannot be strictly limited to research; it also includes the assessment of research. 


\section{Chapter 5 \\ Plagiarism and self-plagiarism}

\section{I VIOLATION OF THE BASIC RULES OF SCIENCE}

Most researchers are well aware of the fact that plagiarism is strictly prohibited in the scientific arena and constitutes a serious violation of the code of conduct. What exactly plagiarism is and when it occurs is less widely understood. Plagiarism as a specific legal concept is not addressed in the Dutch Copyright Act of I9I2 (Spoor, Verkade and Visser 2005: 17I; Verkade and Spoor 1986: II3). This act only refers to the "total or partial adaptation or imitation in a modified form, which cannot be regarded as a new, original work" (Article I 3 of the Dutch Copyright Act). Here, "imitation" refers to many forms of creativity, not just science. The ban on imitation includes literary texts, cartoons, photographs, images, advertising texts and much more. Scientific plagiarism and copyright protection of "creations" are two separate issues, as are intellectual property theft and plagiarism, though many researchers like to refer to plagiarism as "intellectual property theft." Spoor, Verkade and Visser write: "In practice one also speaks of plagiarism in cases that do not constitute an infringement of copyright, e.g. when one presents someone else's scientific theory (not susceptible to copyright protection) as one's own work" (2005: I7I). Foreign intellectual property experts such as LaFolette (1992), Nimmer (2008) in the US and Ohly (2013) in Germany share this view. Plagiarism is seen as a violation of the basic rules of science-a serious offense, of course, but far from a violation of property rights.

In his extensive article "The moral imperative against academic plagiarism," David Nimmer provides an instructive example of a publisher who wanted to publish a new edition of a part of The Path of the Law (I897) by Oliver Wendell Holmes. This work is no longer subject to copyright. However, a law professor who wants to publish the same long passage under his own name 
in a journal article is guilty of a serious violation of scientific integrity and risks losing his position (Nimmer 2008: 490). In the Netherlands, the LOWI had to judge a case where a professor used a part of the text by his deceased predecessor without properly referencing the source. In the end, the deceased author's family chose not to take the case to civil court, so it could not be established whether this was a case of copyright infringement or whether copying would be permitted on the basis of contractual provisions between publishers and authors. Nevertheless, the civil law issues surrounding copyright infringement are separate from the question of scientific integrity (LOWI opinion 2013: 2).

Plagiarism in science is a matter for the academic community itself. Since there is no copyright on scientific laws or theories, it is important to give credit where credit is due. In science, there is a certain prestige that comes with being the first to discover, find or clearly formulate something. Moreover, a scientific law will most likely bear the name of its original designer: Boyle and Lavoisier in chemistry, Mendel and Darwin in biology, Gossen's laws and Axelrod's Tit for Tat in economics, Chomsky's generative grammar, the Thomas theorem in sociology-the list goes on. The person's name can even become a verb, take "to pasteurize" from Louis Pasteur, for example. Of course, the history of science has shown that new discoveries lead to patent battles. However, intellectual property law dictates that patent law must also remain separate from cases of scientific plagiarism. A company can obtain rights to a patent without any involvement from the original author of the scientific article that formed the basis for the patent. Patents can be licensed, making imitation completely legal, but "imitation" without adequate reference to the source in science remains taboo.

This hasn't always been the case. In the Middle Ages, monks copied texts from predecessors, who then provided them with comments in the margins (Kristeller 1992: 95-II4). In the early Renaissance, scholars like Erasmus, Montaigne and Galileo hid their new ideas in extensive quotations from classical writers from antiquity. This was customary at the time and considered a demonstration of scholarship. As Ari Wesseling clearly explains: "Plagiarism was not a problem in the Middle Ages. The humanists used the work of their predecessors and contemporaries without mentioning the source as well. Erasmus's works were already being used early on" (Wesseling 2000: 66). It thus seems unfair to accuse Erasmus or Montaigne of plagiarism in retrospect, as Van Kolfschooten does (I996: 22; 2012: 
30), though Erasmus did include other people's work and discoveries in his Adages.

The protection against academic plagiarism is, however, relatively recent. The plagiarism of Pierson's work in 1872 , as mentioned in Chapter 3, may have raised a few eyebrows, but perpetrator Von Schwarzkopf was not expelled from the academic community. In I923, legal historian Bernard Hermesdorf (I923: 4II-427) argued in an article on scientific property that scientific inventions should fall under the protection of the Patent Act. He believed that this would stimulate scientists' creativity, but he still wrestled with the question of whether one could actually hold the right to an idea. Holding the right to a piece of land means that the owner has the exclusive right to use that land, but how can someone have the exclusive right to an idea? Once the idea has been made public, can you really stop other people from using it? To Hermesdorf, a patent on a new medicine was still unthinkable:

"Once that publication has been released, it becomes part of the published public domain. Everyone benefits from it (...). One thinks of the physician who has discovered an important medicine against a disease that, until that point, had been regarded as incurable. He'll write about it in journals, talk about it in lecture halls and meetings. Maybe he'll become a celebrity. Yet, he will not enjoy the protection provided by the Patent Act for his discovery" (Hermesdorf 1923: 418; see also Van den Belt 2010).

Since Hermesdorf's time, the paths of patents and scientific plagiarism have gone in different directions. Scientists exhibit mutual respect and recognize each other for their ideas and contributions to science. Industrial companies find practical applications for scientific ideas and then protect those applications with patents. The ban on plagiarism in science is primarily intended to protect the reputation of the first to come up with the new ideas, theories and evidence. Anyone who uses these ideas or incorporates them into their own research should mention that person and/or the location where the discovery was made-in other words, give credit where credit is due. This is science's informal reward system. Plagiarism undermines this reward system, while fabrication and falsification, the other deadly sins of science, undermine the reliability of scientific knowledge. 


\subsection{TAKING CREDIT FOR OTHER PEOPLE'S WORK}

Plagiarism extends beyond the scientific field. It occurs regularly in literature, where authors integrate fragments from other authors texts into their own novels, stories or poems. Sometimes this can lead to harsh accusations and disputes. It also occurs in music, the visual arts, journalism and elsewhere. In the Netherlands, there has even been talk of plagiarism on a postage stamp! The photographer who took the photo of the Dutch king was not properly credited for his work.

It is difficult to provide a comprehensive description of authorship and plagiarism. One of the older studies on scientific plagiarism, Stealing into Print: Fraud, Plagiarism and Misconduct in Scientific Publishing (LaFolette 1992) argues: "it has been discovered that finding one definition of authorship acceptable to all institutions and all disciplines is not just 'intellectually difficult', but impossible" (I992: 9I).

A broad definition of plagiarism is given in the Oxford English Dictionary:

"The action or practice of plagiarizing: the wrongful appropriation or purloining, and publication as one's own, of the ideas, or the expression of ideas (literary, artistic, musical, mechanical etc.) of another" (OED, cited by Hexham 2005).

Purloining means "to take dishonestly; to steal, especially under circumstances which involve a breach of trust" (Hexham, idem). While in a metaphorical sense, it may seem logical to associate plagiarism with stealing someone's property, the question remains: how does one actually "steal" a message or a well-formulated idea intended for a wide audience? Doing so would be an infringement of someone else's subjective right (if this has been established by copyright, including damage and causality) and cause damage to a fellow scientist's honor. Plagiarism is a failure to give credit where credit is due-and hence a transgression against one of the basic rules of academia. Article 25 of the Dutch Copyright Act does include the right to be mentioned by name, but this subjective right is not part of the property laws covered under the Copyright Act.

The 2004/2012 Code sent out a clear message to scientific researchers: don't take credit for other people's work. This message makes it clear what 
one should not do, but it doesn't offer any insight into what plagiarism is and is not. The 2014 Code provides a bit more clarity:

"Accurate source references provide a clear indication of the intellectual provenance of cited and paraphrased text. This also applies to information gathered from the Internet and from anonymous sources. The texts and research results of others are never reproduced without a reference."

A number of university regulations on scientific integrity, including those of Utrecht University and the University of Amsterdam, provide a more detailed description. Both mention the use of the Internet, which is understandable given the ease with which online texts can be copied. For students new to academic writing, the genre can sound particularly impressive. They may think they cannot surpass it or summarize it succinctly and simply "forget" to mention where they found it online. Learning is unlearning: novice students need to be taught why and when proper acknowledgment of the source is necessary and why plagiarism is forbidden in science. What plagiarism is and why it is prohibited is not so difficult to explain. Although there are countless formulations, they mostly come down to the following:

"the use of another person's ideas or expressions in your writing without acknowledging the source; simply put plagiarism is using another person's words or ideas without appropriate acknowledgment.

In short, to plagiarize is to give the impression that you have written or thought something that you have in fact borrowed from someone else" (Nimmer 2008: 489; Ong I988: 154).

In other words, plagiarism is presenting someone else's texts or ideas as your own. However, this definition doesn't solve all of our problems when we consider that almost every idea people have-in science or otherwise-is from someone else. Thus, the question is which ideas or parts of the text must be attributed to a source? Any word-for-word quotation, paraphrase, well-formulated argument or theory should come with a citation. But is this always the case? That depends. 
Plagiarism is not like pornography. A judge presiding over a pornography case can operate under the principle of "I know it when I see it." Plagiarism is more difficult to establish, depending on the absoluteness with which the basic rules of academia are applied. Should the author of every idea, thought or written expression be mentioned, including the original source and all of the later sources throughout history? Many expressions and texts can be traced back to the Bible and other sacred books, to ancient literary texts (e.g. the Oedipus complex, from the eponymous play by Sophocles) or were first recorded by well-known philosophers (e.g. Descartes' "I think, therefore I am") and scholars (Newton, Einstein). How far back must one go in crediting the original author? Should every textbook that uses logical reasoning cite Aristotle's Analytica Priora, the original source of syllogisms of deduction and induction? When using Venn diagrams, must one always refer to the original source when the man behind them is mentioned in the name itself? If every failure to mention all (original) contributors is considered plagiarism, the requirement of academic honesty and giving credit where credit is due becomes very time-consuming, if not impossible. Fortunately, established scientific practices provide reasonable solutions for this.

General knowledge within a discipline does not necessarily require a detailed reference; it is sufficient to indicate the name of the original author of a theory or the person who first obtained certain research results. For example, if I am writing an article on the rise in suicide among immigrants married at a young age and want to refer to Durkheim's classic sociological theory of anomie, which is still applicable today, it would suffice to write: "As Durkheim observed...", or if I'd like to be more precise, "As Durkheim demonstrated in his study Le suicide (I897)", etc. However, if I were to copy a literal quote from Durkheim (be it in the original French or in translation), I must be even more precise and also mention the original source in a footnote or reference, as well as the name of the translator.

A quotation is a literal citation from an existing text and must be signaled with quotation marks (also known as "inverted commas"). There is nothing wrong with quoting other people's texts, as long as one does so properly, including their exact punctuation, etc. It is, however, important to keep an eye on the length of the quotes. Longer quotations, for example of more than one page, require separate justification. All of this seems obvious enough, but we know from practice that plagiarism isn't always so simple. There are many forms of referencing and many forms of plagiarism. In a journal specifically 
devoted to FFP, Brian Martin listed fifteen different forms of plagiarism, based on the broad definition that "plagiarism is presenting other people's ideas as one's own" (Martin 2008: 3 ). In doing so, he makes a distinction between conscious and unconscious, intentional and nonintentional, and permissible and non-permissible plagiarism. One nonintentional form is cryptomnesia, a form of memory bias where one thinks that one has come up with a certain idea or expression oneself, when, in fact, it was actually heard from someone else. It is particularly common among older scholars. For example, I might write about "fatalistic suicide" as if I had come up with the concept myself, while having completely forgotten that I had actually read Durkheim's book on the subject fifty years ago during my studies (in other words, the source is forgotten but the concept has remained engraved in my memory).

Nonintentional plagiarism also occurs when the author has no intention whatsoever of deceiving the reader, but simply fails to mention the correct source out of ignorance or unfamiliarity with the conventions of referencing. This is often the case with novice authors or students writing their first paper. One student accused of plagiarism in England even filed a lawsuit, claiming that his teachers had never properly explained how, when and why to refer to sources and that no one had ever told him that plagiarism is punishable by law (Nimmer 2008: 49I). Nonintentional plagiarism does not constitute a violation of integrity, but it can be difficult to prove that the person did not know that copying information from other texts was wrong (although cutting and pasting from the internet does suggest a certain level of carelessness).

Martin (2008: 3-6) describes several forms of plagiarism that are sometimes considered acceptable, namely:

- bureaucratic plagiarism: when a text has been adapted repeatedly, particularly in a bureaucratic context, no one knows exactly who the original author is.

- ghostwriting: a ghostwriter is someone who is hired to write a text or is ordered to do so by a superior (e.g. an entrepreneur, director or politician); both parties benefit from the relationship, although strictly speaking this practice will fall under the definition of plagiarism if the client later publishes the text under his or her own name, without mentioning the ghostwriter. 
- editorial ghostwriting: when the editor of a magazine or book completes an author's texts with a few lines or with an additional explanation, or corrects erroneous source references the author has made without asking for or receiving credit. Editorial ghostwriting is related to supervisory ghostwriting, that is when an advisor substantially improves a PhD student's text without being mentioned or acknowledged.

- honorary authorship (also known as gift authorship): when someone is named as an author or co-author without having made a substantial contribution. Sometimes this is done on the primary author's initiative in order to increase the publication's prestige. This practice is sometimes considered acceptable in science and sometimes not (see Chapter 6);

- self-plagiarism: presenting one's own prior work as if it is new work.

Martin's opinion on the republishing of one's own work is unclear. He mentions self-plagiarism as one of the forms of plagiarism but does not go into detail about to what extent it may be acceptable. He merely notes that it has become easier to detect self-plagiarism thanks to online databases and plagiarism detection software (e.g. Turnitin). "An investigator into self-plagiarism, having found matching text in two different articles, has to check to see whether the author has acknowledged the prior source" (Martin 2008: I4).

The unacceptable forms of plagiarism are those which involve literal or almost literal copying of a text without adequate reference to the original source, thereby making the text seem like it is one's own work. This can be in the form of word-for-word plagiarism or paraphrase plagiarism (Martin, 2008: 4). Word-for-word plagiarism is immediately recognizable when one compares the source text with the copied text. Paraphrase plagiarism involves copying certain word sequences and/or structures from an original text and only changing a few words or replacing certain words with synonyms, without mentioning the source. Paraphrasing other people's texts, as in reproducing someone else's text in your own words, is in itself perfectly permissible, as long as one refers to the original source at the beginning or at the end of the paraphrase, as I am currently doing with the text by Brian Martin 
(Martin, 2008: 4). This is very common in scientific texts. Good examples of correct and incorrect paraphrasing can be found in Hexham's article "The Plague of Plagiarism: Academic Plagiarism defined" (Hexham 2005).

Another form of plagiarism Martin mentions, which is quite common in scientific texts but not mentioned in codes of conduct, is the incorporation of references used in other source texts (e.g. articles or books) without having consulted the text to which reference is made or checked the reference itself. This is often done out of laziness or by authors who state that they don't have the time to check all their references. This is what Martin calls plagiarism of secondary sources. In other words, the author of the text is relying on the work of someone else. If the copied references are incorrect or refer to the wrong pages and/or the reference is mentioned without being checked-not to mention being read-the error is repeated. This form of improper copying is generally uncovered when one directly copies a reference that contains a blatant error. The question is: How bad is this? In some cases, it is a sign of sloppiness and laziness, combined with a desire to show off how many sources one has supposedly consulted. Thus, it is always better to be transparent about the fact that you are using a quote cited by another author. In this case, a footnote or reference would read: "see Hexham 2005, as quoted by Martin 2008".

Oddly enough, one form of plagiarism that Martin does not mention is the plagiarism of ideas, in other words, trying to pass someone else's ideas off as one's own-for example, ideas presented in a research application or in unpublished work. Presenting other people's ideas as if they are one's own, without reference to the original source, is a form of plagiarism. According to Freeland Judson, among others, the plagiarism of ideas is even more disturbing when it comes to the formation of theories, methodical innovations and original approaches. Such plagiarism goes beyond simply failing to give credit where credit is due; it violates the mutual trust between scientists. In contemporary scientific practice, there are two crucial moments that are extremely vulnerable to surreptitious copying of other people's ideas: the assessment of research applications and the peer review process. Young researchers, in particular, have reported submitting their work for assessment and having it rejected, only to see their plans, or parts of their plans, carried out by other researchers later on (Freeland Judson 2004: 267-293; 313). This is more or less what happened in the Baltimore affair. However, things become a bit murky when new ideas emerge during brainstorming sessions and 
it is no longer possible to determine who first came up with them. The same goes for brilliant ideas that come as a result of fruitful conversations between supervisors and PhD students or among colleagues. Unlike "ordinary" plagiarism, the plagiarism of ideas is often difficult to establish or prove. Acknowledgments are usually the best solution. One simply cannot be generous enough when it comes to acknowledging other people's contribution to the formation of one's own ideas.

\section{$5 \cdot 3$ SCOPE AND FREQUENCY OF PLAGIARISM}

What is clear from all of this is that word-for-word plagiarism is a classic example of inadmissible plagiarism. However, the question remains as to when this form of plagiarism is a violation of the code of conduct and whether those found guilty should be tarred and feathered. An accusation of plagiarism is a very serious matter and false accusations can cause irreparable damage to one's reputation. As the saying goes, "where there's smoke, there's fire", even if the matter hasn't yet been fully investigated. Although it is clear by now that plagiarism is not permissible in academic research, there are still plenty of questions about the scope and frequency at which it occurs.

Once you've seen it, plagiarism is easy to recognize. Some examples of academic plagiarism need no further explanation or discussion-the violation is clear. For example, an entire book that has been published in translation under a different author's name is a clear example of plagiarism. Or the case of Hungarian President Pál Schmitt, a former Olympic fencer who resigned in 2012 after he was exposed in the media as having plagiarized large parts of his 1992 dissertation on the history of the modern Olympic games: that was obviously plagiarism (in addition to an apparent conflict of interest in the appointment of members of his examination committee). In another case, the German Minister of Defense, Karl-Theodor Freiherr zu Guttenberg, was forced to resign in $201 \mathrm{I}$ when it was discovered that twenty consecutive pages in his $2007 \mathrm{PhD}$ dissertation at the University of Bayreuth were borrowed from texts by other authors without adequate reference to the source. A comparison with Recht, Demokratie, Politik (2003) by Dr. G. Heller revealed that $\mathrm{Zu}$ Guttenberg had subtly deceived his readers (Weber-Wulff 2013: I35; Weber-Wulf 20I4: passim). Zu Guttenberg did indeed refer to Heller's work, but the placement of the reference created the impression that the preceding 
text was a paraphrase of Heller and that everything thereafter was his own reasoning - while in fact, what follows are several pages of text straight out of Heller's work. In Germany, this new and ingenious form of plagiarism is called the Bauernopfer, or the pawn sacrifice: one sacrifices something in the beginning (i.e. by correctly mentioning the source) with the intention of winning more later-in this case, twenty "stolen" pages (Weber-Wulff, 2013: $135-138$ ).

The University of Bayreuth investigated the case and determined that plagiarism had indeed occurred and revoked the doctoral degree. In the end, the minister resigned. The commotion surrounding scientific plagiarism is often greater than in cases of "ordinary theft", to which it is often compared, although ordinary theft can cause a lot more damage than a few copied pages. Voltaire (I694-I778) once remarked that "plagiarism, even in its worst form, is, of all petty theft, certainly the least dangerous for society" (quoted by Nimmer 2008: 487). While it is true that the content of the body of scientific knowledge is not affected by plagiarism, it is still a violation of the great symbolic value attached to ownership in our current culture. (Incidentally, this may change with the development of the internet. The culture of absolute ownership in the arts and sciences could become less absolute in the digital age, as Lewis Hyde proposes with his "cultural commons" concept, the shared use of cultural and scientific ideas (Hyde 2010). Although this concept does not exclude references to the original creator of ideas and texts, it does mean that they will probably become part of the realm of "general knowledge" more quickly.)

How absolutely should plagiarism be condemned? This question arises when the scope and frequency of plagiarized texts are relatively low. Publishing twenty pages under one's own name without mentioning the source is clearly plagiarism. Whether or not the person intended to plagiarize is irrelevant here, because no one who copies such long pieces of text can say that he or she did so unconsciously or "by accident" (LOWI opinion 2008: I; Van Kolfschooten 2012: IOI-IO2). The same goes for fifteen pages, or five, or one. But when it's about the copying of a few lines or a few stray sentences, it becomes easier to wonder whether the plagiarism was committed consciously or not. Therefore, the basic rule of giving credit where credit is due must be considered and assessed on a case-by-case basis. Clarity is key: one must consider the form, scope and frequency of the plagiarism in question. Given that plagiarism is such a morally and emotionally charged issue, the 
accusation and conviction must be as concrete as possible: are we talking about a few lines, twenty pages or an entire article? Is it only a one-off offense or a repeated and fixed pattern of inadequate acknowledgment of sources? The vague accusation that "plagiarism has been committed" without indicating the scope and frequency of the offense can cause a lot of smoke, when, in reality, the fire is quite small. In plagiarism cases, it's important that the punishment be proportionate to the crime.

There may be exonerating reasons or mitigating circumstances under which the plagiarism occurred. Students and novice researchers-or even advanced researchers-might take notes from articles and books they've studied and forget to write down the source. Later, when they sit down to write their text, they may think that the copied text is actually their own words. This is careless, of course, but it is unlikely that they intended to deceive others or misrepresent someone else's work. The fact that the student did not mean to commit plagiarism is definitely worthy of consideration, but the question remains as to whether he or she should still be sanctioned, by, for example, being excluded from the course or the program. When it is discovered that a paper contains a small amount of plagiarized material, it is better not to assess it and to send it back to be rewritten than to immediately turn the student over to the bureaucratic powers that be. Rather than appointing some kind of university police squad to hunt down and sanction anything that resembles plagiarism, it is better to teach students how to take good notes and refer to sources from the start.

There are plenty of manuals on how to properly quote, format source references, and make use of common abbreviations and reading lists (which are generally drawn up for a specific field of study). One good example is the Leidraad voor juridische auteurs (Guide for Legal Authors) (2010; 2013), which, given its thoroughness, can also be used in other scientific fields. As a result of the Singapore Statement on Scientific Integrity (2010), an international guide for all scientific fields, titled Responsible Research Publication: International Standards for Authors, has been available since 2010 (Wager and Kleinert, 20II: 309-316). 


\section{$5 \cdot 4$ SELF-PLAGIARISM}

In early January 20I4, Dutch scientists were confronted by two issues that, until then, had received very little attention: self-citation and self-plagiarism. In the NRC Handelsblad of January 7, journalist Frank van Kolfschooten accused the renowned VU Amsterdam economist Peter Nijkamp of frequent self-citation and self-plagiarism, which the journalist characterized as a violation of scientific integrity. In his accusation, Van Kolfschooten referred to the opinion of an ad hoc Committee on Scientific Integrity at the VU Amsterdam, which was set up to investigate a case of alleged plagiarism by one of Nijkamp's PhD students. In the opinion of this ad hoc CWI, certain "forms of self-citation" were equated with plagiarism (VSNU website, December 20, 2013). The journalist then accused Nijkamp of "plagiarism" consisting of cases of such "self-citation". In his opinion, "self-plagiarism" counted as full-blown plagiarism. A new academic scandal, known as the "Nijkamp affair", was born.

This accusation led to a public debate about what self-plagiarism is and whether or not it is allowed in science. There were those who were in favor of banning self-plagiarism and those who were opposed. After all, one cannot "steal from oneself" and plagiarism is, by definition, the stealing of other people's ideas. Throughout the public debate, the concepts of "plagiarism", "self-citation", "self-plagiarism", "co-authorship" and "intellectual property" were mixed up considerably, which did not make matters clearer for anyone.

Until the NRC article in early 2014, hardly anyone in the scientific community was talking about the issue of self-plagiarism. The 2004/2012 Code did not contain any reference to self-citation or self-plagiarism, nor did most other national or international codes of conduct. This raises the question as to whether a certain type of scientific behavior that is not mentioned in a code of conduct can really be considered a form of misconduct or as a violation of scientific integrity. And although we have numerous good and bad examples of re-using one's own texts, they do not help us in answering this question.

The ALLEA-ESF Code does mention the issue of self-plagiarism in its "Guidelines for Good Practice Rules" for publication etiquette:

"Publication of the same (or substantial parts of the same) work in different journals is acceptable only with the consent of the 
editors of the journals and where proper reference is made to the first publication. In the author's $\mathrm{CV}$ such related articles must be mentioned as one item" (European Code of Conduct for Research Integrity, ESF/All European Academies, ALLEA 2010: 12).

This rule refers to the simultaneous presentation and/or publication of the same text in two different scientific journals, which is often cited as an example of self-plagiarism. A better example comes from education, where it is strictly forbidden to submit the same bachelor's or master's thesis or a substantial part thereof unaltered to two different degree programs or to two programs at different universities. This is a sensible and perfectly understandable measure for education. However, different rules apply for research. Publishers and journal editors have a right to not want articles to be published by more than one journal at the same time, but it is up to the contracting parties to establish these terms in the contract. As mentioned in Chapter 4, journal publishers and editors have their own rules, such as "Guidelines on Good Publication Practice" in the ALLEA, and the COPE committee to monitor them. However, these private-law agreements between two parties have nothing to do with the codes of conduct that scientists establish amongst themselves.

It seems odd to speak of self-plagiarism in cases where nothing has been published yet. Some authors have to wait a very long time to find out whether or not their article will be accepted by the journal in question, so it makes sense that they try to increase their chances by submitting to more than one journal. Whether or not this is allowed is determined by the individual publisher and is a matter for private law. The issue of intellectual property rights (copyright, transfer of copyright, remuneration, reproduction rights, copyright protection, etc.) is often confused with the university's own rules of conduct on plagiarism.

This also raises the question of whether one is allowed to reuse one's own previously published texts and whether or not this is a violation of scientific integrity. In most cases, this involves using parts of previously published articles and certain formulations that recur in one's own work. According to the ALLEA Code, self-references are allowed "where proper reference is made". In other words, as long as one places quotations marks around the quote and follows it with a proper reference, self-citation is perfectly acceptable. Thus, it is silly to regard self-citation with suspicion-citing other sources, even 
those written by oneself, is a standard part of scientific practice. What is not acceptable, however, is reusing (i.e. recycling) one's own scientific texts or texts one has written with others and attempting to use them for other purposes without acknowledging their provenance. Given how easy it is to copy and paste nowadays, there seems to be a greater temptation to reuse one's own work, and unfortunately, such laziness is often rewarded.

In order to resolve some of the confusion, KNAW set up an advisory committee to decide whether the 2014 Code should include additional rules on self-citation and self-plagiarism. In KNAW's advisory report, titled Correct Citeren [Citing Correctly], from April 2014, the word "reuse" is presented as an umbrella term, and plagiarism is distinguished from self-quotation and self-citation. Self-citation is defined as "a reference to one's own publication, according to bibliographical conventions" (KNAW 20I4: 4). The term self-plagiarism is avoided, because "one cannot steal or repossess his or her own intellectual property" (idem, my emphasis). Once again, even in this official report, the concepts of "intellectual property" and "plagiarism" are confused. The report is right to distinguish between the reuse of one's own texts and/or results with proper acknowledgment of the source and the reuse of one's own texts and/or results without such acknowledgment. Reusing one's texts with proper citation only becomes a problem when authors reuse their own texts in order to to increase the number of publications to their name. According to the report, there is nothing wrong with authors reusing small excerpts from their own texts, but longer excerpts can be more problematic. Without mentioning the original source, re-using one's own texts is, in essence, misleading "the public, editor and/or publisher about the originality of the text on offer, thereby potentially damaging trust in science" (KNAW 20I4: 6). However, also according to the report, these negative effects do not necessarily constitute a violation of integrity, especially when the unreferenced citations are limited to "short passages, texts and ideas in the introduction, theory and methods sections" (KNAW 2014: 7). All in all, KNAW's conclusions are not exactly groundbreaking. They can be summed up as follows: the Code needs to address the issue of "re-using" one's own texts, both with and without reference to the original source, and caution should be exercised when assessing past publications on the basis of rules on reuse that were non-existent at the time of publication (KNAW 2014: 9).

From a legal perspective, this second conclusion seems superfluous and questionable. The fact that one cannot be condemned for past conduct on 
the basis of rules that did not exist at the time is a long-standing legal principle. Simply stating that "caution should be exercised" is not enough-how can one judge whether or not someone has "exercised caution"? If there is no rule in the 2004/2012 Code prohibiting the reuse of one's own texts, one cannot hold someone accountable for it retroactively simply because the KNAW committee has taken a new position on the matter. This would be an infringement on the legal certainty of the defendant and a violation of the ban on arbitrariness. Given that self-plagiarism is often equated with more serious forms of plagiarism, retroactive accusations would make it all too easy to damage the reputation of the defendant.

Nevertheless, these commonsense principles of legal certainty did not stop the VU Amsterdam from setting up an ad hoc Committee on Scientific Integrity in 2013 with the purpose of conducting an integrity investigation into Nijkamp's work following the media's accusations of self-plagiarism. All of the economist's work dating back to 1995 (!) was investigated "retroactively" for "plagiarism" and "self-plagiarism", even though the VU Amsterdam's regulations on scientific integrity did not contain any provisions on the reuse of one's own texts. The evaluation was simply based on the new prohibition clause that was going to be added to the 2014 Code, which the Rector Magnificus of the VU Amsterdam had already insisted on himself. The pertinent question in the Nijkamp case is thus whether this investigation, in which so many legal principles and requirements of fair trial were violated, could itself pass a test of administrative integrity?

Naturally, rules can change; however, when they do, they should only apply from the moment they go into effect and have been communicated to all parties involved. Thus, a rule of conduct for publications should only apply to work that has been published since the rule has been in force-not to work that was published before. In the end, the first recommendation stated in the KNAW opinion was accepted quickly without public debate. In the fall of 20I4, the VSNU amended the Code and several new rules were added. The section on the reuse of one's own texts reads as follows:

I. 5 "Academic practitioners do not republish their own previously published work or parts thereof as though it constituted a new contribution to the academic literature. When republishing previously published findings, they indicate this with a correct reference to the source or by another means accepted 
within the discipline. In many disciplines it is permissible and even customary to reprint short texts from works published with or without coauthors without a source reference when it concerns brief passages of introductory, theoretical or methodological explanation." (Netherlands Code of Conduct for Scientific Practice 2004/2012/2014).

What this new rule actually says is that the reuse of one's own words is technically not allowed, but it is tolerated as long as it is limited to "brief passages of introductory, theoretical or methodological explanations". In this sense, this new rule is an international frontrunner in the further regulation of existing scientific practices, and any committee would be hard-pressed to find a scientist who has never reused any of his or her own work. A German study on plagiarism that appeared after the $\mathrm{Zu}$ Guttenberg affair is very clear about this:

"Likewise, one's own work is quote-free: anyone who reuses passages from his or her own publications does not have to quote him- or herself, since the text is from the same author-it is just not new. There is no such thing as self-plagiarism. This also serves to protect readers who would otherwise be bothered with constant 'as previously mentioned' quotations'” (Rieble 2013: 47).

What Rieble seems to suggest here is that if we demand that authors constantly cite their own work, their texts will quickly become unreadable. Of course, one should not reuse one's own texts too often, but sometimes it is inevitable (as in the case described below). And if one does do it, a one-time reference in a footnote or an announcement beforehand seems sufficient, for example, "The following three paragraphs have been borrowed from...".

It is important to compare the advantages and disadvantages of reusing one's own work. What is absolutely unacceptable is republishing an entire article again in another journal under a new title-this is comparable to the student who submits the same thesis twice. This would clearly be a case of "self-plagiarism": one takes an old text, gives it a new title, and makes no mention whatsoever of the previously published version. Equally questionable is the practice of reusing one's own work under a new title with the sole 
aim of increasing the number of published articles and, if possible, obtaining a position, promotion or subsidy.

Fortunately, there are simple solutions to both of these problems. Not only is the author responsible for his or her dubious behavior, editors and reviewers carry a certain responsibility as well. If journal editors pay more attention to whether or not a submission has already been published elsewhere, cases of self-plagiarism can be filtered out. For example, as an editor of a journal, I was given the opportunity to review an article that was identical to a chapter of a recently published book that I was already familiar with. Instead of filing a "self-plagiarism" complaint, the article was simply rejected, and the author was given a warning. Effective? Most certainly. As long as evaluation committees thoroughly read the submitted material (and perhaps run it through plagiarism-detection software), rather than merely looking at the number of publications by the applicant, they will be able to detect any overlap and filter out cases of self-plagiarism. Furthermore, the author can protect him- or herself from self-plagiarism accusations by simply including a short statement of disclosure, such as "As I have written before and published elsewhere...". After all, it is not unusual for experts to be asked to reformulate their insights on a particular topic for various bodies and publications. In my opinion, this is to be expected of scientists.

One interesting scientific argument in favor of reusing one's own work is provided by Hexham. He compares "self-plagiarism" to selling a second-hand car as if it were brand new. He puts it this way:

“...self-plagiarism, however, must be carefully distinguished from the recycling of one's work that to a greater or lesser extent everyone legitimately does (...) Academics are expected to republish revised versions of their Ph.D. thesis. They also often develop different aspects of an argument in several papers that require the repetition of certain key passages. This is not self-plagiarism if the work develops new insights. It is self-plagiarism if the argument, examples, evidence, and conclusions remain the same without the development of new ideas or presentation of additional evidence" (Hexham, 2005: II; with thanks to M. Hofstede, who pointed this argument out to me). 
Sometimes the repetition of key passages is necessary, particularly if one is building on previous work or finds better or more extensive arguments and evidence for previously held positions. Especially in the socio-cultural fields of science, which are more prone to long, complex arguments than concise mathematical formulas, insights are likely to develop over time. Thus, for the sake of consistency, it is often necessary to use exactly the same wording. Finally, it is important to consider the context in which one's work will be used: reuse as a spin-off from an original idea or reuse in a popular scientific article. Both are, in my opinion, perfectly permissible.

In the above passage, Hexham also points out that many dissertations are often published in revised form, just as many books published by top authors consist of articles that have been previously published and later revised. This is widely considered a sensible scientific practice. In the Netherlands, PhD candidates can use articles they've published in scientific journals as part of their PhD dissertation. This practice has been accepted here for years, and over the last twenty years, it has become customary in an increasing number of scientific fields. In a literal sense, this is the reuse of one's own texts-often in combination with those written together with one's supervisor. Although this practice is quite commonplace, there are numerous CWIs that still view "self-citation", "self-plagiarism" or "the reuse of one's own text" as impermissible-a view that, in my opinion, is as ill-considered as it is debatable.

What strikes me in this discussion about self-plagiarism and the reuse of one's own work is the preoccupation with originality and new knowledgeas if scientists should be constantly coming up with original ideas. In reality, however, most articles in scientific journals are based on the work of predecessors. Every once in a while, someone comes up with a purely original idea, and the major journals compete to be the first to publish it. In my opinion, however, journals and scientists are not only responsible for spreading new knowledge, they are also responsible for debating, discussing, criticizing and passing existing knowledge on to younger generations. This necessary recycling of existing knowledge takes place in manuals, reviews, standard works, readers and textbooks, and-if all goes well-in scientific journals, where people respond to each other's contributions. In these discussions, which can lay the foundations for new research, the reuse of earlier works and quotes from well-formulated texts are often unavoidable and even encouraged (with proper referencing, of course). The discussion of existing 
knowledge has always been part of education and continues to form the bedrock of scientific knowledge.

Moreover, specialists in a certain field are often asked to repeat or rephrase their ideas, particularly those that have been recognized as interesting, new or important, for a different publication or a wider readership. Most are more than happy to do so and don't see anything wrong with reusing their own work in such cases. This is standard practice-everyone does it. However, scientists now suddenly have to worry about being accused of violating "integrity rules". Nobody knows where they stand these days, because it is unclear whether non-compliance with the new provisions in the 2014 Code and the 2018 Code (standard 4I) on the reuse of one's own texts will be regarded as an integrity violation.

Why shouldn't someone publish his or her own ideas two or three times, even without a reference? One wonders whether banning scientists from doing so is a violation of their scientific freedom or freedom of expression. This fear and the overblown discussion about "self-plagiarism" only emerged after the article on Nijkamp in NRC Handelsblad made the topic big news (January 7, 2014). But who decides what is and is not allowed in science? Journalists or scientists themselves?

The view that researchers should only produce "original" texts is, in my opinion, short-sighted. The dissemination, criticism, and discussion of existing knowledge is also part of good scientific practice, and oftentimes, the reuse of one's own texts is unavoidable. An expert in the field of intellectual property, Antoon Quaedvlieg, spoke out against what he called the "criminalization" of self-plagiarism in the Nederlands Juristen Blad. He wrote: "Let's also consider the other side of the story. The near-hysterical frenzy about-often insignificant-partial 'self-plagiarism' is driving us towards an exaggerated administrative formalism in science. It results in a ludicrous parade of self-references that have no more than the tiniest bagatelle meaning. (...) The 'self-plagiarism' puritans are doing science a disservice" (Quaedvlieg 20I4: 853). The lack of appreciation for the value of repeated knowledge and the crackdown on self-plagiarism (which is, as noted, often labeled as full-blown plagiarism) are unfortunate consequences of today's overly competitive scientific world, in which ambition and ostentation are becoming more difficult to distinguish. 


\subsection{PLAGIARISM COMPLAINTS: POWER RELATIONS AND REPORTING}

Plagiarism is one of the easiest scientific misdemeanors to identify: one simply compares the source text with the copied text. Discovering cases of plagiarism, however, is not always so easy. The most notorious cases tend to involve people who select articles from obscure journals, add a new title and a few non-existent co-authors and then submit them to equally obscure journals for publication (e.g. the Alsabti case; Broad and Wade, I983: 38-56; Freeland Judson, 2004: I09). Given the fact that the number of scientific journals has exploded (there are now more than ro,ooo medical journals in the world and hundreds of thousands of other journals dedicated to various disciplines), it is quite possible to find an interesting text somewhere and republish it under one's own name. Who gets caught and who doesn't is generally a matter of chance. New digital search engines (e.g. Medline, Turnitin) are somewhat helpful in this regard (Freeland Judson, 2004: 315-317; WeberWulff 20I4: 7I-II2). Nevertheless, a vast number of scientific contributions go completely unnoticed, hidden in the annals of science until someone finds them and examines them for plagiarism.

When submitting a plagiarism complaint, it is also important to consider the relations among those concerned. As Brian Martin pointed out, the outcome of plagiarism cases can vary depending on the respective status level of the plagiarizer and the plagiarized and also on the respective social position of the accuser and the accused (Martin 2008: 6-I2). Imagine the PhD student who discovers that her supervisor has taken her text to conferences and presented it under his own name, which is a form of plagiarism of ideas (assuming her text has not been published yet). This puts the student in a difficult position, because such a serious accusation against a superior could permanently damage her future employment opportunities. Conversely, a supervisor or research institute director may discover that his young employees have copied other people's texts (the supervisor's, for example) without crediting the source. There is nothing stopping the supervisor from reporting the suspected plagiarism, which could potentially lead to the termination of the young researcher's employment.

Martin studied both types of cases, which he refers to respectively as the case of the weak perpetrator and the case of the powerful perpetrator. In the case of the weak perpetrator, a subordinate (student, assistant, doctoral can- 
didate, young researcher) commits plagiarism and the more powerful party (teacher, supervisor, director, renowned professor) discovers and reports it. In the case of the powerful perpetrator, the subordinate discovers plagiarism committed by a superior and reports it. The nature, course and outcome of both cases of plagiarism are quite different, Martin explains. But in most cases, the stronger party comes out ahead, even when there is strong evidence against him/her (Martin 2008: 8).

When someone in a weak position commits plagiarism, it is often out of ignorance. Due to a lack of experience or self-confidence, students may try to patch together a paper from various sources without proper attribution or ask fellow students to write their texts for them. Martin specifically mentions the weak position of foreign students and junior researchers, who may be faced with the challenge of writing in a foreign language in an unfamiliar culture. For them, the temptation to copy from well-written texts-especially at the beginning of their studies-is great. If their plagiarism is discovered, their defense usually consists of: "I didn't mean to", "I didn't realize it wasn't allowed", or "it's just one little passage". Such cases of unintentional plagiarism can be difficult to assess:

"It is one thing to demonstrate copying with inadequate acknowledgment and another to assess its significance" (Martin 2008: 7).

Forgetting quotation marks but still providing a reference is not the same thing as copying texts from an obscure source and not providing a reference at all, which is often a sign of deliberate deception (Martin 2008: 8). Literally quoting without using quotation marks is unacceptable and certainly foolish, but if a reference to the original author is included, it is still possible to verify the source. However, plagiarism in the purest sense of the word escapes all forms of verification-if no reference whatsoever is provided, the text appears to be the author's original work. If the intention to cheat cannot be established, an educative response is more useful than immediate punishment. When a student demonstrates dishonest scientific behavior, it is the supervisor's job to teach the student about ethical scientific practices. It's as simple as that.

The classic example of plagiarism committed by someone in a powerful position is the professor who appropriates an original idea from a student's 
work and uses it in her own presentations or scientific articles, without properly mentioning the source ("How can a student have such original ideas? I'm more qualified to assess the meaning of these results, aren't I?"). The defense against this kind of plagiarism is often the same: "I didn't mean to", "it was an accident", "I forgot that I had read it in that student's paper", etc. These types of excuses are typical of plagiarism cases. While it is not unusual for the perpetrator in a position of power to claim that the plagiarism was unintentional, if the evidence of plagiarism is undeniable, the situation tends to unfold very differently than in cases where the perpetrator is in a weaker position. First, the one in power tries to keep the whole thing quiet, and if that is not possible, he will blame the assistants-it wasn't his fault that his assistants failed to provide proper references (Martin, 2008: 10). In the past, that is until about 1970, it was customary for professors to use their assistants' work without mentioning them as co-authors at all, but nowadays this is not so easily done. Even still, when things go wrong, the error can always be blamed on a subordinate.

In addition, the superior has more direct access to the administrative powers that be, which can ensure that the seriousness of the case is downplayed and that no official measures are taken against him or her. However, there are plenty of measures that can be taken against a subordinate who has filed a complaint. Threats of dismissal or the refusal to renew the subordinate's contract are often an effective means of putting the matter on hold. The subordinate's level of dependence is often a good indication of how the case will end. In the majority of cases Martin studied, the party in power usually got away with plagiarism one way or another (Martin 2008: 8).

In light of these power relations, the question arises as to whether those in a weaker position, who have a lot to lose from filing a plagiarism complaint against a superior, should not be able to remain anonymous. There are plenty of arguments in favor of anonymous reporting: a PhD student sees something that he suspects is unacceptable but does not want to face the negative consequences that come with reporting it; a researcher suspects that a close colleague is behaving unethically but does not dare to approach her directly about it (after all, these suspicions may not be correct and their working relationship would be damaged for good). As a third argument, one could mention the fact that it's easy to demonstrate that the Code of Conduct has been breached in plagiarism cases, thus it doesn't really matter whether the complainant is known or not. It is also possible to determine 
whether plagiarism has been committed without revealing the complainant's identity.

There are, however, plenty of arguments against anonymous complaints as well. First, there is the fact that the complaint procedure adopted by the VSNU in $200 \mathrm{r}$ explicitly prohibits anonymous complaints. The memorandum which formed the basis for its complaints system states: "The institution must provide for a procedure in which the complainant and accused are heard and rebutted. Anonymous complaints cannot be dealt with; 'whistle-blowers' must be properly protected" (KNAW, VSNU, NWO, 200I: 6). Most likely, the underlying reason for this is the belief that an open procedure will prevent gossip and backstabbing at universities and prevent a toxic atmosphere of suspicion and secrecy in the workplace. Accusations of plagiarism can cause tremendous damage to reputations and careers; thus it is important to consider whether there might be improper motives for filing a complaint (jealousy, personal grudges, revenge, harassment). And if the accusations prove to be false, there is no way of holding an anonymous complainant accountable.

However, a better, more transparent solution is available that would allow those in a weaker position to submit a complaint against someone in a superior position without fear of reprisal: a whistle-blower's procedure, as mentioned in Chapter 4, where the whistle-blower's identity is revealed to at least one member of the institution's Executive Board, who can then decide whether the whistle-blower's identity should continue to be protected. The Board can weigh the complainant's motives for remaining anonymous, and if the accusations turn out to be false, it can still hold the complainant accountable. The VSNU implemented this whistle-blower procedure in its standard complaint procedure, and it has since been adopted by other universities as well. 


\section{Chapter 6 \\ Frequently asked questions about scientific integrity}

\section{I WHO CAN COMPLAIN ABOUT WHOM? TO WHICH AUTHORITY?}

In principle, anyone can submit a complaint about a suspected violation of scientific integrity. Neither the national Code(s) nor university regulations on scientific integrity pose any limit on who can file a complaint. This has to do with preserving trust in science, both among scientists and in society as a whole. People expect scientific research results to be reliable and responsibly generated, and fraud in science undermines that trust.

Scientists build on each other's knowledge and results; therefore, they need to be able to trust each other. If they have reason to believe that someone else's research results have been obtained via incorrect or unethical means, they have a right to complain. Corrupt and fabricated data pollutes the entire body of knowledge.

Private citizens also have an interest in trustworthy, non-fraudulent science. For starters, a great deal of research is paid for with public funds, so the public has a right to keep an eye on how those funds are used. As noted in Chapter I, this was why members of the US Congress became interested in scientific fraud in the first place. Citizens are also often the consumers of scientific knowledge, and they should be able to assume that they are not being deceived. Scientific research results are being reported more frequently, often in news articles and clips published in print and online. However, that research results are reaching a wider audience does not mean that they are more comprehensive or accurate. Concerned citizens are thus entitled to question the scientific practices behind the research.

In theory, citizens do not have to demonstrate that they have a vested interest in a specific article or study to submit an integrity complaint about it. In 
practice, however, demonstrating that one has a vested interest in the matter at stake is a general requirement in many other complaint and objection procedures. After the Stapel affair, the number of complaints from citizens outside academia rose dramatically, thereby increasing the demand for more restriction on what constitutes an "interested party". After all, non-specialists are generally less familiar with the way in which scientific results have been obtained and if citizens (or politicians) do not agree with certain results, this does not mean that they have been obtained in an improper manner. The distinction between a difference of opinion on scientific issues, the quality of research, and demonstrable violations of scientific integrity is not readily apparent to every citizen. Thus, it makes sense to first consult with Confidential Advisors about suspected fraud or other integrity violations before submitting an official complaint. Some university regulations require that an initial notification be submitted to a Confidential Advisor, but it is still up to the complainant to decide whether or not to pursue the complaint.

Anyone can submit a complaint, but not everyone can be the subject of one. In one case, a PhD student submitted a complaint about a news article written by a science journalist. The student believed that the news article had stolen passages from his recently defended dissertation and filed a plagiarism complaint with the Dean of his faculty. The Dean, who was particularly sensitive to integrity violations due to all of the hype surrounding the issue at the time, decided to hold the journalist accountable. The journalist was not only extremely surprised by the accusation but also indignant. He believed, and rightly so, that the Netherlands Code of Conduct for Scientific Practice only applied to university staff and not to independent journalists. He also claimed that this was not a case of plagiarism but of alleged plagiarism (which was later confirmed by the Dean's investigation). Moreover, he argued that universities chasing down science journalists and threatening them with all kinds of false accusations posed a serious through to the freedom of the press, and that the Dean should have gone through the Netherlands Press Council. And things didn't stop there. The journalist felt that he had been so unfairly treated by the Dean and the PhD student that he submitted a complaint of his own... about a violation of scientific integrity! After all, the Code holds scientists to a standard of "honest and respectful behavior."

In another case, the LOWI received a complaint from abroad that a doctor in the Netherlands had published an article in a scientific journal which, in the complainant's opinion, was based on dubious data. The LOWI rejected 
the case because the doctor was not affiliated with any scientific institution in the Netherlands. The same applies for medical research carried out by specialists in non-university hospitals. As a result, one well-known case of research fraud regarding patient registrations at a provincial hospital could not be investigated by the LOWI. The only body that could take action in these cases was the Dutch Health Care Inspectorate, but it did not consider the detection of scientific fraud one of its primary tasks.

These kinds of gaps in the Dutch research world can be filled if more scientific research organizations adopt the Dutch university system of self-regulation. This has been a growing trend in recent years. Various research institutes have joined the LOWI, using it as an appellate body for scientific fraud cases investigated internally. The number of researchers potentially subject to integrity complaints is larger than ever before, but this has not led to more reports from these institutes.

\section{To which authority?}

In principle, a scientific integrity complaint starts and ends with the institution's Executive Board. The Board may commission an investigation and, once the results are in, judge the case and determine the consequences. The rationale behind this approach is that these Executive Boards are employers, and, as employers, they can impose sanctions on employees who have committed a violation of integrity.

However, this can sometimes be problematic in practice, for example, if the (allegedly) fraudulent research was conducted at a certain university or medical center, but by the time it was discovered and a complaint was filed, the defendant was working elsewhere. This was the case with a scientific study carried out at University A as part of one researcher's $\mathrm{PhD}$ research. The researcher later wrote a few articles about it while working as a post-doc at University B, before moving on to become a senior lecturer at University C. In the meantime, complaints about the original study emerged. But the question was, where to file the complaints? Should they be submitted to the university where the research was carried out, to the university where the defendant was working when he wrote the articles, or to his current employer? University C was reluctant to deal with this case (let's not forget that integrity violations bring negative publicity to the institution!), claiming that it had nothing to do with its employee's past research. While University C's position is cer- 
tainly understandable, the LOWI ruled that it was the current employer's responsibility to handle the case because it was the only body that could impose sanctions if the defendant were found guilty. If for some reason University C was unable to accept the case, the institution where the study was carried out was second in line to address it. Researchers are followed by their reputation. If a researcher has committed a violation in the past, this can not only have consequences for the reputation of the institution where the research took place, but also for the institution where the researcher is currently employed (LOWI opinion 20II-4).

But what if the researcher is no longer employed? This is the case for emeritus professors who are no longer affiliated with the university where they previously worked. If the complaint concerns prior research carried out while they were still employed by their university, the procedure is clear (see above). If they continue to conduct scientific research or to assess research applications after their retirement, their former connection to the institution is decisive, because the institution's prestige benefits its emeriti and vice versa; in other words, when it comes to the treatment of integrity complaints, there is still a strong symbolic relationship between the emeriti and their former university. An emeritus professor could still be found guilty of plagiarism or cryptomnesia. In both cases, integrity complaints can be submitted to the former employer, but, according to Dutch labor laws, formal sanctions may not be imposed on former employees. However, in the event that misconduct has indeed taken place, disclosure of the judgment would serve as a symbolic punishment, and that in itself should be sufficient. The Bax affair at the VU Amsterdam is a good example of this: although formal sanctions were no longer possible, the scientific articles in question were withdrawn by the journal editors.

There have also been cases where research carried out in the Netherlands has come under fire, but the author is no longer employed by a Dutch university. This is not all that unusual given the internationalization of the scientific labor market. If the researcher in question has already left the country, the university has no way of imposing sanctions under Dutch employment law. If the violation is proven, the only "sanction" that the university could impose would be to request that the article in question be withdrawn from the journal it was published in. It is then up to the journal's editorial staff to decide whether or not to withdraw the article and why. 
Oddly enough, the universities where researchers carry out their research generally have no say in how or where that research is published. Meanwhile, most of the journal editors are also employed by universities. It is time to review the relationship between universities, the publication of research, and the position of scientific journals. It would also be worth exploring whether open access journals with well-functioning editorial staffs, in collaboration with university libraries, could offer more transparency, better access to research data and improved peer review systems in the future.

\subsection{MATTERS WORTHY OF COMPLAINT (I): FABRICATION AND FALSIFICATION}

In principle, anyone can submit a complaint about a suspected violation of the provisions of the 2004/2012/2014 Code and the 2018 Code. These complaints concern the most serious offences: fabrication, falsification and plagiarism. Plagiarism was addressed in Chapter 5 ; below I will discuss fabrication and falsification.

\section{Fabrication}

Fabricated science is often uncovered quite quickly. Take, for example, Konrad Kujau's I 983 publication of 62 fictitious diary entries by Adolf Hitler, which was exposed as a hoax within two weeks (Stern, April 25, I983; MacArthur 2008). Jan Hendrik Schön's fabricated research data was exposed within two years (Bell Laboratories 2002), and although it took two decades to reveal that anthropologist Mart Bax had based much of his research from I 984 to 1998 on fabricated stories, there were already plenty of signals from expert ethnologists and church historians who doubted the authenticity and historical probability of the religious violence Bax had described. Unfortunately, these signals were largely ignored by the scientific community (Van Kolfschooten 2012: 19I-I97).

Other fabrications in scientific history managed to survive much longer. For example, it took more than forty years to "unmask" the Piltdown Man (1912-I952, Walsh 1996) and more than a hundred years to reveal the fake historiography behind the purported origins of the Scottish kilt (Hobsbawn 1983; Trevor-Roper 1983; 2013). Even the Stapel affair took more than ten 
years to uncover, which is a long time especially given the exceptional scope of Stapel's fabrications.

The hype surrounding the Stapel affair opened the door for complaints against universities for disclosing information about (alleged) integrity violations; as a result, the number of integrity complaints increased. Those submitted after 20II often referred to the Stapel affair and some claimed to concern fraud that was "much worse" than Stapel's. However, the chance that scientific data is being fabricated on a large scale is highly unlikely, and the increase in integrity violation complaints is more indicative of a desire to tarnish reputations than a real increase in data fabrication.

Still, when we consider two reports on recent fabrication cases, there are a few things that stand out. First, both the Levelt report (2012), on Stapel, and the Baud report (2013), on Bax, emphasize that the researcher's fabrications were embedded in a larger pattern of carelessness. This carelessness was observed in their research practices, the documentation of research activities, and the presentation of their results. The Levelt report refers to this carelessness as "sloppy science". Furthermore, both reports indicated that the environment in which the research was conducted was unsatisfactory and indicative of a general tendency in the researcher's scientific fields (social psychology and anthropology, respectively) to reinforce these kinds of careless scientific practices.

After the investigation of the Stapel affair, measures were taken against three social psychologists from Tilburg who forgot to include a dataset in a publication and changed the name of a test subject without mentioning it in the publication. They were found guilty of "gross carelessness and sloppiness". Although they had not knowingly manipulated data, they had failed to comply with the rules of scientific research, namely that "methodological principles be followed as vigilantly and transparently as possible, that all information be properly verified and that any deviations from the standard rules be justified" (NRC January I7, 2013).

The scale on which all this took place is not mentioned in the news article. The actions were judged as reprehensible violations of integrity, but disclosure of the names of those involved was found to be "disproportionate" to the severity of the crime (NRC, idem). In my opinion, this says a lot about the true seriousness of the violation. In this case, non-compliance with the highest standards of methodological diligence and transparency was considered a violation of integrity, which naturally raises the question as to how the less 
diligent methodological research practices (and there are probably a great number of these) ought to be judged. Should forgetfulness really be regarded as a violation of integrity? The strict boundaries between an integrity violation and "sloppy science" were blurred in both the Levelt and Baud reports.

The suggestion that there is a relationship between sloppy science and dishonest science is, in my opinion, fundamentally flawed. Sloppiness and dishonesty are often seen as one and the same or causally linked, but we do not yet have conclusive evidence that this is actually the case. Sloppy science and fabricated science are not the same. Both are regrettable, but for very different reasons. Allow me to use a sports metaphor to explain. A soccer team can play sloppily, making one careless pass after another and constantly missing the goal, or it can play rough, making serious fouls and earning yellow or red cards. In the team's eyes, the goal-winning-justifies all means. This distinction is similar to the one made in Chapter 2 between game rules and goal rules. Poor, sloppy play does not win a match, nor do gross violations of the rules. The team's coach has two options: he can give his players a fiery locker room speech and tell them they have to win by any means necessary or he can have the players practice hard to improve their skills and become better players so they can truly win. In other words, better skills render rule violations unnecessary.

The conclusion is that sloppy scientific practices need to be improved through training, the development of better research skills and a stronger commitment to diligence. Meanwhile, integrity violations and gross violations of scientific rules and standards must also be prevented. While the improvement of research skills may be necessary, it is not sufficient for the total prevention of integrity violations. In scientific institutions, the former falls under the institution's "science policy", whereas the latter falls under its "integrity policy".

Falsification and manipulation of research data

Falsification is more common than fabrication and comes in a greater variety of forms. It can consist of adjusting measurement results, changing average values, digitally re-coloring photos, perfecting images, blots, gels and pictures from laboratory tests (also known as "image tampering"; Comstock 2013: 79-87), deliberately coding interview data to theoretically desirable patterns, and tweaking research data via statistical tests until they exhibit 
the hypothetically desired results. And let us not forget the notoriously disputed research practices of trimming and cooking identified by Babbage in I830, and other contemporary questionable research practices, such as the improper rounding of $p$-values, the extra processing of data, and the selective omission of test subjects (a form of cooking).

All these forms of data manipulation are a violation of scientific integrity. Here, too, the emphasis is still on whether the falsification was carried out deliberately, but both the manipulations and the intention behind them can be difficult to determine. Researchers accused of falsification are often quick to hide behind denials of intent and may reject accusations against them on the grounds of carelessness, unfortunate errors and hastiness, or they may try to shift the blame onto a fellow researcher who allegedly provided them with erroneous or manipulated data without their knowledge. The only way to resolve these disputes is for the CWI in charge to conduct a thorough investigation, but unfortunately most CWIs in the Netherlands do not have the resources to do so. Rarely are they able to question everyone involved, ask witnesses to testify under oath or confiscate personal computers to be examined for incriminating evidence. In the US, however, this is more standard procedure: in the Baltimore affair, for example, the CIA was even called in to determine exactly when the accused researcher made lab journal entries and with what ink.

When cases of suspected falsification arise, the ability to re-examine and verify the original research data is of great importance. The best defense against accusations of falsification is a well-maintained data file containing a thorough record of all research decisions made and codifications usedin short, all verifiable data. When the disputed data are no longer available ("I got rid of those files years ago") or can no longer be retrieved ("My computer crashed"), this is a violation of the principles of "reliability" and "verifiability". Naturally, these offences are less serious than deliberate falsification, but in combination with other offences and in the presence of statistical anomalies there can be talk of "culpable carelessness", which goes beyond pure carelessness or unintentional errors.

One interesting question is whether manipulations or falsifications of research data can be identified purely on the basis of statistical anomalies. Often a statistical improbability is the first sign that the data have been falsified. This was what happened in the Burt case, where results from different research populations with exactly the same correlation coefficient were dis- 
covered, as well as in the Stapel case, where values were too low and unlikely for Cronbach's alpha. Results that are too good to be true give rise to suspicions, but if no other sign of manipulation can be found, a judgment cannot be reached with absolute certainty.

In science, falsifications and manipulations must also be distinguished from "blunders". Mistakes are part of science. Scientists are free to speculate and theorize at any time, they can even make mistakes, but they must respect the facts. This fundamental distinction between the status of theories and the status of facts was expressed by the physicist Freeman Dyson as follows:

"Science consists of facts and theories. Facts and theories are born in different ways and are judged by different standards. Facts are supposed to be true or false. They are discovered by observers or experimenters. A scientist who claims to have discovered a fact that turns out to be wrong is judged harshly. One wrong fact is enough to ruin a career. Theories have an entirely different status. They are free creations of the human mind, intended to describe our understanding of nature. Since our understanding is incomplete, theories are provisional. Theories are tools of understanding, and a tool does not need to be precisely true in order to be useful. Theories are supposed to be more-or-less true, with plenty of room for disagreement. A scientist who invents a theory that turns out to be wrong is judged leniently. Mistakes are tolerated so long as the culprit is willing to correct them when nature proves them wrong" (Dyson, 2014: 4).

This precise formulation also underlines why, in discussions and disputes about scientific integrity, actual fraud and manipulation must continue to be clearly distinguished from errors, theoretical differences of opinion, scientific controversies and qualitative interpretations of "facts". In all these cases, a high degree of tolerance is necessary, and it is striking that in today's scientific climate, with its tough competition, such skeptical leniency is becoming harder and harder to find. If one wishes to criticize the quality of a fellow researcher's scientific work or vision, this ought to be done in an open discussion within the scientific community, not in the form of a scientific integrity complaint in the hope that this will eliminate competitors. 


\subsection{MATTERS WORTHY OF COMPLAINT (II): CO-AUTHORSHIP}

There are a variety of problems that can arise in a co-authorship. When scientific research is carried out as a team and more than one author has worked on an article, it is possible that certain researchers may receive too little or too much credit for their contributions. The first case is known as denial of authorship: the co-author does not receive due credit for his or her contribution. The second case is called gift authorship: a co-author receives credit that he or she does not deserve. Another form of gift authorship is honorary authorship, which refers specifically to cases where an author is only mentioned because his or her name offers a certain sense of prestige. Gift and honorary authorship are both forms of "empty" co-authorship. There are two other interesting types of co-authorship worth mentioning here as well: guest co-authorship and ghost co-authorship, as well as the clever combination of the two- the ghost guest.

\section{Too little recognition}

Before we discuss the problems that can arise from having too many authors, we should -in light of issues related to scientific integrity-devote our attention to the problem of non-recognition of authorship. Article I.4 of the 2004/2012/2014 Code clearly states "Authorship is acknowledged. Rules common to the scientific discipline are observed." The 2018 Code contains a similar point. Standard 30 states: "Ensure a fair allocation and ordering of authorship, in line with the standards applicable within the discipline(s) concerned." While it is true that the standards of co-authorship can vary greatly per field, there is one requirement that holds true in all disciplines: one cannot ignore someone who has made a substantial contribution to a study or to a joint article by omitting his or her name from the list of co-authors.

In 2008, the LOWI was asked to assess a complaint from a research institute employee who had independently developed a pedagogical test for children. Following a disagreement with his professor, the employee's temporary appointment was not extended. After finding work elsewhere, he was surprised to discover that his test had been published without his name on it. He filed an integrity violation complaint and won (LOWI opinion, 2008-3). Another case involved a young, employee who had carried out the majority of work on a commissioned study in the social sciences. Upon completion 
of the research report-most of which he had written-his appointment was not renewed. Afterwards, he struggled to find work in the Netherlands and decided to go abroad. The original report was later converted into a book and published under the names of his former colleague and professor. The young researcher's name was not mentioned. From abroad, he asked why his name had been omitted. As a young researcher, he could have certainly benefited from being the co-author on this groundbreaking study. At first, the authors tried to claim that the book was completely different from his original report, but that could easily be refuted by comparing the two texts: his contribution was still easily recognizable. Initially, it was suggested that the book be taken off the market, but it was later decided that the employee had to be mentioned as co-author in the first edition (via an inserted page) and in subsequent editions on the cover. Although this case resembles plagiarism, it had more to do with the collaborative nature of the publication. Issues related to co-authorship must remain distinct from those of plagiarism, where the social relationships between those involved are quite different and generally non-existent.

The similarity between these two cases, both of which are fairly recognizable, is that no clear agreements were made at the beginning of the research project or during the writing of the report, and co-authorship was "forgotten" or ignored after the employment relationship was terminated. And if there has been a disagreement on the work floor, it becomes all the more difficult to produce articles together. But this is precisely why clear agreements are needed in the first place. Based on the principle of due care mandated by the Code of Conduct, the LOWI considers it a duty of research leaders to make sound agreements in advance about who may be considered co-author of what (LOWI opinion 2013-6). Article I.5 of the 2004/2012/2014 Code states that the principle of due care also applies to the mutual relationships between scientists. One good example of this would be a timely agreement on co-authorship. There is no reason for every quarrel over co-authorship to develop into a scientific integrity complaint. These kinds of problems can and should be solved in the workplace. Only in cases where co-authorship agreements are, for whatever reason, not complied with would an integrity violation complaint be appropriate.

That said, there is no general consensus on when a person is entitled to co-authorship. This varies greatly from one scientific discipline to another. In my own sociological research group, our rule was that only researchers 
and professors who had actually written parts of the text could be mentioned as co-authors. If the professor had not actually written anything, he or she would not be mentioned as a co-author. Thesis supervisors were not automatically mentioned as co-authors of articles written by their $\mathrm{PhD}$ students. Any employees and students who had helped in other ways, for example by recording interviews, encoding data or conducting computer analyses, were mentioned in the acknowledgments. The writing work was distributed according to mutual agreements, and feedback was provided to each writer on his or her share. This approach to co-authorship may be stricter than in many other fields, but it does provide a clear criterion.

Too much recognition?

Compared to the non-recognition of co-authorship, the ever-expanding circle of co-authors seems like a luxury problem. At first glance, the problem of having too many co-authors seems to cause less harm to individuals because everyone seems to benefit. Complaints about honorary co-authorship are therefore much less common than those concerning the denial of co-authorship. Co-authors are not so quick to call each other out (at most they argue about the order in which their names will appear) and most of the time, readers have no idea who did what during the research and writing process. Nevertheless, the fact that an increasing number of scientific articles are being published with a long list of co-authors is a problem. It is becoming difficult to assess the contribution of individual researchers and judge its quality. During the job application and promotion process, it is increasingly common for candidates to submit publication lists that contain no single-author articles. In cases where the candidate is frequently listed as a middle author, it can be difficult to assess the true quality of his or her publication history. When does this luxury problem become a matter of scientific integrity?

The fact that more and more articles are being written with a series of co-authors is understandable. Modern science takes teamwork. Only in the oldest scientific fields of theology and law, the humanities and some fields of social science is the tradition of writing an article or an entire book by oneself still honored and cherished. But even in these disciplines, working and publishing together is becoming more common. In the natural sciences and biomedical research, it is quite normal for many people to work together 
on the final result. One researcher may carry out tests or devise the methodology, while another synthesizes substances or digitally processes the experiments and creates computer simulations. The level of each co-author's contribution can mostly be seen in the order in which their names appear on the publication: the first author is the one who carried out the main experimental research, the last author was responsible for overseeing the entire project and communication with journals, and the co-authors in the middle are generally those who have provided indispensable services and support. Young researchers prefer to be named first author, while more advanced researchers prefer to be the last, and the established professor or research director appreciate seeing their responsibility and involvement acknowledged in the form of co-authorship. The system works to the advantage of all parties: young authors benefit from having an established name mentioned as co-author on their study and older authors can continue building an impressive list of publications.

So far, so good, but this becomes an integrity problem when the motives for frequent and extensive co-authorship become disingenuous and dishonest. "Just put my name on it" can have a double meaning: on the one hand an established name can help young researchers in terms of guidance and management, but on the other, it can also be a sign of laziness and a desire to rack up as many publications as possible, especially if guidance and management have been virtually non-existent, which is all too often the case.

There seem to be three motives for the increased number of co-authors in modern-day scientific research: the desire for recognition from financiers and organizers, the increased specialization of science and the drive to publish more articles more often to increase one's chances of being cited. Citations work both ways: if I quote certain colleagues often, there is a greater chance of them quoting me. In some cases, authors even agree to refer to each other's work, which results in calculating behavior and artificial elements that may undermine a careful assessment of scientific quality. Two of the most well-known examples of long lists of co-authors are the CERN study (some articles have more than $\mathrm{I} 80$ co-authors) and the Human Genome study, in which two research collectives tried, in 200I, to outdo each other in terms of the number of co-authors, 200 and 275 respectively (Freeland Judson 2004: 302). 
Another problem with having too many co-authors is that oftentimes there is no one overseeing the entire project. If a few researchers are careless in the documentation of their observations and their mistakes are not detected during the review process, their contribution can damage the entire project and lead to accusations of fraud, as was the case in a large-scale cancer research project in the United States (Freeland Judson, 2004: 296-298). The lack of social control in large research projects can thus become a major disadvantage; it does not necessarily cause scientific fraud, but it does make it easier to commit.

In terms of scientific integrity, there is also the question of how honest everyone has been about their contribution. In cases of co-authorship, the problem is generally not failing to give credit where credit is due, because most of the time the authors are all mentioned, but rather that certain authors may profit from the merits of others. However, this problem is not particularly difficult to solve. Freeland Judson suggests that specific contributions to scientific articles be mentioned by name, like in the closing credits at the end of a film (2004: 310). This would give a clear indication of who actually contributed to the article's content and which authors' contributions were more symbolic (" $\mathrm{X}$ was the director of the institute where the research took place”). Some scientific journals already do this. They require a detailed explanation of each co-author's contribution so that each person can be held personally accountable for his or her own work. The underlying issue at stake here is that authors are under too much pressure to accumulate as many publications and citations as possible; this pressure can be reduced by emphasizing quality over quantity. Providing "closing credits" for scientific articles can certainly help to provide more clarity about each author's contribution, but we still need to reduce the obsessive preoccupation with the number of articles published and focus instead on scientific excellence.

Another remedy for scientific fraud would be to make all co-authors responsible for the integrity of any publication bearing their name. This, however, seems unfair. In some major fraud cases, such as that of the physicist Schön, investigations revealed that the co-authors were completely unaware that fraud was taking place. No one-neither the co-authors nor the peer reviewers-noticed that some calculations were incorrect or that measurement results from other articles had been reused. Even still, in regard to the Schön case, Donald Kennedy remarked: 
"If the benefits are enjoyed jointly and severally by all authors, then shouldn't the liability be joint and several too? The answer has to come in the form of a decision by the scientific community" (Kennedy 2002: 495).

The question of liability comes up again and again in the assessment of fraud cases involving multiple authors. Which of the three authors is to blame? Which of the seven? Which of the seventeen? Were the other co-authors aware of each other's actions? Researchers working in a team need to be able to trust and rely on each other-yet this trust can be betrayed. A fraudster with truly malicious intent is difficult to stop. In the Levelt (2012) report on the Stapel affair, the co-authors were not held responsible for the fraud because they did not know it was going on and it was outside their control. There are other cases, however, that-at least in my opinion-should have been judged more strictly owing to the fact that some co-authors could have requested access to raw data prior to publication. I find it strange that co-authors who fail to notice highly improbable statistical results or choose to overlook them are not held responsible for them as well. Sometimes it can be all too easy to heap the blame on one person and to absolve the co-authors of any responsibility.

In my opinion, the idea of making all co-authors responsible for potential fraud could have a preventive effect. It could motivate all members of the team to be more meticulous and check each other's work more carefully. The burden of proof for complicity would thus be reversed: only if ignorance can be clearly demonstrated is one assumed innocent. As a result, co-authors will be less likely to request that their name be put on an article that they haven't worked on or examined closely themselves.

Another clear form of integrity violation related to co-authorship has to do with the strange combination of guest and ghost authorship. It tends to occur in research carried out by industrial companies: the company will have an employee conduct scientific research and then pay a well-known scientist to put his or her name on it. In this way, the scientist becomes a guest-researcher without having to take part in the research at all. The company then hires a ghostwriter to write an article about the study and mentions the high-profile scientist as co-author, after which the article is submitted to well-known scientific journals (Freeland Judson 2004: 308-309). The peer reviewers may not notice this or the fact that the research just so happens to show results that are favorable for the company's products. The toxic com- 
bination of three G's (gift, guest and ghost) can result in a scientific integrity nightmare and such practices should be vigorously combatted. One way (and perhaps the best way) to fight this type of scientific dishonesty would be the "closing credits" strategy mentioned before, in which each contributor's role is clearly defined.

\subsection{IS THERE A STATUTE OF LIMITATIONS FOR SCIENTIFIC MISCONDUCT?}

Yes, the possibility of assessing, condemning and punishing violations of scientific integrity are subject to a statute of limitations. Limitation periods are quite common in law. Their purpose is to prevent conflicts, such as those over property rights or punishable offenses, from lasting forever. Exceptions to this rule are crimes against humanity, war crimes and other violations of basic human rights; the statutes of limitations for such crimes have been abolished in the last decade. In criminal law cases, the limitation period usually lasts for thirty years for serious crimes (with some exceptions, such as murder) and five to ten years for smaller crimes, such as tax evasion. Terms of limitation are not about "forgiving and forgetting", and they do not change the nature of the crime. A term of limitation simply means that after a certain period of time the right to prosecution lapses.

There are also terms of limitation in science. Misdemeanors involving the manipulation of data can become less significant over time. This is particularly the case in the sciences and biomedical research, where it is said that articles lose relevance within five years of publication due to the rapid expansion of scientific knowledge. This seems a bit exaggerated to me since it is likely to take ten to twenty years to determine whether the knowledge accumulated during the research process can stand the test of time. Nowadays most university regulations for scientific integrity cases have a limitation period of ten years - the amount of time it apparently takes for scientific knowledge to become outdated (although this certainly does not apply to the humanities and social sciences). The period was increased to ten years in 2012, arguing that many research results are only published in journals after one to two years. And then it can take a while for errors in the study to come to light-for example, five years-which only leaves a small window for submitting a complaint. 
According to the 2004/2012/20I4 Code, ten years is the standard period for submitting a scientific integrity complaint. In serious cases of fraud and plagiarism, this period may be extended. The 2018 Code does not specify a limitation period. Thus, for all research carried out before October I, 2018, ten years is the general limitation period, which raises the question: if the fraud is so serious, as in the Stapel affair, and it is only discovered after twelve years, is there really no way to file a complaint? Are we going to let major fraudsters off the hook that easily? The answer is no, because, as previously mentioned, there are exceptions for serious cases. Take, for example, the plagiarism case of the Hungarian ex-president Pál Schmitt, mentioned above. It took twenty years to discover that his dissertation was largely borrowed from other sources without proper referencing. His political adversaries were all too happy to dig up some dirt on his past. The same happened to the German Minister of Education Karl-Theodor zu Guttenberg (Dreier und Ohly, 2013), also discussed in Chapter 5 . In both cases, their fraud went unnoticed by the scientific community and was later revealed by non-scientists. This says something about both the scientific community and the motives for accusing someone of violating scientific integrity: the scientific community and the peer review system are not foolproof and the motivations for submitting an integrity complaint are not always pure.

After the Stapel affair in September 20II, there were numerous accusations of scientific integrity violations that had occurred a long time ago: tampering with laboratory samples in I99I, plagiarism in a dissertation from 1976 , an unreliable methodology in a medical study published in 2002 and 2003, and questionable results in a student thesis from 2003. When such complaints arise, the reviewing bodies, CWIs, Executive Boards and the LOWI all need to ask themselves whether the term of limitations applies or whether the allegations are so serious that a deviation from it, may, in principle, be an option. Then, of course, there is the question of why the complainant waited so long to file a complaint. What motives did he or she have, other than concern for the sanctity of science?

The rationale behind having a term of limitations is to protect defendants, who need to know where they stand before the law. Arbitrariness in the filing of complaints should be avoided as much as possible: why this person, why now? Accusations of misconduct many years after the fact can be very unfair to the accused if the accusations prove to be false. 


\section{Retention requirements}

Given the standard ten-year limitation period, researchers are required to retain all research materials for ten years as well. The proper archiving of research remains a weak point in many research projects. Too little attention is paid to proper documentation, and we do not yet have a long tradition of systematically recording research projects and storing data. When complaints arise, it is not unusual for the original research data to be missing: either the raw data has been discarded, sometimes within five years of conducting the research, or the dataset has been lost in a computer crash-both excuses are common but unconvincing. According to the 2018 Code, retention requirements should be observed as follows: "Manage the collected data carefully and store both the raw and processed versions for a period appropriate for the discipline and methodology at issue" (2018: 17, Standard 24). Both complainants and defendants are required to exercise due care so that claims and evidence-the very heart of scientific practice—can be substantiated.

\subsection{MINOR ERRORS, MAJOR NEGLIGENCE AND QUESTIONABLE RESEARCH PRACTICES}

Chapter 5 , on plagiarism, and this chapter address issues that can lead to complaints about suspected integrity violations. There are also scenarios that, although they frequently give rise to integrity complaints, are rarely regarded as true violations of scientific integrity. In many cases, the complainant is not fully aware of what does and does not constitute a matter worthy of complaint. One can be indignant about the content of a certain scientific article or not believe claims in a journal, but that does not mean that the research itself is flawed or that the data has been tampered with. However, indignation can easily lead to a quality judgment: this article or that study is not reliable. But what does "reliable" really mean? Is there something in the study that is ineffective or unsatisfactory or has the author violated the rules of scientific integrity?

There are plenty of examples of unsatisfactory research. In quantitative studies, measurement errors are quite common and even inevitable, because no measurement is a perfect reflection of reality. Thus, standard deviations and acceptable error margins must be taken into account. Scientific resear- 
chers make mistakes all the time. Mistakes are part of being human, and they provide excellent learning opportunities, as Karl Popper argued extensively in Conjectures and Refutations (Popper I989). In short, if a complainant deems a certain scientific study unreliable, it will have to be determined what went wrong, whether the Code of Conduct has been explicitly violated and whether the violation was on purpose or by accident. This is the difference between error and fraud. An error is where a researcher violates, usually unintentionally, the functional reliability of good scientific research (i.e. the goal rules). Fraud, on the other hand, involves intent: a researcher violates the rules of honest conduct in the presentation of research results (i.e. the game rules).

Distinguishing between error and fraud is therefore one of the key issues in the complaint procedure for violations of scientific integrity. There is also an intermediate space between errors, which are clearly and immediately recognizable as such, and fraudulent actions, which can only be proven through thorough investigation. This intermediate space is often described as a "gray area"; this is not necessarily due to the nature of the actions themselves, but rather because the rules of conduct are so vaguely formulated.

The 2004/2012/2014 Code and the 2018 Code make it both easy and difficult to file an integrity violation complaint. Because the Codes mention a large number of desirable behaviors, such as being meticulous and truthful, responding to criticism, correcting errors, remaining fully transparent about the research process, and ensuring that all steps are verifiable, it is easy to accuse someone of non-compliance with one or more of these requirements of exemplary scientific behavior. At the same time, however, the Codes make it clear that such regulations and desirable behavior are examples of best practices, from which one may deviate under certain circumstances (which are not specified) and that failure to adhere to its best practices does not automatically constitute a violation of scientific integrity.

Thirty-eight of the 61 standards in the 2018 Code are actually best practices (2018: 23); however, all 38 should still be complied with. This means that one can complain about conduct that is not in full compliance with the Code, but the complaint is not likely to be judged as an integrity violation. It can thus happen that small, negligible errors and careless mistakes get blown way out of proportion because they demonstrate a failure to comply with the best practices laid out in the Code. Take, for example, standard 43: "Avoid unnecessary references and do not make the bibliography unnecessarily long" (2018: 18). What is unnecessarily long and who decides how many references 
are needed in the bibliography? The lack of clarity in both of the two current Codes (2004/2012/2014 and 2018) leads to dissatisfaction on all sides: the defendants feel as if they have been wrongly accused and complainants feel as if they are not being heard.

The space between error and fraud is thus not a gray area of indeterminate behavior. The behavior itself is easy enough to define; the problem is that the Code does not make it clear which behavior is classified as "unreliable" and which as "unacceptable". No distinction is made between serious and minor violations, nor between conduct that is prohibited and conduct that is not; some behavior can be condemnable without being a violation of any law. In criminal law, there is a clear distinction between two different types of offences: actions that are inherently bad (mala in se) and thus worthy of maximum punishment and actions that are not bad in and of themselves but are regarded as such because they are forbidden (mala prohibita), such as submitting one's tax return after the deadline. The same distinction is needed when it comes to interpreting violations of the Code-which actions constitute serious offenses, and which are the result of "culpable carelessness"?

To this end there are four categories of behavior to be discussed: Errors (both major and minor), carelessness (both major and minor), questionable research practices and violations of integrity.

Examples of errors

- incorrect use of statistical tests, such as one-sided testing in cases where two-sided testing would be more appropriate; calculating a standard deviation with an $\mathrm{n}$-value that is too low; incorrect display of data in tables

- arithmetic errors or typos that distort numbers, such as the incorrect placement of a decimal point

- incomplete or incorrect source references (e.g. wrong page numbers, dates, journal titles)

- failure to mention that the wording of a survey question was changed during the research process 
- unclear problem definitions

- unnecessary repetitions in the text

Examples of carelessness

- failure to indicate the calculation methods used

- neglecting to include $\mathrm{p}$-values in the verification of hypotheses

- failure to explain and justify choices made at the beginning and end of the research process

- neglecting to account for population and sample size

- omitting crucial literature on the subject under discussion

- drawing conclusions that do not correspond to the research data or arguments shown

- neglecting to put quotation marks around quoted material

- neglecting to mention certain sources in the bibliography

- accidentally copying a few sentences from another text without mentioning the source

- neglecting to mention all co-authors in the case of a source mention (to be distinguished from omission in the publication; see below);

- failure to respond to serious criticisms and questions about one's own publications

- unclear writing and reasoning

- an accumulation of various recurring errors 
There is no place for such errors and carelessness in sound scientific research, but that is not to say that the researcher did not have good intentions. Errors and carelessness may damage the quality of the research, but they do not constitute a violation of scientific integrity by themselves. However, the question remains: When have there been so many careless errors that the integrity of the research becomes questionable? In other words, where is the boundary between sloppy science and a scientific integrity violation? Equating sloppy science with dishonest science is dangerous because it would mean that a broad range of unreliable research could fall into the category of scientific misconduct when there was no intention to deceive. The amount of unsound research out there is not yet known. There are estimates that $20 \%$ to $30 \%$ of scientific studies are unreliable (Martinson, Andersen and de Vries 2006), and certainly not all of them contain violations of integrity. However, it is clear that the reliability of research needs to be improved. In evidence-based medicine and evidence-based policy, for example, it is very important that these sloppy scientific practices, as well as responsible research practices, be thoroughly investigated (Bouter 20I4), and that institutions take measures to counter questionable research practices.

\section{Examples of questionable research practices}

Traditionally, questionable research practices (QRPs) are those that can be considered deceptive, such as trimming and cooking, but other dubious practices have emerged that are often regarded as not entirely correct but are still tolerated. For example:

- omitting outliers from the analysis and reporting

- deciding at the end of a project to eliminate subjects who do not meet certain criteria without explanation or justification

- selecting additional subjects who do meet the right criteria after a trial or experiment has been completed

- not repeating a test or experiment (once or multiple times) to verify results 
- editing and modifying images without describing the steps taken in doing so

- using the same image twice but presenting it as two different images

- rounding down p-values in statistical tests to generate a more favorable significance level

- omitting historical data that do not support the theory or hypotheses in archival research

- presenting correlations without explanation of the causal relationship

- generalizing results from small samples as indicative of the entire population

- prematurely disposing of raw data and other research material that could be used to justify the research

- failing to document the most significant research data, making it impossible to be held accountable at a later date.

There is something dubious about all these practices. Rarely do these things happen by accident. They could be an indication of a sly researcher trying to make his or her research look more perfect than it actually is in the hopes that it will be more easily accepted. Some of these practices clearly violate the game rules (especially those involving the omission of data) while others are examples of bad science that does not adhere to the goal rules (e.g. hasty generalizations).

A recurrent justification for some of these questionable practices, such as the omission of outliers, is that journal editors sometimes require it. In most cases, outliers are not relevant, and the editor may want to avoid superfluous information in the text. Sometimes SPSS programs are already programmed in such a way that outliers are automatically removed from the analysis. In other words, the omission of outliers is not always regarded as a questionable research practice; thus, it is important to consider the standards in the 
field on a case-by-case basis. So when can the above-mentioned practices be regarded as violations of scientific integrity?

Examples of scientific integrity violations

The answer to this question is not covered by the three deadly sins of scientific research: fabrication, falsification and plagiarism. In addition to these three, there are several other forms of integrity violations, such as:

- not recognizing co-authors

- incorporating non-scientific interests (e.g. commercial, political, religious) into research outcomes and reporting

- not mentioning commercial interests or other conflicts of interest in the research

- not obtaining the patients' consent to participate in medical research

- not informing participants of the nature of the study they are participating in and that their responses may be used as scientific data.

\section{Conclusion}

Based on the four categories of undesirable behavior discussed above, I propose a reformulation of the question of whether sloppy science is a form of integrity violation:

When can questionable research practices (e.g. statistical manipulations, the withholding of crucial information, poor documentation), combined with a pattern of carelessness, be considered fraudulent behavior and thus regarded as a violation of integrity? 
Or vice versa: When does a pattern of carelessness combined with one or more questionable or fraudulent acts and behaviors constitute a violation of integrity?

One-time errors and careless acts that occur independently of each other are rarely judged as integrity violations. In such cases, the offender is likely to get off with a warning. But once the errors start occurring repeatedly and in combination with other errors, it is quite possible that an integrity violation is taking place. Repeated errors and sloppiness, particularly after the offender has already received a warning, may very well constitute a violation of integrity. However, this needs to be assessed on a case-by-case basis. All of these errors and bad practices form a stark contrast to the good practices described in the Code of Conduct. 



\section{Chapter 7 \\ Integrity: regulation, prevention, instruction}

\section{I TRUST IN SCIENCE: SELF-CORRECTION AND SELF-REGULATION}

Fraud damages trust in science, just as it damages trust in the banking world, the legal profession and the church. It is a clear indication that the representatives of these social institutions are not living up to the standards they have set for themselves and for others. Nothing is more conducive to the loss of trust than hypocrisy, that is saying one thing and doing the opposite.

However, we do not yet know the extent of fraud in science (see Chapter 3). Thus, the question of whether the scientific system as a whole can no longer be trusted cannot be answered. Of course, each case of fraud is one too many, but it is important to distinguish between the normative question about the seriousness of scientific fraud, the empirical question about the frequency and extent to which fraud occurs, and the causal question about the damage that fraud causes to society and science. The three main forms of fraud, FFP, should not occur-let the normative judgment be clear-but their significance for science and society can vary tremendously from case to case.

The self-correcting power of science

Honesty and enthusiasm for science are two factors that contribute to the quality of scientific research. A true lover of science seeks real answers, so there is no reason for him or her to distort reality. A true lover of science is interested in reliability, quality and integrity. Science is based on trust in the scientific method. Although this method is not always followed perfectly in daily practice (Grinell, 2009: 2I-58), it offers some assurance in the foundation of knowledge, especially compared to other ways of answering questions 
and responding to doubt (Peirce I877; I935, Volume V: 358-387). Competitors to the scientific method include:

- prejudice: if we don't know something for sure, we can stubbornly cling to what we do know and base our beliefs on old, outdated theories and "truths"; in other words, falling back on assumptions like "this simply cannot be true" or "people with characteristics $\mathrm{X}, \mathrm{Y}$ and $\mathrm{Z}$ can't be trusted."

- an ideological or metaphysical belief system: if we are not sure of something, we can appeal to our traditional or learned worldview, which offers unverifiable answers to all questions; these answers may provide certainty, but of a rigid kind that is not grounded in reality.

- trust in authorities: "If so-and-so says it, it must be true" or "That famous professor said so on television". The authority argument still plays a role in modern society and can creep into science unexpectedly.

By comparison, the scientific method delivers far more successful results. It teaches us that science is constantly correcting our assumptions and itself. Its competitors are not self-correcting, but self-perpetuating. We are thus much better off relying on the scientific method, as long as we keep the following two realities in mind (Peirce, ibidem).

First, we can never know anything for sure and science does not offer absolute certainty (Peirce, I935, Volume I: IO-I3; Pollack 2003). Knowledge is fleeting-something that is often forgotten in discussions about trust in science. But the transience of knowledge is not necessarily a disadvantage: in practice, old knowledge can be highly applicable and useful. However, one must bear in mind that knowledge acquired through inductive reasoning may still be reliable. Following the example of American philosopher Charles Sanders Peirce, Karl Popper referred to this as "fallibilism" (Popper I972: 4I; 64; I34). Although the problem of induction may be impossible to solve in theory, as Popper believed, it is still possible to live and work with it in practice. The fact that scientists often disagree with each other is not the exception, but rather the rule. 
Secondly, scientific progress is almost always subject to specific conditions under which a given situation is or is not the case, or a given mechanism does or does not work. This means that science is becoming increasingly nuanced and specialized. Research is being carried out under ever more specific conditions; therefore, one must be cautious when it comes to formulating generalizations. The urge for differentiation and specification inherent to science is also often forgotten or suppressed in public and political debate.

Science provides accuracy and clarity for opinions already present in society and scientific circles, which have often already been expressed with great certainty. Undermining this certainty and replacing it with carefully tested perspectives is one of the most important functions of science. A good example of this is the case of Lucia de Berk, a Dutch nurse who was found guilty of seven murders and two attempted murders and sentenced to life in prison in 2003. Her sentence prompted philosopher of science Ton Derksen to reexamine the evidence presented in her trial, which included statements from scientific witnesses and experts. Derksen was able to show, in a scientifically convincing way, that the evidence against her was flawed. The judges were not fully versed in probability arguments and the statistical pitfalls of the small numbers; they had also ignored certain indisputable facts that invalidated the accusations and systematically omitted the counterarguments and evidence from the defense (Derksen 2006). Fortunately, Derksen received support from other scientists and years later, his efforts led to De Berk's complete acquittal. A miscarriage of justice was rectified through scientific reasoning and analysis. Without Derksen's scientific attitude and enthusiasm for research, Lucia de Berk would have spent her entire life in prison.

In short, science is vital for the correction and improvement of social judgment. In a sea of irrationality, the scientific method offers a rational approach to scientific and societal questions.

From self-correction to self-regulation

Scientists judge the work of other scientists. This self-correcting practice emerged in the seventeenth century with the establishment of the Royal Society in London in I660. New ideas and new discoveries were presented, commented on and discussed by an elite group of natural philosophers, including Newton, before being published in one of the first scientific journals, 
Philosophical Transactions. The first secretary of the Royal Society, Henry Oldenburg, maintained contacts with a large number of correspondents, including Dutch scholars Huygens and Spinoza. The Society was a distant forerunner of the current peer review system, which emerged after the Second World War (Freeland Judson 2004: 272-274; 276). The scientific community has thus created a system of continuous criticism, one which does not end in a final ruling by a supreme authority or some other powerful institution proclaiming which theory is correct. The self-correcting function of science is thus carried out by the scientific community itself, which is constantly making new discoveries, adjusting existing knowledge and offering new insights.

However, in light of the recent cases of scientific fraud, it has been noted that the self-correcting capacity of science has failed us in the past (Stroeber, Postmes and Spears 2012; NRC September 2I, 2012). Stroeber, Postmes and Spears investigated forty known cases of scientific fraud in support of their thesis on the not-so-self-correcting nature of science and found that several major cases of scientific fraud have gone unnoticed by the scientific community, in this case by peer reviewers. The Levelt report already pointed this out in the Stapel affair (Levelt, 2012). During the peer review process, one's work is assessed by fellow scientists before publication, not after. "Peer review is the process of subjecting an author's scholarly manuscript to the scrutiny of others who are experts in the field, prior to publication" (Ware 2008: 6). But is the primary purpose of the peer review process to uncover potential fraud, thereby preventing the spread of false information? If so, then peer review is not so much about self-correction over the long term as about short-term self-cleansing, which is another matter entirely.

In order to answer the question of whether the peer review process is even capable of detecting fraud, let us first examine what the process entails. Peer review is a remarkable institution: experts in a particular field are asked to judge the work of colleagues, who are also, in some cases, their competitors. To ensure fairness, assessments are carried out anonymously (double-blind or single-blind), but in reality, reviewers may be able to tell by the references and/or method whose manuscript they are assessing (Ware 2008: I8). Moreover, that the anonymous reviewer cannot be publicly held to account may lead to unfair or distorted assessments. Research indicates that bias in peer review particularly disadvantages novice authors, female researchers and researchers who take an unorthodox approach (Freeland Judson 2004: 266;27I). Freeland Judson also points out that the peer review system has be- 
come overly bureaucratic and time-consuming and the actual improvements to the material under review are often marginal.

There is also the fact that the reviewers are not looking for fraud (they do not necessarily check all calculations or have access to all the research data required to do so). They are mainly looking for new theoretical insights and discoveries. The anonymity provided by the peer review system can also increase the temptation to plagiarize ideas, as demonstrated in the Wachslicht-Rodbard case (see Chapter 3) (Freeland Judson 2004: 283-284).

What we need is a more open system, where both the name of the researcher and the name of the reviewer are known (double open), or at the very least, the name of the reviewer is known (single open). Another solution would be to make the peer review process available through open access, in other words, to publish the entire review process online so that anyone can access the original research data, the evaluators' comments, the reviewers' critique and the author's response. This would make the discussion much more transparent, as discussions among scientists should be.

Stroeber, Postmes and Spears (2012) concluded that "corrective mechanisms such as peer review are not effective for detecting fraud" and that the system of "self-regulation" fails. This sounds plausible, but there seems to have been a subtle shift in their reasoning, namely from self-correction to self-cleansing and from self-cleansing to self-regulation. However, the self-correction and self-cleansing of scientific work presuppose a scientific opinion. Scientists are good at formulating opinions-it's one of the main tasks of their profession. However, one's opinion on whether something is fraudulent and unacceptable is a normative legal judgment and one that is based on existing rules and standards. When judging their colleague's work, scientists may not be aware of the normative nature of their judgments. They tend to focus on the theoretical and/or practical insights that the article under review has to offer. This is well illustrated in the articles that Bax published between 1984 and 1998 in the Amsterdams Sociologisch Tijdschrift and the Sociologische Gids. The editors and reviewers were so interested in his theories about the relationship between religious regimes and political violence that no one bothered to examine the reports from his anthropological observations. They simply trusted that the reports existed and were in alignment with the findings published in Bax's articles. As noted above, twenty years later, eleven articles had to be withdrawn (Sociologie 20I4, IO.I: 3-4). 
Questions about the self-correcting capacity of science should thus not be confused with questions about scientists' capacity to establish whether the standards of scientific practice have been violated. By self-regulating, in other words by adhering to rules and principles for scientific practice that have been devised by scientists for scientists, we are entering a new, normative terrain.

\subsection{A CLOSER LOOK AT THE SYSTEM OF SELF-REGULATION}

In a system of self-regulation, scientists judge the work of other scientists. This is the same wording I have used in the preceding section to describe the self-correcting function of science and the peer review system, but self-regulation presents us with a different perspective. In a self-correcting system, the scientific community and peer reviewers assess scientific quality (i.e. the effective implementation of goal rules); in a self-regulating system, they assess the propriety of the researcher's conduct and determine what is and is not permitted when conducting and publishing scientific research (i.e. compliance with the game rules). The freedom of science means that a lot is permitted-especially in cases of advanced, cutting-edge research (Vandenbroucke 2013)—but not everything. In a system of self-regulation, scientists must...

- establish their own rules;

- put them into practice;

- determine when these rules have been violated;

- decide how violations should be dealt with.

There are several alternatives to self-regulation that are effective both in theory and in practice. It is thus useful to consider how such matters are addressed in other intellectual professions that, like science, are characterized by independence and a high degree of professional autonomy, such as medicine, law, architecture, accounting, and journalism. For example, doctors and lawyers in the Netherlands are bound by statutory regulations for their profession. These legally binding codes of practice regulate admission 
into the profession, set standards for properly exercising the profession, and require that there be an independent body in place to assess whether those standards have been complied with. The reason that these professions are governed by law is, of course, the importance of protecting patients and clients in their interactions with professionals who enjoy a high level of autonomy. As for these professionals, not only can they insure themselves against malpractice, they can also have a say on disciplinary boards. Together with objective, legally experienced industry outsiders, they can help determine the boundaries of what constitutes proper behavior within their profession.

Unlike in the medical and the legal profession, the self-regulation of scientists and academics is not (yet) governed by law. In the Netherlands, as in other places, the scientific community has drawn up its own rules, and it evaluates the behavior of its own members. Self-regulation in science most closely resembles the system of self-regulation in journalism. In the Netherlands, journalists have established their own code of conduct, known as the Leidraad [Guideline]. The boundaries of professional journalistic practice are assessed by an internal committee, the Netherlands Press Council, to which those who feel they have been improperly treated by journalists can address their complaints. Originally, the members of this Council were all industry outsiders, but nowadays it is composed entirely of journalists. Scientists and journalists do not have individual clients like doctors and lawyers do, and they serve a wider audience with interests that extend beyond those of the individual. Both attach great importance to independent reporting and hold themselves to high standards of truthfulness.

Nevertheless, this system of self-regulation in science raises questions, especially when it is compared to the disciplinary codes for doctors and lawyers. Is the Code of Conduct a list of recommended best practices or a summary of scientifically inappropriate conduct? Apparently, it's both, but the two functions are not clearly distinguished. Consider, for example, the preamble to the 2004/2012/2014 Code (previously cited in Chapter 2):

"The principles defined in this Code are detailed further in "best practices'. These best practices, which provide a certain set of norms for the conduct of teachers and researchers, reflect the national and international understanding of good scientific teaching and research. Under particular circumstances, deviation may be justified. The applicability of the provisions depends on 
the concrete circumstances under which the scientific practitioner operates. Moreover, the circumstances under which the university operates are also regularly subject to change. Nonetheless, every practitioner must, if required, be able to explain and motivate if - and if so, to what extent and why - he is at variance with the best practices of the university Code of Conduct (the rule 'apply or explain')" (The Netherlands Code of Conduct for Scientific Practice 2004/2012/2014: 7, preamble; my emphasis).

The 2018 Code is based on the same ideas and most of its 6r standards are "best practices": for example, how to formulate a good research question, how to choose the right research method, how to be transparent about potential conflicts of interest, etc. Only fabrication, falsification and plagiarism are mentioned as clear "violations of scientific integrity", whereas violations of other standards need to be examined on a case-by-case basis to determine the level of seriousness.

Thus, the Code offers certain standards from which one can deviate. After all, the term "best practices" assumes that, in addition to the "best", there are good and not-so-good research practices that could also be considered acceptable. Best practices are mainly used as a benchmark for institutions or organizations (or in this case scientific disciplines), and the term itself suggests that there is also a wide variety of legitimate, but less advisable, practices. The purpose of a code of conduct is clear: to define what constitutes desirable behavior and to encourage practitioners to achieve this "best" behavior. But such a code does not answer the question of what should be done if this ideal behavior is not achieved. What if the principles of good research are not upheld?

In practice, best practices for scientific research can pose new problems:

- They can lead to differences of opinion about the quality of scientific research: "This research meets / does not meet the standards of scientific excellence defined in the Code".

- Not only are errors and careless mistakes considered scientifically unsatisfactory, they are also labeled as morally inappropriate behavior, a violation of integrity, or, in the case of the 2018 Code, as "questionable behavior" (2018: 24). 
- Non-compliance with the best practices mentioned in the Code can be mistaken for an integrity violation, leading to an increased number of scientific integrity complaints.

This third problem is mostly a practical one (too many vague complaints about violations of vaguely formulated standards), but the first two are more fundamental: When does low-quality research-which should in principle be corrected by the scientific community or during the peer review processwarrant a scientific integrity violation complaint? Clearly, such a complaint can damage a researcher's reputation, even when there was no intention of cheating. A slow shift is taking place in the evaluation of scientific research. Where we once focused on the scientific quality of the work, now we are increasingly judging the morality of the researcher. This is where the comparison with the legally binding codes of practice in the medical and legal professions becomes relevant. Do we need a similar code of practice in the academic profession?

The two Codes of Conduct currently in effect, 2004/2012/2014 and 2018, attempt to fulfill two different functions. But by not distinguishing these two functions, they produce more conflict, in complainants who feel that their (broadly formulated) complaints are not being taken seriously and researchers who feel wrongly accused of violating (broadly formulated) standards. At the same time, there is a tendency within the system to confuse judgments of scientific quality with judgments of morality. Instead of focusing on the scientific content of the study, one focuses on whether the arguments are "reliable". This moralization of research often replaces scientific criticism and monitoring within the scientific community.

In my opinion, this may be a hindrance to scientific freedom. The primary function of a scientific code of conduct is to clearly indicate which behaviors are a violation of the fundamental standards - the game rules-of professional scientific practice. There should be no misunderstanding about these behaviors. As long as scientists are in compliance with these fundamental standards, they should be free to choose how they work.

In the Stapel affair, it was not difficult to pinpoint which behaviors constituted a violation of scientific integrity, especially after Stapel confessed. The hard part was cleaning up the damage. Separating the 55 contaminated articles from 82 non-contaminated articles was no easy task; it required a tremendous amount of research and expertise. All 55 articles had to be 
withdrawn, but this retraction process alone was not enough to repair the damage that had been done, especially to Stapel's junior co-authors. The withdrawal of scientific articles has become much more common in recent years, and we are not yet sure how this will affect the body of knowledge as a whole (Grienesen and Zhang 20I2).

The double function of the Code of Conduct can be traced back to its origins. Almost all scientific codes of conduct were formulated immediately after a serious case of plagiarism, fraud or fabrication occurred. These cases always bring about a demand for rules and measures, and a principled choice between a self-regulatory system and a legally binding academic code of practice has been preempted by the speed at which these decisions have to be made. This choice retains its importance today, but for now the practical question is: How does the chosen system of self-regulation work when it comes to addressing suspected violations of integrity?

\subsection{THREE CONDITIONS FOR SELF-REGULATION}

In cases of suspected integrity violations, scientists must evaluate both the work and the behavior of the scientist in question. However, as indicated above, scientific researchers are more accustomed to making scientific quality judgments than to assessing their colleagues' compliance with rules, even though they may have played a role in making those rules themselves. In addition, all cases of suspected integrity violations must meet the standards of fair trial, which places new demands on the scientists' ability to adequately judge the case. Thus, the question can be formulated as follows: What conditions must be fulfilled by the system for handling suspected integrity violations in order to justify and perpetuate the self-regulatory function of science?

First, allow me to describe the scientific integrity complaint procedure followed in most Dutch universities. It is fairly hybrid in nature and not unlike a civil procedure. The complainant and the defendant each have the chance to present their case before the CWI. They exchange written evidence back and forth with comments from both sides, while the CWI acts as a pseudo-judicial body. However, in state-subsidized research organizations, like most universities, the complaint procedure is governed by Book 9 of the $\mathrm{Aw} B$, which falls under the general regulations of the $\mathrm{AwB}$ (although this does not extend to special agencies such as the non-state-subsidized reli- 
gious universities, the VU Amsterdam, the Radboud University and Tilburg University). The administrative law procedure allows for severe punitive sanctions, such as dismissal, suspension, warning, exclusion from a research grant, discontinuation of doctoral studies or the revocation of a doctoral degree. Given the seriousness of these punishments, a precise formulation of exactly which behavior constitutes a violation is essential. The question is whether the current provisions of the two Codes of Conduct offer such a formulation. The regulations for scientific integrity at most universities are often more concrete and clearly formulated than the national Codes, and CWIs and Executive Boards are bound by their own regulations as well.

In view of this lack of clarity, wouldn't it be better if there were a disciplinary procedure established by law, with permanent judicial boards instead of ad hoc committees of scientists that are constantly changing? Is the current complaint procedure still effective given that anyone can submit an integrity complaint nowadays? Would a system like the one used in Norway, where scientific integrity and plagiarism complaints are taken to the Public Prosecutor, and thus handled outside the institution concerned, be fairer and more sensible?

\section{Professional performance}

The system of self-regulation is highly dependent on professional performance, which may be lacking in practice. Ad hoc committees are often composed of emeriti, who are well versed in matters related to their specific scientific field, but have no idea how to carry out a thorough fair legal procedure. They assess what they themselves consider self-plagiarism instead of first asking whether there are any applicable rules on the subject. Other examples of unfair procedures include applying rules and insights retroactively (as discussed in Chapter 5) and treating small errors as serious forms of misconduct without asking whether the complainant might be exaggerating.

Of course, these difficulties could be overcome with the help of good legal support, but universities must be willing to invest in this. Some universities have already taken this step and incorporated legal knowledge and experience into permanent CWIs. Other institutions are not yet ready to make this step. All too often, the defendants are literally "put on the stand", where they can suffer serious reputation damage, even if the complaint turns out to be unjustified or false. 
Knowledge of the rules

Knowledge of rules and regulations is often lacking among those involved in the case and authorities, such as Deans, Confidential Advisors, Executive Board members and professional advisors. Deans often like to get involved in all the details of complaints cases, but they may also have to make other decisions later in the procedure, for example on labor law matters. In one case regarding plagiarism in a $\mathrm{PhD}$ dissertation, the CWI was composed of the Rector, the Dean and a third professor; thus, the Rector and Dean who had first been formally involved in the evaluation of the $\mathrm{PhD}$ dissertation were later also involved in the decision about the complaint. There was a lot to learn from this case, both theoretically and practically. It is important to keep separate the roles of Confidential Advisor (responsible for giving advice and information to the complainant and the defendant and mediation between parties if possible), the CWI (responsible for investigating, establishing the facts and forming an opinion), and the Executive Board (responsible for making the final decision on the case). Any overlap between them runs counter to the principle of fair trial. Since 2014, all Dutch universities have acknowledged this fact and separated the role of Confidential Advisor from the other roles.

\section{Coordination among universities}

The LOWI was established to coordinate the application of regulations in scientific integrity cases. This has proved necessary. At one point, four plagiarism cases from four different universities were brought before the LOWI. What would happen if these four universities were to adhere to their ownvery different-views on plagiarism, fraud or misconduct and ignore the recommendations of the LOWI? Theoretically, the system could collapse into as many jurisdictions as there are universities, each with its own interpretation of the rules. This risk is further exacerbated by the fact that the coordinating body is dependent on whether or not the complainant or the defendant chooses to make an appeal to the LOWI. If minor offences lead to heavy sentences at one university and serious offences lead to minor sentences at another, this constitutes a disturbing disparity. If one university allows anonymous complaints and another does not, you could end up with a situation where a complaint is submitted anonymously against a co-author employed 
by the one university and publicly against a co-author employed by the other. This would certainly raise questions about equal treatment.

In other words, is a coordinating body with a purely advisory role enough to ensure consistency among the universities themselves? This consistency is crucial, and I do not understand why universities cannot work together to coordinate their decisions on integrity violations. Ultimately, these decisions are based on the same Code of Conduct. Following the example set in the medical field, one option would be to limit the number of CWIs to three or four and have them handle integrity complaints at multiple universities and advise the Executive Boards in question. This would provide continuity, longterm experience and expertise, and improved coordination, and it would help to reduce the mistrust of internal committees, which may be too close to those involved in the case and their interests. In Finland, this coordination problem has been solved by requiring universities to submit all decisions on integrity cases to the National Office of Research Integrity, which can then, if necessary, advise the university to reconsider the decision at the request of the coordinating body (Finnish Code of Conduct for Scientific Research).

One thing is clear: the system of self-regulation needs good legal support in its implementation and good lawyers to implement it. But not only lawyers, because there is something to be said for scientists evaluating other scientists. Surely it is better to be judged by colleagues who have been in the lab and conducted research themselves than by outsiders who are not familiar with scientific research at all? This demand for fellow professionals in the disciplinary process has been heard in various industries, from journalism to sports, law to medicine. The example of a legally binding medical code of practice, overseen by experienced judges in five mixed regional tribunals (three outsiders, two insiders) and one Central Medical Disciplinary Court to make binding decisions, is, in my opinion, both attractive and efficient.

\subsection{PREVENTION OF FRAUD AND MISCONDUCT: INTEGRITY POLICY}

The KNAW advisory report titled Responsible Research Data Management and the Prevention of Scientific Misconduct (2012) emphasized the general need for improvement in all phases of the research cycle. Researchers need to be more 
vigilant, and their work needs to be checked more frequently. After all, good research practices are a prerequisite for trust in the results. Sloppy research, though not in the same category as dishonest research, must be vigorously combated. The answer to sloppy science is to insist on improvement; the answer to fraud is prevention. Sloppy science requires good research policy, whereas fraud requires good integrity policy. A healthy research climate must be created and supported by practitioners at all levels, by the management and members of research institutes and by Faculty Boards, Executive Boards, journal editors and the management and membership of professional associations. They are all responsible for maintaining trust in science, both within the scientific community and among the general public.

Nevertheless, policy on scientific integrity has been slow to develop. Perhaps this is due to the moral weight attached to concepts such as integrity and fraud. No one wants to be accused of fraud or dishonest behavior. Organizations don't want such behavior taking place under their roof, and if it does take place, they would rather keep it as quiet as possible. In the Stapel affair, Tilburg University was wise to opt for a more transparent strategy, which ended up being a major turning point for all Dutch universities.

At the Third World Congress on Scientific Integrity (2013), Yarborough gave a lecture in which he compared the integrity policies of universities around the world with the safety policies of airlines, which, like universities, are highly dependent on the trust of the general public. He compared the five phases of safety control in the aircraft industry to the integrity policy of universities. The first phase involves a pathological apathy for risk, or a "that doesn't happen here" attitude. Airlines can have this attitude towards safety risks and universities towards integrity risks. If accidents or cases of scientific misconduct do occur, the second phase is marked by a defensive reaction. The company or institution tries to keep things quiet. The third phase begins with the recognition that the problem can no longer be denied. This phase generally involves a risk analysis: What will cause more reputational damage-keeping things quiet and denying that anything happened or acknowledging the issue and trying to control the fallout? The organization is likely to opt for the most advantageous option based on the risk management strategies learned over time. The fourth phase is more constructive: policy development. Rather than merely reacting to a crisis, the organization develops a proactive policy aimed at ongoing improvement. The fifth and final phase involves achieving an open atmosphere of risk awareness, 
regular audits and ongoing learning, resulting in "work the public can trust" (Yarborough 2013).

In my opinion, integrity scandals at Dutch universities tend to occur between the second and third phases. The same goes for international organizations, which rarely get much farther than recommendations for principles of good research (e.g. honesty, fairness, objectivity, reliability, skepticism, accountability, openness) and leave it up to the scientific organizations they hire to make sure that these principles are adhered to (Responsible Conduct in the Global Research Enterprise, a Policy Report, IAP, 2012). Erasmus University Rotterdam was one of the first universities to adopt a systematic and proactive integrity policy in all faculties (Wynstra, Van Donzel and Dijkstra 2013). After receiving a stern message from the Executive Board that integrity had become a serious policy issue, the university faculties were given one year to make adjustments within their departments. Each faculty had to appoint an integrity officer, set clear guidelines for researchers on what is and is not permissible in research, create a relevant course in all academic programs, and establish a standing committee to investigate suspected violations. What's more, all new PhD students were required to take an oath at the start of their position, following completion of the integrity course. This helped to create a culture of conscious risk management, the fourth and fifth phases of Yarborough's policy.

Another example of a meaningful integrity policy was found at Eindhoven University of Technology. Here the Board spent an entire year meeting with scientists in the university's research institutes to discuss the desired content for new, university-wide regulations on scientific integrity. One year later, the university had a widely supported policy that described which behaviors were and were not permissible.

The experiences of the integrity officers who investigate misconduct cases are also valuable when it comes to setting up an integrity policy. David Hudson, a physician from Virginia State University, summed up his fifteen years of experience by saying: "Assessing scientific misconduct is like eating soup with a knife, messy and slow." His recommendations include: do not allow any misconduct that is not related to the scientific research in question to interfere with your case; do not allow quarrels about authorship to get out of hand-take quick action early on; show equal respect to everyone involved; avoid drawing conclusions until you've heard both sides of the story, don't jump to conclusions; first set out a suitable procedure and clearly explain that 
procedure to all those involved; be well prepared for interviews and hearings; keep a thorough record of all interviews; listen, don't give your opinion too quickly; be mindful of your own behavior; use plagiarism detection software but don't rely on it completely. Finally, he reminds us to "hope for the best but prepare for the worst". His last piece of advice should come as an encouragement to any scientist: "your investigation is research, behave like a researcher" (Hudson 2014). In this sense, the impartiality and independence of an integrity officer runs completely parallel to that of a scientific researcher.

One of the pitfalls of an integrity policy is its integral approach. Scientific integrity cases should investigate inappropriate conduct in scientific research, not assess the quality of the research in question or other forms of misconduct on the part of teachers and students. In other words, issues of scientific integrity should not be confused with other issues related to overall integrity. There are other preventive measures and procedures in place for other forms of integrity violations, such as criminal conduct (e.g. abuse, embezzlement), sexual harassment, discrimination, blackmail, financial fraud (unless directly linked to research fraud) and professional misconduct under employment law (being late to work or absent without leave, using an employer's stationery for private purposes, etc.). This all goes without saying but given that "integrity" can be such a loaded term and violations can have major consequences, a sharply delineated scientific integrity policy remains necessary.

\subsection{CAN INTEGRITY BE LEARNED? EDUCATION IN SCIENCE ETHICS AND OTHER SKILLS}

One of the recurring discussions on integrity policy is the question of how and when the subject of scientific integrity should be addressed in education. We know that the matter needs to be discussed, but at what stage of education? Until recently, scientific integrity was not an integral part of university curricula, but that is not to say that it wasn't taught. It has long been part of the "hidden" curriculum, that is all the things that one learns from instructors that are not explicitly included in the curriculum. For example, in my first year at university (I96I-I962), I learned about scientific citation and other forms of referencing. Later as a young research assistant, I learned that plagiarism constituted a major transgression and one should never 
withhold data. Personal guidance and learning by example have always been, in my experience, the best way to transmit norms and values in science. But is this still realistic given the high number of young, inexperienced researchers and $\mathrm{PhD}$ candidates? Nowadays, some professors are supervising so many PhD students (I have seen cases of 25 or more!) that it is difficult for them to provide intensive guidance.

In light of recent scandals, students are often required to take a structured course on "integrity" in the hope that they will exhibit proper scientific behavior in the future. However, the link between scientific integrity courses and honest behavior has not been thoroughly researched. Just because one knows what is right does not mean that one will do the right thing. Ironically, some of the most high-profile fraud cases have involved middle-aged researchers with well-established scientific careers, and here we are trying to prevent this behavior by teaching the youngest generation about integrity.

Attempting to use education to prevent scientific misconduct is based on the presumption that we know exactly what to prevent and what the causes of misconduct are. If one of the causes of misconduct is a pressure to publish, then we need to try to reduce that pressure; if another cause is too little guidance, then we need to provide better guidance. If the problem is merely a lack of knowledge of academic standards, then perhaps we should require students to take an exam on the subject. But let's not forget that there are other, more stimulating reasons to promote scientific integrity in education, namely, to show students how much fun science is and to teach them what science is all about. In their life-long discovery of the joys of science, they will come to understand and appreciate that honesty is a natural part of scientific research.

Some are in favor of introducing the topic of plagiarism in primary school, where children are already learning to conduct basic research online (e.g. teaching them to properly cite and not to copy-paste information without a reference). Others believe that the issue of plagiarism should be addressed at the secondary-school level when students encounter more research assignments and have more opportunities to copy-paste texts. How much can we really expect from incoming university students?

During the first years of their university studies, these students will quickly learn that researchers are held to a certain standard of integrity and that there is no room for lies and deception in science. They will also learn about the importance of properly citing sources and giving credit where credit is 
due. A writing course combined with a visit to the library and explanation of the bibliographic reference system should be sufficient at the bachelor level. Students learn by doing, so it is important that teachers regularly correct their students' mistakes (learning to read and write well is the secret to success, just like in primary school). Students in academic programs with a heavy writing requirement will most likely master basic writing and referencing skills within one to two years.

Ideally, these basic skills should be complemented by a course in the philosophy of science, in which bachelor students learn about the specific values of science (preferably with numerous examples from their field) and come to understand that there are many conflicting views in science and thus every argument needs to be attributed to a source. In other words, the importance of referencing sources is reinforced in the context of another course. Such a course would also devote a bit of extra attention to the ethics of science (perhaps one or two sessions), thereby completing the students' introduction to scientific integrity during the first phase of their higher education.

\subsection{TEN RULES OF SCIENTIFIC INTEGRITY}

At the end of their university or professional studies, all graduates should be aware of the game rules of scientific research and scientific integrity. There are only ten of them, so they should be easy enough to remember:

I. Do not fabricate data

2. Do not falsify or manipulate data

3. Do not plagiarize

4. Do not let scientific interests get tangled up with other interests

5. Disclose any potential conflicts of interest in the final publication of results

6. Recognize as co-authors all those who have made a substantial contribution 
7. Do not grant or accept unwarranted co-authorship

8. Do not falsely accuse anyone of an integrity violation

9. Do not try to cover up integrity violations

Io. Treat both the complainant and the defendant with fairness

For those students who choose to continue in scientific research, the question remains as to how and when they should be informed about more specific issues related to scientific integrity. Most authors on the subject agree that in this second phase of education (i.e. from the master's level onwards) extra instruction on scientific integrity should be provided for novice researchers. At this point, it is not enough to simply remind them of the FFP standards. They need to gain a more precise understanding of what FFP is, which practices it entails and under what circumstances it occurs; it is also important to talk about special cases and possible exceptions.

For this reason, a Penal Code would be more precise in its descriptions of disapproved and punishable conduct than, for example, biblical commandments such as "Thou shalt not lie." (Katz I987: 4-7; 210-252). For example, the fact that one can "lie" with statistics is well known, but learning how to carry out advanced statistical processing, the rationale behind it and its potential risks is another thing entirely. Rather than devoting an entire course to ethics and morality, I think we would be wiser to address ethical questions in a skills course (if these questions were not already covered in the first phase of education). The style of teaching can vary depending on the subject: ethical issues are best addressed in a discussion-based format, whereas technical and advanced scientific skills are best obtained through practice and mentorship. Finally, the principles of scientific integrity should be published and publicized online, and read and discussed.

By the time students reach the PhD level, instruction on the standards of scientific integrity could involve a combination of the following:

- reflection on the importance of ethics and values of science, preferably within the framework of the philosophy of science (examples include Van Schravendijk 2012; Cornelis 2013)

- advanced skills training and statistical consultation 
- personal guidance and mentoring

- required reading of On Being a Scientist (2012) or similar literature

- taking a scientific oath (Wynstra et al. 2013)

- practice modules: specially programmed instruction per scientific field and online games (e.g. Dilemma Game, The Lab)

The latter two forms of instruction are still up for debate. Some feel that taking a scientific oath is superfluous: Why promise something that ought to be self-evident? But proponents see it as equivalent to the oath of office taken by civil servants, bankers, lawyers and doctors. When young researchers find themselves in situations that challenge their integrity, they can recall their promise to adhere to the highest standards of honesty. They can also remind their colleagues of this promise and use it to explain why they have chosen to do or not to do something.

An oath can also reinforce the internalization of integrity standards, though we do not have any confirmation from scientific research that this is indeed true. The same goes for online training modules. We do not yet know for sure whether digital instruction and online games are as effective for the internalization of scientific integrity standards as mentoring and the sharing of personal stories and ideals. What we do know, however, is that just because a university has published scientific integrity material online, this does not mean that it has a sufficient integrity policy (personal conversation with Simon Godecharle, KU Leuven).

Researchers and departments are free to choose any combination of methods to transfer standards, knowledge and skills related to scientific integrity. The chosen method may vary according to place, time and scientific discipline. The most important thing is that these methods are initiated and executed. One idea is to incorporate them into annual researcher gatherings, where $\mathrm{PhD}$ students meet with other junior and senior researchers to discuss their research. This can be an excellent opportunity for an open discussion on various practical issues and integrity questions. What matters is that the most important message rings loud and clear: 
"The classic obligation and desire of the scientist is to be his own first and most watchful critic" (Freeland Judson 2004: 208).

\subsection{WHAT CAN WE LEARN FROM INTEGRITY?}

What have I learned from writing this study? First, that too much emphasis on integrity and morality can be counterproductive. Second, integrity should not be seen as an absolute virtue, just as no virtue should be pursued in absoluteness. A virtue is a balance between two extremes: for Aristotle, courage was the balance between overconfidence and cowardice. Integrity is somewhere between an obsessive fear of contamination and the desire to deceive others. If scientific integrity is regarded in overly absolute terms and every aspect of scientific research-down to the minute details-is held to the highest standards of integrity, we will end with a witch-hunt on our hands. Modern science is by nature an imperfect art, and there is no room for fanaticism and intolerance (cf. Atlan 2013). If scientists are frantically looking for fault in each other's research so that they can point fingers and say "see, this person has committed a scientific integrity violation," something is wrong.

Naturally, this does not mean that we should not take violations of scientific standards seriously. In essence, it is all about learning to distinguish between error and fraud. Minor errors, one-time mistakes and accidental shortcomings are not nearly as damaging to society and science as deliberate deception and long-term fraud. As previously mentioned, criminal law makes a clear distinction between crimes and misdemeanors, and for good reason. Such a distinction would not be out of place in codes of conduct for scientific practice.

The third thing I learned from this study is that in the pursuit of integrity (in general and also in science), there is an interesting tension between the intrinsic and extrinsic motivations for one's behavior. In the first chapter, integrity was described as a standard for one's own behavior, as a promise to oneself: "This is how I am going to behave and continue to behave, even if the people around me hold different views". It's about staying strong in difficult situations and sticking to your principles. These principles are the internalized standards that researchers live by when no one is watching, whether they be alone in the lab, deep in the library archives, or out in the 
field. It is their own intrinsic motivation that compels them to adhere to the standards of scientific integrity.

The fact that, nowadays, many institutions are facing integrity problems and scandals has contributed to an excess of protocols, audits, supervisors and, in many cases, economically driven incentives. All of these factors can serve as excellent extrinsic motivation. In this respect, scientists are no longer driven by the pure joy of "figuring things out" or the desire to discover the secrets of nature. Science is chosen as a career path, as a way to achieve fame and make money. In one of the integrity courses that I teach, a young researcher once said to me: "My goal is to publish a couple of articles in one of the top scientific journals because after that I'll have it made." This comment is a good illustration of the tension between intrinsic and extrinsic motivation.

Scientific integrity presupposes a high degree of autonomy and personally internalized norms and values; at the same time, however, scientific norms and values are now primarily being taught and enforced through more control, peer pressure, supervision, compulsory courses, bonuses, and punishments-in other words, through extrinsic motivation. Now the challenge is to promote scientific integrity as an intrinsic value and to pass that value on to younger researchers, and to cherish our own intrinsic motivation in the process. It is that intrinsic motivation that allows us to continue to uphold our norms and values without having to deny that science is a constantly evolving social force. Thus, we can believe in the value of scientific research and trust in the scientific community to support us in upholding that belief. 


\section{Works cited}

Abma, R., De publicatiefabriek [The Publishing Factory], Nijmegen, Vantilt, 2013.

Ackroyd, P., Newton, London, Doubleday, 2006.

ALLEA \& ESF, The European Code of Conduct for Research Integrity, Amsterdam/Strasbourg, All European Academies (ALLEA) \& European Science Foundation (ESF), 20II; revised edition, Berlin, ALLEA, 2017.

Andenaes, J., 'General prevention, illusion or reality?', Journal of Criminal Law, Criminology and Police Science, 1952, vol. 43, no. 2: 176-198.

Atlan, H., Fraud, the World of Ona'ah, Stanford, Stanford University Press, 2013.

Babbage, C., 'Reflections on the Decline in Science in England and Some of Its Causes', London, B. Fellowes, I830; in: A. Hyman (ed.), Science and Reform: Selected Works of C. Babbage, Cambridge/New York, Cambridge University Press, I989.

Bamforth, N., 'Combating Plagiarism: The Experiences at Oxford University', in: Th. Dreier \& A. Ohly, (eds.), Plagiate, Wissenschaftsethik und Recht [Plagiarism, Ethics of Science and the Law], Tübingen, Mohr Siebeck, 2013: 66-80.

Baud, M., S. Legêne \& P. Pels, Draaien om de werkelijkheid, rapport over het antropologisch werk van prof.em. M.M.G. Bax [Dodging Truth: Report on the Anthropological Work of Prof. Em. M.M.G. Bax], Amsterdam, Vrije Universiteit, 2013.

Beasley, M.R., S. Datta, H. Kogelnik, H. Kroemer \& D. Monroe, Report of the Investigation Committee on the Possibility of Scientific Misconduct in the Work of Hendrik Schön and Coauthors, Boulogne-Billancourt, Bell Laboratories, 2002.

Beebe, J., Integrity in Depth, New York, International Publishing Corporation, I995.

Bell Laboratories, On the Schön Affair, New York, 2002.

Belt, H. van den, 'Robert Merton, Intellectual Property and Open Science: A Sociological History of Our Times', in: H. Raddar (ed.), The Commodification of Academic Research, Pittsburgh, University of Pittsburgh Press, 2010: 187-230.

Berkel, K. van, 'Quality and Thrift in Scientific Research', in: K. Schuyt \& E. Taverne, 1950: Prosperity and Welfare. In series Dutch Culture in a European Perspective, New York, Palgrave MacMillan, 2004.

Berkhout, K. \& E. Rosenberg, 'Op zoek naar zonden' [In Search of Sins], NRC Weekend, I4 januari 20I2: 8-9.

Bird, G., 'The Languages of Chess', in: G. Bird, Philosophical Tasks, London, Hutchinson \& Co, I972: IIO-II6. 
Botton, A. de, How Proust Can Change Your Life, New York, Vintage International, I998.

Bouter, L.M., Perverse Incentives or Rotten Apples, inaugural adress, Amsterdam, Vrije Universiteit, 2014.

Brecht, B., Der kaukasische Kreidekreis. Text und Kommentar, Frankfurt am Main, Suhrkamp, 1955 (edition 2003). (English: The Caucasian Chalk Circle).

Broad, W., 'Imbroglio at Yale (I): Emergence of a Fraud', Science, vol. 210, I980: 38-4I.

Broad, W. \& N. Wade, Betrayers of the Truth: Fraud and Deceit in the Halls of Science, New York, Simon \& Schuster, I983.

Callaway, E., 'Fraud Investigation Rocks Danish University', Nature News, 7 January 201.

Carter, S.L., Integrity, New York, Basic Books, I996.

Chiong Meza, C., De Nederlandse universiteiten 2012: feiten en cijfers 6 [Dutch Universities, 20I2: Facts and Figures], Den Haag, Rathenau Instituut, 2012.

Cicero, De Officiis: A New Translation, edited, with an introduction and notes by J. Higginbotham, London, Faber \& Faber, 1967.

Colman, A.M., List, bedrog en feiten in de psychologie [Guile, Deceit and Facts in Psychology], Amsterdam/Lisse, Swets \& Zeitlinger, I989.

Comstock, G., Research Ethics: A Philosophical Guide to the Responsible Conduct of Research, Cambridge, Cambridge University Press, 2013.

Cornelis, G.C., Eerlijke wetenschap: Waarom hebben wetenschapsmensen een geweten nodig? [Honest Science. Why Do Scientists Need a Conscience?], Tielt, Lannoo, 2013.

Derksen, T., Lucia de B.: Reconstructie van een gerechtelijke dwaling [Lucia de B.: A Reconstruction of a Miscarriage of Justice], Diemen, Veen, 2006.

Dreier, Th. \& A. Ohly, (eds.), Plagiate, Wissenschaftsethik und Recht [Plagiarism, Ethics of Science and the Law], Tübingen, Mohr Siebeck, 2013.

Drenth, P., 'What Lessons Can We Learn from the Stapel Case?' In: N. Steneck, M. Anderson, S. Kleinert, T. Mayer (eds.), Integrity in the Global Reserach Arena, World Scientific Publishing, London, 2015: I47-I55.

Durkheim, E., Le suicide: Étude de sociologie, Paris, Presses Universitaires de France, I897, nouvelle édition I96o. English: Suicide: A Study in Sociology, ed. with an introduction by George Simpson, translated by John A. Spaulding and George Simpson, New York, Free Press, 1960, orig. 195I.

Dyson, F., 'The Case for Blunders', in: The New York Review of Books, vol. 61, no. 4: 6 March, 20I4: 4-8.

Erasmus, The Adages of Erasmus, selected by W. Baker, Toronto, The University of Toronto Press, 200I (original in Latin, Basel, I500/I533, $8^{\text {th }}$ edition).

ESF, Fostering Research Integrity in Europe, European Science Foundation (ESF) 2010.

Fanelli, D., 'How Many Scientists Fabricate and Falsify Research? A Systematic Review and Meta-Analysis of Survey Data', PLOS ONE, vol. 4, no. 5, 2009: e5738. 
Fanelli, D., 'Do Pressures to Publish Increase Scientists' Bias?' PLOS ONE, vol. 5, 2010: eI027I.

Fleischacker, S., Integrity and Moral Relativism, Leiden, Brill, I992.

Freeland Judson, H., The Great Betrayal: Fraud in Science, New York, Harcourt, 2004.

Gallagher, R., 'Fairness for Fraudsters', in: The Scientist, vol. 23, no. 7, 2009: 13-I5.

Goldacre, B., Bad Science, London, Harper Collins, 2009.

Goldacre, B., Bad Pharma, London, Harper Collins, 2012; 2nd ed. 2013.

Goldman, K.A. \& M.K. Fisher, 'The Constitutionality of the "Other Serious Deviation from Accepted Practices” Clause', Jurimetrics, vol. 37, I997: I49-I66.

Goodstein, D., On Fact and Fraud: Cautionary Tales from the Frontlines of Science, Princeton: Princeton University Press, 2010.

Grant, J., Corrupted Science: Fraud, Ideology and Politics in Science, Wisley Surrey, Sterling Publishing Inc., 2008.

Grieneisen, M.L. \& M. Zhang, 'A Comprehensive Survey of Retracted Articles from the Scholarly Literature', PLOS ONE, vol. 7, no. Io, 2012: e44II8.

Grinnell, F., Everyday Practice of Science: Where Intuition and Passion Meet Objectivity and Logic, Oxford, Oxford University Press, 2009.

Grudin, R., Time and the Art of Living, New York, Harper \& Row, I982.

Gutwirth, S. \& J. Christiaens, 'It's the Science Policy, Stupid! Over wetenschapsfraude als bliksemafleider' [It's the Science Policy, Stupid! About Scientific Fraud as a Lightning Rod], Panopticum, vol. 35, no. 4, 2014: 267-287.

Haan, W. de, 'Intellectuele schatplichtigheid en wetenschappelijke ethiek' [Scientific Indebtedness and the Ethics of Science], Cultuur en Criminaliteit, nr. 0, 20II: Io9II2.

Heilbron, J., M. van Bottenburg \& I. Geesink, Scientific Research: Dilemmas and Temptations, Amsterdam, KNAW, 2000; 2nd. ed. 2005.

Hempel, C.G., Philosophy of Natural Science, Englewood Cliffs, Prentice Hall, Ig66.

Hermesdorf, B.H.D., 'Wetenschappelijk eigendom' [Scientific Property], Rechtsgeleerd Magazijn Themis, I923: 4II-427.

Hexham, I., The Plague of Plagiarism: Academic Plagiarism Defined, website I. Hexham, 2005, http://people.ucalgary.ca/ffihexham/content/articles/plague-ofplagiarism.html.

Hobsbawn, E., 'Inventing Traditions', in: E. Hobsbawn \& T. Ranger (eds.), The Invention of Tradition, Cambridge, Cambridge University Press, I983 (22nd ed. 20I3: I-I4).

Horace, Verzamelde gedichten [Collected Poems], edited, translated and annotated by P. Schrijvers, Groningen, Historische Uitgeverij, 2003. 
Houtzager, H.L., 'De eed van Hippocrates in historisch perspectief' [The Hippocratic Oath in Historical Perspective], in: V. Kirkels (ed.), Eed van Hippocrates: Nog van deze tijd? Annalen van het Thijmgenootschap, vol. 92, no. 2, 2004: II-26.

Huberts, L.W.J.C., Integriteit en integritisme in bestuur en samenleving [Integrity and Integrtism in Governance and Society], inaugural lecture, Amsterdam, Vrije Universiteit, 2005 .

Hudson, D., 'Stories and Lessons from a Research Integrity Officer', paper presented at the Third World Congress on Scientific Integrity, Montreal, 5-8 May 2013.

Hyde, L., Common as Air: Revolution, Art and Ownership, New York, Farrar, Straus \& Giroux, 20I0, paperback ed. $201 \mathrm{I}$.

Institute of Medicine, Committee on Assessing Integrity in Research Environments, Integrity in Scientific Research: Creating an Environment that Promotes Responsible Conduct, Washington DC, National Academies Press, 2002.

IAP, Responsible Conduct in the Global Research Enterprise, Amsterdam/ Trieste, InterAcademy Council (IAC)/ IAP - Global Network of Science Academies, 2012.

Jump, P., 'Research Intelligence: The Good Conduct Guide', Times Higher Education Supplement, 5 August 2010.

Johnson, G., 'Robert Milikan: In the Borderland' in: G. Johnson, The Ten Most Beautiful Experiments, New York, Alfred Knopf, 2008: 138-156.

Kalleberg, R., 'Plagiarism as Violation of Law in Norway: On Inappropriate Juridification of Research Ethics', paper presented at the Third World Congress on Scientific Integrity, Montreal, 5-8 May 2013, in: N. Steneck, M. Anderson, S. Kleinert, T. Mayer (eds.), Integrity in the Global Research Arena, World Scientific Publishing, London, 2015: I25-I40.

Kamin, L.J., The Science \& Politics of IQ, New York, L. Erlbaum Associates, I974, Penguin edition, 1977.

Katz, L., Bad Acts and Guilty Minds: Conundrums of the Criminal Law, Chicago, University of Chicago Press, 1987.

Kemmeren, J.M., A. Algra \& D.E. Grobbee, 'Third Generation Oral Contraceptives and Risk of Venous Thrombosis: Meta-Analysis', British Medical Journal, no. 323, 200I: I3I-I38.

Kennedy, D., 'Next Steps in the Schön Affair', Science, vol. 298, no. 495, I8 October 2002.

Kersten, A., Een organisatie van en voor onderzoekers: De Nederlandse Organisatie van Zuiver-Wetenschappelijk Onderzoek (Z.W.O.) 1947-1988 [An Organization of and for Researchers: The Netherlands Organization of Pure Scientific Research (Z.W.O.) I947 - I988], Assen, Van Gorcum 1996.

Kevles, D.J., The Baltimore Case: A Trial of Politics, Science and Character, New York, W.W. Norton, 1998. 
Klotz, I.M., 'Cooking and Trimming by Scientific Giants', Science News, vol. 6, March I992: 227I-2273.

KNAW, NWO \& VSNU, Memorandum on Scientific Misconduct, I995; Notitie inzake wetenschappelijk wangedrag, Amsterdam, KNAW, 1995.

KNAW, NWO \& VSNU, Memorandum on Scientific Integrity: Norms for Scientific Research and a Netherlands Board on Research Integrity, 200I; Notitie wetenschappelijke integriteit: over normen van wetenschappelijk onderzoek en een Landelijk Orgaan voor Wetenschappelijke Integriteit, Amsterdam, KNAW $200 \mathrm{I}$.

KNAW, Commissioned Research, Amsterdam, KNAW 2005; Wetenschap op bestelling: over de omgang tussen wetenschappelijk onderzoekers en hun opdrachtgevers, Amsterdam, KNAW, 2005.

KNAW, Responsible Research Data Management and the Prevention of Scientific Misconduct, Advisory Report, Amsterdam, KNAW, 2012; Zorguuldig en integer omgaan met wetenschappelijke onderzoekgegevens, Amsterdam, KNAW, 2012.

KNAW, Citing correctly, Amsterdam, KNAW, 20I4; Correct citeren, briefadvies, Amsterdam, KNAW, 20I4.

Köbben, A.J.F. \& H. Tromp, De onwelkome boodschap, of hoe de vrijheid van wetenschap bedreigd wordt [The Unwelcome Message, or How Scientific Freedom Is Coming under Threat], Amsterdam, Mets \& Schilt, 1999.

Kolfschooten, F. van, Valse vooruitgang: bedrog in de Nederlandse wetenschap [False Progress: Fraud in Dutch Science], Amsterdam, Pandora/Contact, I993, tweede druk 1996.

Kolfschooten, F. van, Ontspoorde wetenschap: over fraude, plagiaat en academische mores [Derailed Science: On fraud, Plagiarism and Academic Culture], Amsterdam, Uitgeverij de Kring, 2012.

Komter, A., 'Laakbarewetenschap: Overalledaagseverleidingen en normoverschrijding in de wetenschap' [Reprehensible Science: On Everyday Temptations and Violations of Norms in Scientific Research], Mens en Maatschappij, vol. 87, no. 4, 2012: 415-436.

Koshland, D., 'Fraud in Science', Science vol. 235, no. 4785, I987: I4I.

Kristeller, P.O., Medieval Aspects of Renaissance Learning: Three Essays, New York, Columbia University Press, I974, paperback ed. I992.

LaFollette, M.C., Stealing into Print: Fraud, Plagiarism and Misconduct in Scientific Publishing, Berkeley, University of California Press, 1992.

Lakoff G. \& M. Johnson, Metaphors we Live By, Chicago, University of Chicago Press, I980.

Lamboo, T., Integriteitsbeleid van de Nederlandse politie [Integrity Policy of the Dutch Police], PhD dissertation, Amsterdam, Vrije Universiteit, 2005. 
Leidraad voor juridische auteurs [A Guide for Legal Writing], Kluwer, Deventer, I997, seventh and revised edition 2013.

Levelt, W.J.M., M.S. Groenhuijsen, J.A.P. Hagenaars \& S.A.M. Baert, Interim Rapportage inzake door Prof.dr. D.A. Stapel gemaakte inbreuk op wetenschappelijke Integriteit [Interim Report on Prof.dr. A. Stapel's Violations of Scientific Integrity], 3I October 20II, Tilburg, Tilburg University, 20II; second interim report, April 2012.

Levelt, W.J.M. M.S. Groenhuijsen, J.A.P. Hagenaars \& S.A.M. Baert, Falende wetenschap: de frauduleuze onderzoekpraktijken van sociaal-psycholoog Diederik Stapel [When Science Fails: The Fraudulent Research Practices of Social Psychologist Diederik Stapel], Tilburg, Commissie Levelt, Commissie Noort, Commissie Drenth, 2012.

LOWI: Netherlands Board on Research Integrity, advisory rulings and opinions 2007-2018.

MacArthur, B., 'Hitler Diaries Scandal: “We'd Printed the Scoop of the Century, Then it Turned to Dust"', Telegraph (UK), 25 April 2008.

Mackintosh, N.J., 'Review of Cyril Burt: Psychologist by L.S. Hearnshaw', British Journal of Psychology, 7I, I980: 174-175.

Macrina, F.L., Scientific Integrity: Text and Cases in Responsible Conduct of Research, Washington DC, ASM Press, 1995, third ed. 2005.

Markovits, D., 'The Architecture of Integrity', in: D. Callcut (ed.), Reading Bernard Williams, New York, Routledge, 2009: IIO-I29.

Marks, J., 'Scientific Misconduct', in: J. Marks, Why I Am Not a Scientist, Berkeley, University of California Press, 2009: I62-197.

Martin, B., 'Plagiarism Struggles', Plagiary: Cross-Disciplinary Studies in Plagiarism, Fabrication and Falsification, vol. 3, 2008: I-30.

Martinson, B.C., M.S. Anderson \& R. de Vries, 'Scientists Behaving Badly', Nature, no. 435, 2005: 737-738.

McCook, A., 'Life after Fraud', The Scientist, vol. 23, no. 7, 2009: 28-37.

McDonald, L. \& P. Robinson, A Colossal Failure of Common Sense, New York, 2009.

Mersch, R., Oogklepdenken [Blinkered Thinking], Antwerpen, De Bezige Bij, 2012.

Merton, R.K., 'Science and Democratic Social Structure', in: R.K. Merton, Social Theory and Social Structure, New York, The Free Press, I949; third ed. I966: 550-56r.

Meyers, M.A., Prize Fight: The Race and the Rivalry to be the First in Science, New York, Palgrave MacMillan, 2012.

Miedema, F., Science 3.0. Real Science, Real Knowledge, Amsterdam, Amsterdam University Press, 2012.

Netherlands Code of Conduct for Scientific Practice 2004/2012/2014, The Hague, The Dutch Universities Association, 2014; Nederlandse Gedragscode Wetenschapsbeoefening, Den Haag: VSNU, 2004/2012/2014. 
Netherlands Code of Conduct for Research Integrity 2018, Amsterdam, KNAW, VSNU, NWO, 2018.

Nichols-Casebolt, A., Research Integrity and Responsible Conduct of Research, Oxford, Oxford University Press, 2012.

Nimmer. D., 'The Moral Imperative against Academic Plagiarism', in: D. Nimmer, Copyrights Illuminated: Refocusing the Diffuse U.S. Statute, New York, Wolters Kluwer, 2008: 427-500.

Nudds, D., 'Charles Babbage (I79I - I87I)', in: J. North (ed.), Mid-Nineteenth Century Scientists, London, Pergamon Press, I969: I-34.

On Being a Scientist. A Guide to Responsible Conduct in Research, third ed., Washington DC, National Academy of Sciences, I989 (seventh ed. 2012).

OCW, Privacy-wetgeving en het gebruik van persoonsgegevens voor wetenschappelijke en statistische doeleinden [Privacy Legislation and the Use of ID Data for Scientific and Statistical Research], Rijswijk, Ministerie van Onderwijs, Cultuur \& Wetenschap (OCW), I997.

Ong, K.R.S., The Melancholy Anatomy of Plagiarism, New York, Basic Books, I988.

Oreskes, N. \& E.M. Conway, Merchants of Doubt, New York, Bloomsbury Press, 2010.

Peirce, C.S., Collected Papers, Volume I-VI, edited by C. Hartshorne \& P. Weiss, Cambridge, Mass., Belknap Press of Harvard University Press, I93I-I935 (third printing 1974).

Persson, M., 'Wetenschappelijk wangedrag' [Scientific Misconduct]. Academia, Forum voor de academische gemeenschap, vol. 5, no. 4: I7-2I, September 200 I.

Pollack, H.N., Uncertain Science, Uncertain World, Cambridge, Cambridge University Press, 2003.

Popper, K.R., Objective Knowledge: An Evolutionary Approach, Oxford, Clarendon Press, I972.

Popper, K.R., Conjectures and Refutations, London, Routledge, I989.

Postmes, T., 'Zelfreinigende wetenschap is mythe' [Self-Cleansing Science Is a Myth], NRC, 2I September 20I2: I3.

Protocol. Ethics for scientific research and guidelines for administrative procedures in (alleged) scientific misconduct cases. Leiden, Faculty of Social and Behavioral Sciences, I998; Protocol: Ethiek voor wetenschappelijk onderzoeken en richtlijnen voor het handelen bij (vermeend) wetenschappelijk wangedrag, Leiden, Faculteit der Sociale Wetenschappen, Leiden University, I998.

Quaedvlieg, A., 'Zelfplagiaat is geen wetenschapsfraude' [Self-Plagiarism Is Not

Fraud], Nederlands juristen blad, vol. 89, no. 13, 2014: 853 .

Rawls, J., A Theory of Justice, Cambridge, Mass., Belknap Press, I97I.

Resnik, D.B., The Ethics of Science: An Introduction, London, Routledge, I998. 
Rhees, R., Wittgenstein and the Possibility of Discourse, edited by D.Z. Philips, Oxford, Blackwell Publishing, I988, ed. 2006.

Rieble, V., 'Erscheinungsformen des Plagiats' [Manifestations of Plagiarism], in: Th. Dreier \& A. Ohly, (eds.), Plagiate, Wissenschaftsethik und Recht [Plagiarism, Ethics of Science and the Law], Tübingen, Mohr Siebeck, 20I3: 3I-50.

Rijn-van Tongeren, W. van, Metaphors in Medical Texts, Amsterdam, Atlanta, I997.

Schachman, H.K., 'What is Misconduct in Science?', Science, no. 26I, I993: I48-I49.

Schravendijk, Chr. van, Wetenschappelijk denken: Een inleiding voor de medische en biomedische wetenschappen [Scientific Thinking: An Introduction for Medical and Biomedical Sciences], Leuven, Acco, 2007, ed. 2012.

Schuyt, C.J.M., Rechtssociologie, een terreinverkenning [Sociology of Law: An Introduction to the Field], Rotterdam, Universitaire Pers Rotterdam, I97I.

Schuyt, K., 'Tussen preventie en repressie' [Between Prevention and Repression], in: Steunberen van de samenleving [Pillars of Society], Amsterdam, Amsterdam University Press, 2006a: I60-I68.

Schuyt, K., 'De wil om dingen uit te zoeken: de wetenschappelijke houding' [The Will to Figure Things Out: the Scientific Attitude], in: K. Schuyt, Steunberen van de samenleving [Pillars of Society], Amsterdam, Amsterdam University Press, 2006b: 233-24I.

Schuyt, K., 'Wetenschappelijke integriteit: de andere kant van wetenschappelijk wangedrag' [Scientific Integrity: The Flipside of Misconduct], De Gids, vol. 176, no. 4, 2013: 20-2I.

Schuyt, K., 'Gevraagd: een enthousiaste wetenschapsbeoefenaar (m/v). De wil om dingen uit te zoeken' [Wanted: An Enthusiastic Scientist (m/f): The Will to Figure Things Out], in: L. Consoli en R. Welters (red.), De goede wetenschapper, Annalen van het Thijmgenootschap, vol. I02, no. 2, 2014: I4I-I58.

Schuyt, K., 'Als je merkt dat niemand het merkt: Over fraude in de wetenschap' [When You Notice That Nobody Notices: Fraud in Science]. Justitiële verkenningen, vol. 40, no. 3, 2014: 73-85.

Schuyt, K., 'Research Integrity and Solid Data Management: The Dutch Experience', paper presented at the Third World Congress on Scientific Integrity, Montreal, 5-8 May 2013, in: N. Steneck, M. Anderson, S. Kleinert, T. Mayer (eds.), Integrity in the Global Research Arena, World Scientific Publishers, London, 20I5: I4I-I46.

Schuyt, K. \& E. Taverne, 1950: Prosperity and Welfare, in series Dutch Culture in a European Perspective, New York, Palgrave MacMillan, 2004.

Shapin, St., The Scientific Revolution, Chicago, University of Chicago Press, I996.

Sokal, A., 'Transgressing the Boundaries: Toward a Transformative Hermeneutics of Quantum Gravity', Social Text, vol. 46/47, I996a: 217-252; published also in: Sokal and Bricmont I998: 212-258. 
Sokal, A., 'A Physicist Experiments with Cultural Studies', Lingua Franca, May/June I996b: 62-64.

Sokal, A. and J. Bricmont, Fashionable Nonsense: Postmodern Intellectuals' Abuse of Science, New York, Picador 1998 (original in French Impostures Intellectuelles, Paris, Editions Odile, 1997).

Spinner, H., Das wissenschaftliche Ethos als Sonderethik des Wissens [The Scientific Ethos as a Special Branch of the Ethics of Knowing], Tübingen, Mohr \& Siebeck, 1985.

Spoor, J.H., D.W.F. Verkade \& D.J.G. Visser, Auteursrecht, naburige rechten en databankenrecht [Copyright Law, Neighboring Rights and Database Rights], Deventer, Kluwer, I985, third printing 2005.

Stapel, D., Ontsporing [Derailed], Amsterdam, Prometheus, 2012.

Steen, R.G., 'Retractions in the Scientific literature: Is the Incidence of Research Fraud Increasing?', Journal of Medical Ethics, vol. 37, 20II: 249-253.

Steneck, N.H., 'Fostering Integrity in Research: Definitions, Current Knowledge and Future Directions', Science and Engineering Ethics, vol. I2, 2006: 53-74.

Steneck, N.H., M.S. Anderson, S. Kleinert \& T. Mayer (eds.), Integrity in the Global Research Arena, London, World Scientific Publishing, 2015.

Stewart, J.B., Tangled Webs: How False Statements are Undermining America: from Martha Stewart to Bernie Madoff, New York, Penguin Books, $201 \mathrm{I}$.

Stroeber, W., T. Postmes \& R. Spears, 'Scientific Misconduct and the Myth of SelfCorrection in Science', Perspectives on Psychological Science, vol. 7, no. 6, 2012: 670688.

Swazey, J.P., M.S. Anderson \& K. Seashore Louis, 'Ethical Problems in Academic Research', American Scientist, vol. 8I, I993: 542-553.

Trevor-Roper, H., 'The Invention of Tradition: The Highland Tradition of Scotland', in: E. Hobsbawn \& T. Ranger (eds.), The Invention of Tradition, Cambridge, Cambridge University Press, 1983 (22nd printing 2013: 15-42).

Tudge, C., In Mendel's Footnotes, London, Vintage, 2002.

Vandenbroucke, J.P., 'Moet wetenschap in een keurslijf?' [Does Science Need a Straitjacket?], De academische boekengids, maart 2013: 9-Io.

Vanheste, J., De wijsheid van de roman: literaire antwoorden op filosofische vragen [The Wisdom of the Novel: Literary Answers to Philosophical Questions], Budel, Damon, 2012.

Verbeke, R., 'Een op de twaalf: Fraude in biomedisch onderzoek' [One in Twelve: Fraud in Biomedical Research], EOS, Belgisch Wetenschapstijdschrift, nr. 4, 20I3:2433 .

Verkade, D.W.F. \& J.H. Spoor, Auteursrecht [Copyright Law], Deventer, Kluwer, I986.

Verhoeven, C., 'Integer' [Integrity], in: Dierbare woorden [Cherished Words], Budel, Damon, 2002: 208. 
Verrijn Stuart, A.C., 'Levensbericht van Mr. Nicolaas Gerard Pierson (I839- I909)' [Obituary of N.G. Pierson I839 - I909], in: Levensberichten, Handelingen en Mededelingen van de Maatschappij der Nederlandse Letterkunde, I9Io- I9II.

Wager, E. \& S. Kleinert, 'Responsible Research Publication: International Standards for Authors: A Position Statement Developed at the 2nd World Conference on Research Integrity', Singapore, July 22-24, 2010, in: T. Mayer \& N. Steneck (eds.), Promoting Research Integrity in a Global Environment, Singapore, World Scienitific Publishing, 2011: 309-3I6.

Walsh, J.E., Unraveling Piltdown: The Science Fraud of the Century and its Solution, New York, Random House, 1996.

Ware, M., Peer Review. Benefits, Perceptions and Alternatives, London, Publishing Research Consortium, 2008.

Weaver, D., M.H. Reis, C. Albanese, F. Costantini, D. Baltimore \& Th. ImanishiKari, 'Altered Repertoire of Endogenous Immunoglobulin Gene Expression in Transgenic Mice Containing a Rearranged Mu Heavy Chain Gene', Cell, 25 April I986: 247-259.

Weber, M., 'Science as Vocation', in The Vocation Lectures, translated from German by Rodney Livingstone, and edited by David Owen and Tracy Strong, Illinois: Hackett Books, 2004.

Weber-Wulff, D., 'Technische Möglichkeiten der Aufdeckung von Verstössen: Was kann, wie und durch wen kontrolliert werden?' [Technical Possibilities for Detecting Misconduct: What Can be Checked, How and by Whom?], in: Th. Dreier \& A. Ohly (eds.), Plagiate, Wissenschaftsethik und Recht [Plagiarism, Ethics of Science and the Law], Tübingen, Mohr Siebeck, 2013: I35-I54

Weber-Wulff, D., False Feathers: A Perspective on Academic Plagiarism, Berlin, Springer, 2014 .

Wesseling, A., 'Erasmus en plagiaat' [Erasmus and Plagiarism], in: Z. von Martels, P. Steenbakkers \& A. Vanderjagt (eds.), Limae labor et mora: Opstellen voor Fokke Akkermans t.g.v. zijn zeventigste verjaardag [Limae Labor et Mora: Essays for Fokke Akkermans on the Occasion of his Seventieth Birthday], Budel, Damon, 2000: 66-70.

Williams, B., 'A Critique of Utilitarianism', in: J.J.C. Smart\& B. Williams, Utilitarianism: For and Against, Cambridge: Cambridge University Press, I973, Io druk I989: 77I50, especially \$ 5 , 'Integrity'.

Wittgenstein, L., Philosophical Investigations, ed. by G.E.M. Anscombe \& R. Rhees, Oxford, Blackwell, I953, revised ed. 1958.

Wynstra F., M. van Donzel \& G. Dijkstra, Fostering Professionalism and Integrity in Research: Final Report of the Taskforce Scientific Integrity, Erasmus University Rotterdam, 2013.

Wood, N., Cicero's Social and Political Thought, Berkeley, University of California Press, I988. 
Yarborough, M., 'The Characteristics of Trustworthy Science and Practices that Promote It', paper presented at the Third World Conference on Scientific Integrity, Montreal, 5-8 May 2013.

Zilsel, E., The Social Origins of Modern Science, eds. Diederick Raven, Wolfgang Krohn, and Robert S. Cohen, Dordrecht: Kluwer Academic Publishers, 2000 (original edition in German: Die sozialen Ursprünge der neuzeitlichen Wissenschaft, Frankfurt am Main, Suhrkamp Verlag 1976, ed. 1985). 



\section{Index}

ALLEA Code of Conduct 37, 8I, I09, IIo

Babbage, Charles 6o, 61, 128

Baltimore, David I4, 38, 39, 74-76, 79, I05, 128

Baud, Michiel 58, I26, I27

Bax, Mart 58, 74, I24-I26, I5I

Boldt, Joachim 36

Burt, Cyril I7, 22, 58, 74, I28

constitutive rules: see game rules

Copernicus, Nicolaus 26

Darsee, John 77, 78

Darwin, Charles 58, 74, 98

Derksen, Ton 149

Diekstra, René I5, 4I, 42, 45, 79, 88

Durkheim, Emile I02, I03

Dyson, Freeman John I29

Einstein, Albert 2I, 40, I02

Erasmus, Desiderius 98, 99

Ethics 8, 9, I5, 39, 42, 76, 78, 79, 95, I64, I65

Fabrication 26, 37, 39, 47, 51, 52, 58, 60, $62,66,77,95,99, \mathrm{I} 25-\mathrm{I} 27, \mathrm{I} 44, \mathrm{I} 54$

Falsification 26, 37, 39, 47, 51, 52, 58, 60, 62, 66, 99, I25, I27-I29, I44, I54

Fanelli, Daniele 25, 62, 65, 68

FFP 23, 26, 35, 37, 39, 40, 47, 51, 60, 62, $67,89,103,147,165$

Fleischmann, Martin 33, 35

freedom of science $38,40,152$

Freeland Judson, Horace Io, 15, 23, 39, 40, 66, 72, 74, 75-77, I05, II7, I33, I34, I35, I50 game rules $35,43,54,55, \mathrm{I} 27, \mathrm{I} 39, \mathrm{I} 43$, I52, I55, I64

goal rules 35, 54, 55, I27, I39, I43, I52

Goldacre, Ben 70, 72

Hexham, Irving Ioo, I05, II4, II5

Holmes, Oliver Wendell 97

Horace I8

Imanishi-Kari, Thereza 74-77

integrity: chapter I and throughout

Kamin, Leon 22

Klotz, Irving 34, 74

Köbben, André 27, 45, 70

Kolfschooten, Frank van 32, 58, 67, 80, 98, I07, I09, I25

Leibniz, Georg W. $5^{8}$

Levelt, Pim 31, 63, I26, I27, I35, I50

LOWI 7, 8, I5, 23, 44-46, 80-84, 87-90, 93-96, 98, I07, I22-I24, I30, I31, I37, 158

Lysenko, Trofim 2I, 40

Martin, Brian I03-I05, II7-II9

Mendel, Gregor 34, 74, 98

Merton, Robert King 2I, 24

Millikan, Robert 34, 58, 74

Misconduct $15,33,36,38-45,48,52,59$, $60,62,63,65,7 \mathrm{I}, 76,78,8 \mathrm{I}-85,88$, $89,94-96$, 109, I24, I36, 137, 142, I $57-\mathrm{I}_{3}$

National Office of Research Integrity I4, 159

Netherlands Board on Scientific Integrity: see LOWI 
Netherlands Code of Conduct for Research Integrity 2018 7, II, 49

Netherlands Code of Conduct for Scientific Practice 2004/2012/2014 II, I5, 4I, 45

Newton, Isaac 58, 74, I02, I49

Nijkamp, Peter 48, I09, II2, II6

Nimmer, David 97, 98, I0I, I03, I07

Pasteur, Louis 74, 98

Peirce, Charles Sanders 148

Pierson, Nicolaas G. 67, 99

Piltdown Man 33, 34, I 25

plagiarism 9, II, I5, 23, 33, 37, 39, 42, $43,47,48,51,52,58,60,62,63,66$, $67,72,73,79,80,85,88$, 9I, 97-I20, I22, I24, I3I, I37, I38, I44, I54, I56I58, I62, I6 3

Pons, Stanley 33-35

Popper, Karl I39, I48

questionable research practices $34-36$, $38,53,60,62,68, \mathrm{I} 28, \mathrm{I} 38$-I 45
Rawls, John I4

regulative rules: see goal rules

Resnik, David ıo, I9, 26, 72, 75, 76

Schachman, Howard 39, 40

Schön, Jan Hendrik 32, 74, 77, I25, I34

Semmelweis, Ignác 34

sloppy science II, I26, I27, I42, I44, I6o

Sokal, Alan 23, 24

Stapel, Diederik 3I-33, 36, 45, 57, 58, 63$65,75,8$ I, 87, I22, I25, I26, I29, I35, I37, I50, I55, I6o

Summerlin, William 32, 74

Wachslicht-Rodbard, Helena 73, 96, I5I

Wakefield, Andrew 70, 7I

Wallace, Alfred Russel 58

Weber, Max 2I

Williams, Bernard I8, 20

Wittgenstein, Ludwig 35

Zu Guttenberg, Karl-Theodor 106, II3, I37 